\title{
Ammonia generation in the gut and the influence of lactulose and neomycin: review of the literature and experimental studies in the rat
}

Citation for published version (APA):

van Leeuwen, P. A. M. (1985). Ammonia generation in the gut and the influence of lactulose and neomycin: review of the literature and experimental studies in the rat. [Doctoral Thesis, Maastricht University]. Rijksuniversiteit Limburg. https://doi.org/10.26481/dis.19851220pl

Document status and date:

Published: 01/01/1985

DOI:

10.26481/dis.19851220pl

Document Version:

Publisher's PDF, also known as Version of record

Please check the document version of this publication:

- A submitted manuscript is the version of the article upon submission and before peer-review. There can be important differences between the submitted version and the official published version of record.

People interested in the research are advised to contact the author for the final version of the publication, or visit the DOI to the publisher's website.

- The final author version and the galley proof are versions of the publication after peer review.

- The final published version features the final layout of the paper including the volume, issue and page numbers.

Link to publication

\footnotetext{
General rights rights.

- You may freely distribute the URL identifying the publication in the public portal. please follow below link for the End User Agreement:

www.umlib.nl/taverne-license

Take down policy

If you believe that this document breaches copyright please contact us at:

repository@maastrichtuniversity.nl

providing details and we will investigate your claim.
}

Copyright and moral rights for the publications made accessible in the public portal are retained by the authors and/or other copyright owners and it is a condition of accessing publications that users recognise and abide by the legal requirements associated with these

- Users may download and print one copy of any publication from the public portal for the purpose of private study or research.

- You may not further distribute the material or use it for any profit-making activity or commercial gain

If the publication is distributed under the terms of Article 25fa of the Dutch Copyright Act, indicated by the "Taverne" license above, 


\section{AMMONIA GENERATION IN THE GUT AND THE INFLUENCE OF LACTULOSE AND NEOMYCIN}

Review of the literature

and experimental studies in the rat

\section{Proefschrift}

ter verkrijging van de graad van doctor in de geneeskunde

aan de Rijksuniversiteit Limburg te Maastricht, op gezag van de Rector Magnificus

Prof. Dr. F. I. M. Bonke, volgens het besluit van het College van Dekanen

in het openbaar te verdedigen in de aula van de universiteit op vrijdag 20 december 1985 , des namiddags te twee uur

door

Paulus Aloysius Marie van Leeuwen 
Promotores: Prof. Dr. J. M. Greep

Prof. Dr. C. P. A. van Boven

Co-promotores: Dr. P. B. Soeters

Drs. A. E. J. M. van den Bogaard

Referenten: Prof. Dr. med. J. Bircher

Prof. Dr. J. A. Flendrig 
To Mieke

To my parents 


\section{Contents}

1. Introduction

1.1. Outline of the thesis

1.2. The origin of ammonia in the gut

I.3. Lactulose: the mode of action and efficacy

1.4. Lactulose in hepatic encephalopathy

1.4.1. Uncontrolled trials

1.4.2. Controlled trials

1.4.3. Controlled double blind trials

1.4.4. Lactulose in acute portal-systemic encephalopathy

1.4.5. Lactulose enemas

1.5. Neomycim in hepatic encephalopathy

1.5.1. Neomycin: the mode of action and efficacy

1.5.2. Uncontralled and controlled trials

I.5.3. Lactulose and neomycin combined in the treatment of hepatic coma

1.6. Ammonia in relation to the hepatic coma syndrome

I.7. References

II. In vitro ammonia and amino acid production in small and large intestine of the rat and the influence of neomycin and Tactulose

II. 3. Results

II.4. Discussion

II.5. References 
III. Metabolic characteristics of villous and crypt enterocytes of conventional and germ-free rats and the influence of neomycin and lactulose

III.1. Introduction

I11.2. Material and methods.

III.3. Results

III. 4. Discussion 98

III.5. References

IV. Morphological effects of high dose neomycin sulphate on the small and large intestine

IV.1. Introduction

IV.2. Material and methods

IV.3. Results

IV.4. Discussion

IV.5. References

V. The effect of intestinal flora modulation on ammonia production in the rat intestine

V.1. Introduction

V.2. Material and methods

V.3. Results

V.4. Discussion

V.5. References 
4. The effect of neomycin and lactulose on ammonia production In the small and large intestine in relation to the intestinal flora

VI.1. Introduction

WI.2. Material and methods

VI.3. Results

VI.4. Discussion

VI.5. References

VII. Portal arterlal differences for amino acids and ammonia across the intestine in conventional and germ-free rats and the influence of lactulose and neamycin

VII.1. Introduction

VII.2. Material and methods

VII. 3. Results

VII.4. Discussion

VII. 5. References

VIII. General discusstion 


\section{INTRODUCTION}

\subsection{Outline of the thes is}

These studies and the review of the literature in this thes is were undertaken because no clarity exists about the site of ammonia generation in the gut and how lactulase and neamycin, both generally accepted in the treatment of hepatic coma, decrease ammonia generation. Most if not all clinical literature still claims that ammonia generation primarily takes place in the calon where the major part of the bacterial flora is situated.

In the colon bacterial degradation of urea and of luminal contents derived from dietary residue and epithelial exfoliation, results in the production of ammonia and $\mathrm{CO}_{2}$. The ammonia diffuses by the mechanism of non-ionic diffusion through the colon and reaches the portal vein whereafter it is finally metabolized to urea in the liver. According to the literature degradation of urea is the main producer of ammonia (3), although it is not clear how urea reaches the colon via the ileum. Moreover according to a recent study of Wrong (9), urea is not an important source for faecal ammonia. In a recent study of Vince (5) who investigated the substrate for ammonia production in several strains of bacteria it was concluded that ammonia generation "in situ" is not derived exclusively from urea, but also from bacterial deamination af amino acids, peptides and proteins. The clinical literature still points to bacteria as main producers of ammonia, although several lines of evidence from the biochemical literature indicate that ammonia may be derived from intermediary metabolism in the gut $(13,14,15)$. Both the small and large bowel are capable of generating ammonia in the gut wall. The chilef precursor for this ammonia generation is glutamine, which may be derived from the blood 
and from the gut lumen.

Efforts to explain the effects of nemycin and lactulose by their action on bacteria are far from convincing. Neomycin is known to exert its action mainly on aerabic bacteria, especially the enterobacteriaceae. They constitute only one percent to one promille of the total gut flora. It is difficult to conceive that manipulation of this small part can result in a significant decrease of ammonia production.

Several potential effects of lactulose have been described to explain its action, all of which deal with interference of bacterial action. These explanations do not take into account the suggestions from the fiterature reviewed, that a large part, possibly 75\%, of the ammonia production is not bacterially mediated.

Studies were initiated in this direction trying to answer the following questions:

1. How much ammonia is produced in the small and Targe bowel and is this ammonia production bacterially mediated or from mucosal origin?

2. How is ammonia generation in the gut influenced by necmycin and lactulose?

In chapter 1 therefore the literature will be reviewed concerning the mechanism and sites involved in the generation of ammonia in the gut. This is followed by a review of the proposed action of lactulase and neomycin. At the same time proof will be sought for in the literature for beneficial effects of lactulose and neonycin on hepatic encephalopathy. Subsequently it will be shown that research in the field of ammonia metabolism is still relevant because ammonia still plays a role in most theories concerning the genesis of hepatic encephalopathy.

In the second chapter the in vitro ammonia production of pieces of small and large intestine and the influence of lactulose and neamycin on this production is described.

In the third chapter in vitro incubations carried out with mucosal cells are described. Mucosa cells of conventional and germ-free rats were used in order 
to separate the effect of muscle upon anmonia production from mucosal action and in order to distinguish bacterial and mucosal action.

In the fourth chapter the morphological effects of neomycin on mucosa of the small and large intestine are described.

In chapter five a study is described concerning the influence of intestinal flora modulation in relation to ammonia production in the gut of the rat. Rats were first selectively decontaminated in order to remove the aerobic or anaerobic flora and in addition gem-free rats were colonized with a defined aerobic, anaerobic or aerobic/anaerobic flora. Ammonia concentrations in the portal vein were related to this gut flora modulation. The effect of neonycim and lactulose on the luminal and gutwall associated flora related to ammonia concentrations in the portal vein of small and large intestine are described in chapter VI. Portal arterial differences $(P-A)$ for amino acids and ammonia across the intestine in conventional and gerim-free rats are described in chapter VII together with the influence of neomycin and lactulose on the P.A. differences.

In the last chapter a comprehensive review of the experimental data is given and put into perspective against data from the 1 it terature. 


\subsection{The origin of ammonit in the gut}

The word ammonia is derived from the Greek "Aupwy "used in Libya as an epitheton for Zeus near whose temple the ammonium salt is said to have been prepared from Camels dung.

Ammonia exists in two forms, in solution as gaseous ammonia and as ammonium ion as shown in the following formula:

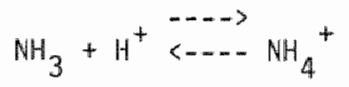

Gaseous armonia is capable of diffusing freely through cell membranes, but the polarized ammonium radical does so oniy with difficulty and at the expense of energy. In this chapter ammonium refers to $\mathrm{NH}_{4}{ }^{*}$ and ammonta gas to $\mathrm{NH}_{3}$.

The equilibrium constant for ammonia is 9.5. At the pH (fig. 1) of extracellular fluid and arterial blood $(7,4) 1-3 \%$ of ammonia is in the non-ionized form and $97-99 \%$ is in the ionized form.

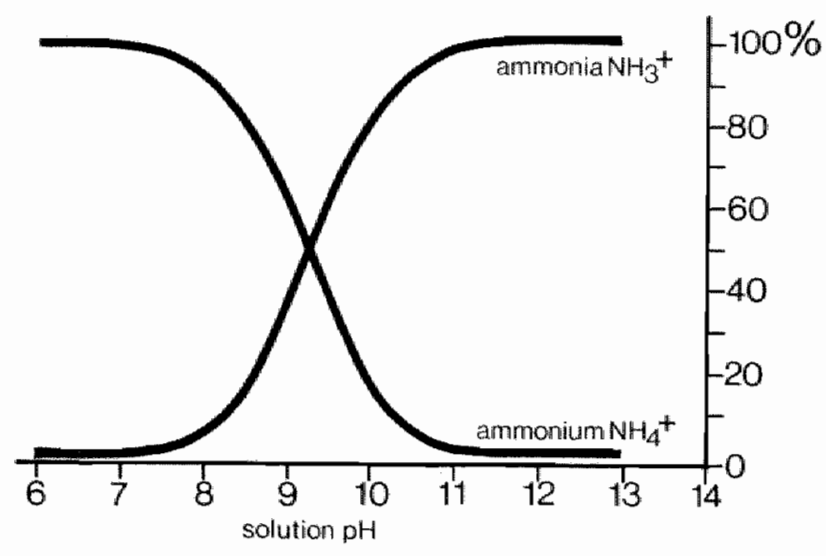

Figure 1: Fraction of ammonia and ammonium ion as a function of pH. 
The partial pressure of ammonia in the intracellular and extracellular

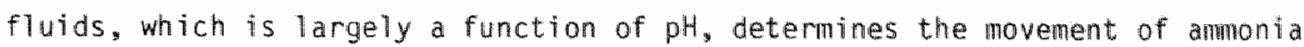
between these compartments. Diffusion occurs from areas of greater pressure to those of lesser pressure. Every factor that increases the pH gradient between the extracellular and intracellular fluid favours the passage of ammonia into the cells. In the intestine transfer of ammonia from the mucosal to the serosal surface against a concentration gradient is obserwed in the jeum but not in jejunum (1). It is suggested that ammonia is absorbed in the Heum by active ionic transport. In the human colon however studies clearly indicate that non-ionic diffusion is operative in ammonia absorption (2).

It is generally accepted that intestinal ammonia is produced by enzymatic breakdown of protein metabolites and urea. As a result of the finding that about $13 \mathrm{mM}(7.8 \mathrm{~g})$ of urea is daily broken down to ammonia in the intestine of healthy human volunteers (3), it has been suggested that urea is the major substrate for intestinal ammonia production. Apart from small quantities of mucosal urease in the stomach and small bowel, intestinal urease is of bacterial origin and is lacated in the colon (4). Many viable intestinal organisms like Bacteroides spp, bifidobacteria, Clostridia spp, Proteus spp and Klebsiella spp possess urease activity. Others, notably Escherichia Coll (the predominant Gram-negative aerobic bacteria in the intestine of most species), do not, so that ammonia released by these organisms arises from deamination or deamidation of substances other than urea.

Some organisms produce ammonia by both mechanisms. Vince indicated in her study with a faecal incubation systern that the source for bacteria is the aminonitrogen of faecal protein, polypeptides and amino acids (5). She casts doubt on urea as the intermediate source of faecal ammonia. Two separate studies in man, using intestinal perfusion have shown that the large intestinal mucosa is virtually impermeable to urea $(6,7)$ and the amount of urea entering from the ileum is known to be insufficient to account for more than $10 \%$ of the rate of urea destruction in man (8). The role of urea as a pre- 
cursor of faecal ammonta is therefore in considerable doubt. In a recent study of Wrong (9) it was demonstrated that endogenous urea is not, as has generally been asslimed, the major source of faecal ammonia. The endogenous urea pool was labeled in two human subjects with ${ }^{15} \mathrm{~N}$-urea given as a constant intravenous infusion and constant production of endogenous ( ${ }^{14} \mathrm{~N}$ urea) was ensured by identical hourly meals throughout the study. After the first intestinal transit several samples of stool were abtained from both subjects and enrichment of ammonia nitrogen was measured in samples of faecal dialysate, ultracentrifugate, and 48-hours faecal incubations. Expressed as a percentage of plasma urea $\left({ }^{15}\right.$ N) labeling, the labeling of stool was very simillar in the two studies averaging $8.54 \pm 1.33 \%$ of the various samples of faecal ammonia and significantly less $(p<0.05)$ at $6.88 \pm 0.68 \%$ for faecal total nitrogen.

The labeling of oral salivary protein and plasma albumin was much less showing that faecal ammonia labeling was not derived from alimentary secretions or plasma proteins. By exclusion, faecal ammonia must be mainly derived from other mitrogen sources in the large intestine which are chiefly the residues of dietary protein, intestinal secretions and shed epithelial cells.

Protein ingestion can also increase blood ammonia. A number of investigators has shown that the administration of protein is followed by an increase in blood ammonia levels in cirrhotic patients. Bessman and clarke e.a. $(10,11)$ showed that blood ammonia levels increase after various types of dietary protein or blood. Clarke found that a typically diphasic increase in venous ammonia levels occurs following a high protein meal. There appears to be a hierarchy in the degree of "toxicity" of different types of protein. Blood appears to be more toxic than meat which in turn appears to be more toxic than vegetable protein. Various explanations have been offered for the varying toxicity of various proteins. It has been suggested that different proteins may be digested at different rates in the digestive tract and that the products may be absorbed different1y. 
As explained, ammonia generation occurs in several ways, although the literature still indicates that metabolism of bacteria is the most important (12). Nevertheless recent literature reveals that germ-free animals can also develop hyperammonemia, which may be derived from intermediary metabolism in the gut. Nance and his associates reported that germ-free dogs with Eck-fistulae developed porta-systemic encephalopathy (PSE) with hyperammonemia (13). Furthermore they showed that a blood meal induced the same increment in ammonia concentration. Several other lines also indicate that ammonia may be derived from intermediary metabolism in the gut. In 1973 Matsutaka (14) and co-authors demonstrated that small and large bowel of rats can take up glutamine in vitro and at the same time produce ammonia and giutamic acid. Schalm and Van der Mey found in 1979 that hyperammonemia accurs in liverless germ-free rats (15). Warren and Newton (16) have found increased portal vein bload ammonia levels in germ-free rats. In 1978 Weber (17) found that in dogs the large quantity of ammonia released by the small intestine into the portal blood is equal to that released by the uncleansed colon. In the small bowel, it was apparent that the amount of ammonia released by the small intestine was stoichiometrically equivalent to the uptake of glutamine amide nitrogen from arterial blood. Here glutamine was the most likely source of the armonia released. Felig e.a. demonstrated that glutamine and glutamic actid in the splanchnic bed are largely taken up by the gut and not by the 1 iver (18).

\section{Metabolism of glutamine by intestinal mucosa.}

As indicated in the previous pages, the intestine seems to play a significant role in processing the waste nitrogen from other organs. Oxidation of the glutamine carbon provides an important source of energy for the epitheltal cells of the intestinal mucosa where glutaminase is largely located (19). Neptune's work in 1965 (20) showing that glutamine was oxidized to $\mathrm{CO}_{2}$ by incubated ileal tissue from several animal species, is the first reported study indicating that glutamine may be a preferred substrate for the intestine. More direct clues emerged from arterio-venous different measurements 
across the non-hepatic splanchnic organs of dogs $(21,22)$, sheeps $(23)$, rats 14) and men (18). These studies revealed an uptake of circulating glutamine by the combined organs drained by the portall vein. Arterio-venous differences for glutamine in vivo across the tissues drained by the superior mesenteric vefn were found to be even larger than those measured across all portal-drained argans, localizing much of the uptake in the small intestine (24). The localization was done by windmueller with an isolated vascularly perfusate preparation of rat intestine. With $L\left(U-{ }^{14} \mathrm{C}\right)$ giutamine in the perfusate and from analysis of labeled tissue metabolites he concluded that the largest part of glutamine uptake and metabolism occurred in the small intestinal mucosacel1s. Malcolm Watford (25) harvested columnar absorptive cells (villous cells) in order to study the metabolism of the chicken enterocyte with special reference to the role of glutamine as a precursor of citrulline. He concluded that among added substrates, glucose, glutamine and glutamate are the preferred fuels for respiration in the chicken. Other studies have confirmed that isolated mucosal cells contain a group of enzymes that can account for the metabolic products of glutamine (26). In order to determine quantitatively the metabolic fate of luminal as well as arterial glutamine Windmueller used autoperfused intestinal segments. He concluded that intestinal segments of rats (non-fasted state) utilize arterial glutamine and glucose at about twice the rates, expressed per tissue weight, observed in fasted animals (27). The utilization rate was not increased when the lumen contained amino acids which are transported by carrier-mediated transport. Therefore, the utilization rate of arterial glutamine is concentration dependent, approximately equal to the rate for glucose, and is not increased during carrier mediated transport of substrates which are not metabolized and reduced by fasting.

In the same preparation he measured the radio-active products of $L-\left(U^{14} C\right)$ glutamine. The carbon was partly incorporated into tissue acid soluble material (14\%) and the rest reappeared with little delay in intestinal venous blood in $\mathrm{CO}_{2}(57 \%)$, citrulline $(6 \%)$, proline $(5 \%)$, arnithine $(2 \%)$, alanine 
(3\%) and organic acids (18\%) predominantly citric acid and lactic acid. The product distribution of the arterial glutamine carbon was similar in conventional or germ-free rats, precluding the intestinal microflora as a source for any of the metabolic products. The rate limiting step for the glutamine catabolism is apparently its deamidation and not the metabolism of the resulting glutamate since none of the $L-\left(U^{14} C\right)$ glutamate administered luminally escaped metabolism during its transfer across the intestine. The ${ }^{14} \mathrm{C}-1$ abeled products of glutamate catabalism were the same as those arising from glutamine (28). The results of windmueller also indicate that glutanine was metabolized identically whether it entered the mucosal cells across the brush border from the lumen or across the basolateral membrane from the arterial blood, suggesting that a single mucosal pool exists. During digestion two sources of gllutamine "compete" for the same enzymes. The presence of glutamine or glutamate in the lumen reduced the rate of glutamine utilization from the blood. However since most of the luminal glutamine is also metabolized, the total rate of glutamine metabolized was increased by $70 \%$ when both sources of glutamine were available (28). Therefore he cancluded that the utillization rate of arterial glutamine was not reduced by fasting, which was in contrast to the study of Hanson (29), who found a higher glutamine utilization in rats deprived of food.

Windmueller also studied the metabolic fate of the glutamine nitrogen. Nitrogen taken up by jejunum as glutamine could be accounted for by the net release of ammonia, ornithine, alanine, proline, glutamate and citrulline. About $75 \%$ of the glutamine amide nitrogen, released by a phosphate dependent glutaminase, could be accounted for as ammonia and the remainder as one of the two nitrogen atoms of citrulline. The glutamine amino group could be accounted for by the remaining nitrogen of citrulline and the other amino acids. Windmueller (26) proposed pathways of glutamine metabolism in rat intestinal mucosa. The first step of catabolism is catalyzed by a phosphate dependent glutaminase. Mucosal scrapings indicate that rat small intestine contains sufficient protein glutaminase to account for the rates of glutamine 
breakdown observed. Although other glutamine degrading enzymes have been found the concentrations of these enzymes are too low and insufficient to account for the breakdown of glutamine (26). Distribution of glutaminase was found in the small intestine of all animals he surveyed (rat, dog, cat, hamster, mouse, monkey, rabbit, guinea pig and chicken). Glutaminase distribution is consistent with its proposed role. High activity of this enzyme was found in duodenal, jejunal and ileal mucosa, and relatively low glutaminase activity was found in mucosa from rat stomach, coecum and colon (19). Consistent with this, rat stamach utilizes relatively little vascular glutamine (30). The phosphate dependent enzyme is located in the mitochondria and can be activated by phosphate (19). Activity of intestinal glutaminase in rats was not increased by feeding large amounts of glutamine, nor was it decreased by fasting (19).

In the proposed pathway of Windmueller (fig. 2) other enzymes than glutaminase are needed to support this. The remaining ammonium, which is not released into the portal vein, is converted by carbamoyl-phosphatase. Rat intestine contains $N$-acetyl glutamate synthase and the co-factor needed for this enzyme is $\mathrm{N}$-acetyl glutamate (31). The glutamate produced in reaction $I(f i g \cdot 2)$, is reduced to glutamic acid- $\gamma$-semialdehyde which can be further reduced to proline or transaminated to ormithine.

Glutamic acid- $\gamma$-semialdehyde is converted to pyrroline-5 carboxylate. The enzyme that converts glutamate to pyrroline-5 carboxylate has been characterized in the mitrochondria from rat intestinal mucosa $(32,33)$. Ornithine carbamoyl transferase catalyzes the conversion of ornithine and carbamoylphosphate to cftrulline. Citrulline is then released into the portal vein. The intestine appears to be the rare mammalian tissue that can effect a net symthesis of ormithine and protein from glutamate $(34,35)$. If glutamate is not utllized to form proline or to form ornithine via glutamic-acid-semialdehyde, it can be transaminated with pyruvate to alanine. 


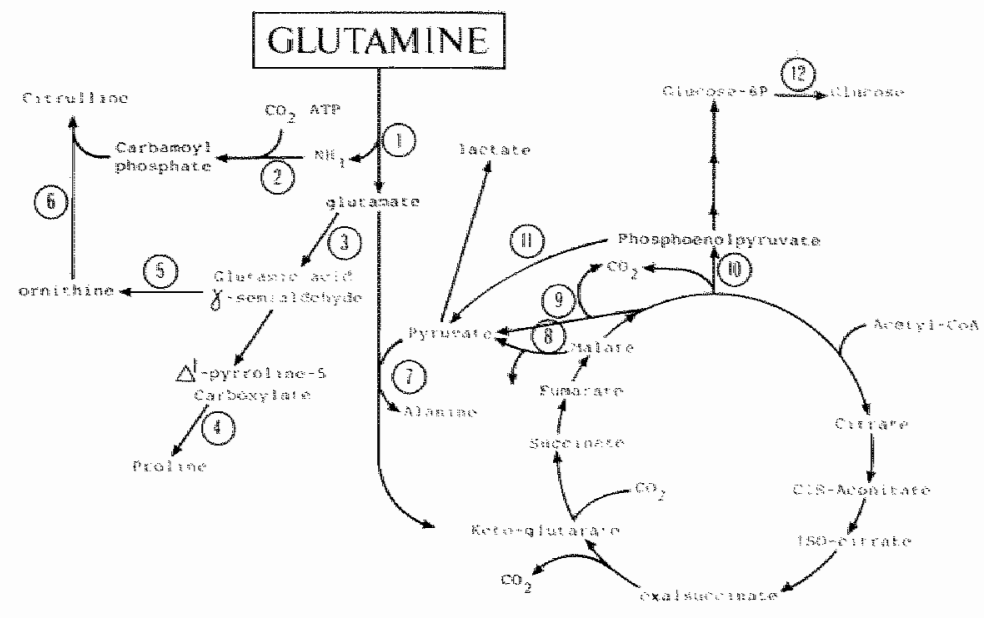

Figure 2: Pathways suggested for glutamine metabolism by rat intestinal mucasa (Windmuel ler, 26).

The importance of glutamine as a respiratory fuel.

Windmueller indicated the importance of glutamine as a respiratory fuel for the intestinal cells in several studies with rats $(24,34,37)$. In tracer studies he discovered that more than half of the $\mathrm{CO}_{2}$ produced by intestine of fasted rats was derived from the metabolism of circulating ketone bodies and $36 \%$ was derived from glutamine. Although glucose and glutamine were utilized in approximately equal amounts, most of the glucose carbon appeared in alanine and lactate and only $11 \%$ in $\mathrm{CO}_{2}$. Likewise, when in this experiment animals were fed with a diet containing $50 \%$ of glucose and $15 \%$ corn starch, the contribution remained sma 11 .

A specific role for glutamine in the physiology of the animal.

There is little evidence that, apart from its role as a respiratory fuel, glutamine serves a more specific function in the physiology of the intestine. Glutamine has been reported to stimulate the transport of glucose, water and sodium ions by intestine incubated in vitro. Whether this is a specific 
function of glutamine is not known but it could be related to its energy producing capacity. As a primary site for metabolizing plasma glutamine, the intestine plays an important role in processing the waste nitrogen produced by other tissues. All of the nitrogenous end products, as revealed in fig. 2 of intestinal glutamine metabolism can serve ultimately as urea precursors. The nitrogen flux along this pathway is large and windmueller (26) estimates that $30 \%$ of the nitrogen utilized for hepatic ureagenesis in non-fed rats is derived from the nitrogenous products of intestinal breakdown. The carbon atoms of alanine, proline and lactate are available for gluconeogenes is in the liver. Citrulline serves as a precursor for arginine in the brain and in the kidneys, which are an important endogenous arginine source for protein synthesis in muscle.

Although it was previously beliewed that the liver also releases citrulline, recent studies indicate that this is not true (36). Windmueller showed that the kidneys take up circulating citrulline at about the same rate as its release by intestine. No additional significant sites for citrulline release or uptake were revealed by arterio-venous measurements across ather major argans $(37)$.

Although the clinical literature still indicates the bacterial flora in the colon as the main producer of ammonia, a review of the literature, espectally the biochemical literature does stress that metabolic ammonia generation in the gut is important. 


\section{3. Lactulose: the mode of action and efficacy}

Lactulose is a synthetic water-soluble disaccharide consisting of galactose and fructose in combination as 1,4-B-glalactosido-fructose.

The molecular weight of lactulose is 342.3 and its melting point is situated between $169.5-170.4^{\circ} \mathrm{C}$.

\section{LACTULOSE}

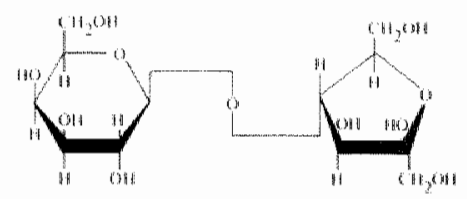

Figure 3: Lactulose

Although lactulose is a disaccharide and is chemically similar to other disaccharides such as lactose, lactulose does not occur naturally and there are no enzymes in man or animal capable of hydrolyzing lactulose (38). Only bacteria contain enzymes that are capable of hydrolyzing lactulose (39). Like other intact disaccharides, unhydrolyzed lactulose is vilitually nom-absorbable in the small intestine. Experiments in baboons and rats have shown that: after ingestion of enormous amounts of lactulose (15-20 ger $\mathrm{kg}$ ) only minute quantities $(10-100 \mathrm{ug}$ per $\mathrm{ml})$ could be detected in the serum (40). The main site of degradation of lactulose must be the colon since relatively few bacteria are found in the small intestine (41). Thus lactulose reaches the colon almast intact and there bacterial degradation begins. Hoffmann e.a. (38) identified lactic acid as the principal metabolite of the bacterial breakdown of lactulose. In addition small amounts of volatile fatty acids and ethanol are formed which acidify the colonic content so that an impressive 
decrease in stool pH is achieved.

Potential mode of action.

1. The original hypothesis of Bircher and his associates (42) that lactulose exerted its beneficial effect by changing the bacteriall flora of the intestine, has not been supported by subsequent studies. Bircher hypotheslzed that lactulose enhanced the growth of no urease containing bacteria such as Lactobacilli. In normal subjects given lactulose Flock e.a. (43) were unable to detect significant changes in the pattern of faecal flora during administration of lactulose, nor were any significant changes in the flora pattern observed during treatment of cirrhotic patients. Hoffmann e.a. (39) found significant decreases in total bacterial counts of Escherichia coli and Bacteroides spp with no more than a proportional increase in Lactobacil1 and no alteration in faecal ammonia values. In cirrhotic patients lactulose produced clinical improvement one to three weeks before the development of consistent changes in faecal bacteriology and benefit was obtained even in patients whose stools contained no Lactobacilli. Zeeger e.a. (44) observed a significant increase in faecal Lactobacilli during lactulose administration, but found no consistent changes in coliforms or in Bacteroides spp. Conn e.a. (45) found no significant change in the number of Lactobacilli in normal subjects or in circhotic patients being treated with lactulase although lactulose administration was associated with a decrease in the total number of aerobic bacteria and in the number of coliform bacteria. Vince e.a. (46) however in a recent report showed a considerable increase in both aerobic and anaerobic species of Lactabacilli. Results however were not consistent in all patients. Counts of E.Coli decreased during lactulose therapy in one patient who responded clinically and in one who did not. Counts increased dramatically in another who responded clinically. Counts of Bacteroides spp increased during lactulose therapy in one and decreased in the other both of whom responded well clinically due to lactulose 
treatment. Therefore results were difficult to relate to the change in flora. The contradictory results in these studies tell us very little about the role of intestinal organisms in the induction or recovery of P.S.E. Also none of these investigators studied the effect of lactulose on the gut-wall associated flora in several locations of the intestine. It still leaves us with the question: are Lactobacilli or E. coll of crucial importance or the total number of aerobic and/or anaerobic bacteria?

2. A second mechanism by which lactulose may act is through trapping ammonia in the acidified content of the bowel. In the iumen of the gastro-intestinal tract acidification increases the $\mathrm{pH}$ gradient between gut content and mucosa and reduces ammonia absorption from the bowe1. Summerskill e.a. (47) published a report on quantification of ammonia concentration and output in the upper gastro-intestinal tract in health and in patients with diseases of the liver. High concentration gradients between the gastro-intestinal tract and the blood were found under basal conditions. Most of the findings in this respect were consistent with non-ionic diffusion of ammonia due to the relative $\mathrm{pH}$ difference between opposite sides of the gut membrane. Castel e.a. (48) demonstrated that absorption of ammonia from the isolated colon varies directly with the pH of the perfusate. Bircher e.a. (49) showed in dogs that reduction in pH of the lumen resulted in reduction of the ammania concentration of venous blood leaving the colon and found that $\mathrm{pH}$ levels of less than 6.2 reversed the absorption of ammonia. Several studies have shown a fall in stool pH $(39,50)$ due to lactulose treatment, although only one study has been carried out in humans in vivo. This study was carried out by Bown (51) who used a radiotelemetry capsule and found a fall in the pH of the colonic cantents in humans. The lowest level was observed in the right hemicolon. When the low pH enhances the excretion of ammonia in the colon, loss of ammonia should be detected in the faeces. Studies on 
ammonia loss however did not show the expected increase (44,52). Agostini e.a. (52) used other cathartics besides lactulose (sodium sulphate, manntol and sorbitol) but he did not observe an increase in the concentration of faecal ammonia either. He clatmed that despite the increase in the quantity of faeces no increase in the absolute amount of ammonia was observed in the faeces due to lactulose treatment, although the other purgatives did show a modest rise. Vince e.a. (53) claimed that a decrease of the pil reduces ammonia both by lowering production and absorption. In her study on ammonia production by intestinal bacteria a significant decrease in count of the enterobacteriaceae at low pH was noted. Ammonia production by Escherichia coli decreased significantly when the pH was lowered from $\mathrm{pH} 7.2$ to $\mathrm{pH}$ 4.6. Considerabie variation was noted in the ability of different species to produce ammonia. Experiments with cultures containing both Escherichiacoli and Proteus Milrabilis showed that more ammonia was produced at low $\mathrm{pH}$, than was produced by cultures of single species.

Although less ammonia was produced at low pH, a still significant amount. of ammonia was generated at $\mathrm{pH}$ 5.0. When using a faecal incubation system, Vince noted that acidification to 5.0 or less with hydrochloric acid or a lactic acid mixture, sifgnificantly reduced ammonia generation from faecal cultures. Whether this pH lowering effect to 5.0 or less significantly contributes to a decrease in the production of ammonia in the lactulose treatment is difficult to say because a pH lower than 5.0 after lactulose treatment was only measured in the coecum (51) in the study of Bown, whereas in the rest of the colon the $\mathrm{pH}$ amounted to 6.7 and 6.6 respectively.

3. A third mechanism by which lactulose may act is via the catharsis which may develop due to acid products resulting from the breakdown of lactulose. It is known that acid has a cathartic effect on the intestine. Lactic acid in krebs solution, which reduced the luminal pH to 3.6 caused 
enhanced fluid propulsion and increased circular muscle contractions (54). Indeed after lactulose administration these effects, acid stools and increased bowel activity proportional to the amount of carbohydrate ingested, can be the consequence of control substances such as sorbitol and magnesium sulphate. They both produce an acid stool, whereby sorbitol is known to be converted to organic acids by bacteria. However both mannitol and sorbitol do not appear to produce clinical improvement in hepatic encephalopathy (52).

4. A fourth mechanism was proposed by Vince (53). The presence of carbohydrates facilitates the growth of bacteria and the incorporation of nitrogen into bacterial protein. Vince suggested that lactulose actually stimulated incorporation of ammonia into bacterial protein. In her study she tested this phenomenon by incubating lactulose and ammonia with several strains of bacteria. During the final 6 hrs, ammonia disappeared completely from al 1 lactulose-incubation systems. Administration of other substrates like glucose, mannitol and sorbitol also caused a fall in ammonia concentration, similar to that observed with lactulase. Vince has therefore claimed: 1) preferential use of lactulase as a carbon and energy source would exert a sparing effect on the metabolism of the bacteria, resulting in a decrease of the production of ammonia, liberated normally as byproduct during metabolism; 2) a readily avallable energy source would presumably encourage assimilation of ammonia, an energyrequiring process which may not occur so readily under conditions of carbon limitation.

It is not clear how these four mechanisms integrate. Furthermare none of these mechanisms takes the non-bacterial ammonia production in the gut into consideration (chapter I.2.). 
1.4.

\section{I.4.1. Uncontralled trials}

Most of the studies done in the early days were devised to study whether lactulose had any demonstrable effect. None of these studies attempted to evaluate the response to oral lactulose by introducing a control treatment period. These studies unforturately contained few patients and even individual cases. However the results do suggest that it was passible to increase protein intake and that lactulose did improve mental state in patients with chronic portal-systemic encephalopathy.

Markhoff (55) reported a case of a 50 year old male suffering from portalsystemic encephalopathy, who became conscious six days after beginning with lactulose therapy. Writing tests reverted to normal and his arterial ammonia fell drastically.

Pallm (56) reported a study of 5 patients to whom lactulose was administered immediately postoperatively in patients having undergone a portocaval shunt. clinical and hematological findings were evaluated in comparison with those observed in another 20 patients having undergone the same surgical operation. Lactulose made rapid bowell movements possible. Ammonia levels 48 hours after the shunt mere always lower than mean values in untreated subjects and remained within normal range after resumption of oral diet and the increased protein intake. Palma showed excellent results, although the number of patients was limited.

Lande and Clot (57) reported a study of 12 patients with liver cirrhosis. Ten patients responded well to the therapy. Two did not. They concluded that lactulose is very effective in the therapy of hepatic coma.

Rottiers (58) reported a study in which patients were divided into three groups. Group A consisted of five cirrhotic patients having a portacaval shunt who were mospitalized with the clinical picture of hepatic precona or coma and received lactulose as on ly treatment at a dosage of $150 \mathrm{ml} /$ day. 
Group $B$ consisted of six cirrhotic patients without surgical portacaval shunt, who were hospitalized with the clinical picture of hepatic cona. Group $C$ consisted of four cirrhotic patients who did not show symptoms of hepatic coma and in whom the development of the fasting ammonemia following a 3 day course of 150 mil lactulose syrup daily was studied. Moreover in three of them an ammonia tolerance test was carried out before and after the same administration of lactuliose syrup daily, also for three days.

In the first group of cirrhotic patients there was an obvious improvenent of the clinical condition with lactulose treatment in all five cases. The results were different in the second group of cirrhotic patients. In two cases the results were very good. In one case the result was insignificant. One died, one had heart fajlure so that the result was difficult to assess. In the last case, there was improwement with a higher dosage. In the third group, the fasting blood ammonia levels dropped significantly after a three day course of lactulose in three out of four cases. As to the three ammoniumchloride tests, the following can be stated. Only one showed a clear difference, both regarding the clinical manifestation, the blood ammonia levels and the EEG after lactulose administration. Rottiers therefore concluded that the best indication for the treatment with lactulose seems to be the chronically recurring encephalopathy, which occurs in relatively well stabilized cirrhotic patients, mainly in those with a surgical portacaval shunt.

Fung and khoo (59) studied two patients with chronic recurrent hepatic encephalopathy. They were used as their own control, since their hepatic encephalopathy was first treated in the conventional way, using neonycin syrup, protein restriction and colanic washouts and then lactulose therapy alone (30 $\mathrm{ml}$ three times a day) without protein restriction in their diet. Lactulose therapy produced marked improvement with disappearance of flapping tremor and constructional apraxia. The patients became fully conscious. This improvement occurred in spite of 70 to $80 \mathrm{gr}$ of protein per day in their diet. There was also a clear improvement in the EEG recorded during lactulose therapy. 
Demeulenaere (60) reported in 1969 a similar study. He added however an additional group to his study, in which he gave cirrhotics a lactulase enema. Although he stated that results were correllated with EEG, ammonia level and clintcal signs, results demonstrated that these parameters were only determined occasionally. He concluded that prolonged administration of lactulose in lucid and active cirrhotics is a very useful and inexpensive therapeutical modality. Also rectal administration of lactulose improves the mental condition and sometimes spectacularly.

Helms (61) reported a study of 10 patients. Significant improvement was reached in two patients.

Combes (62) evaluated long term protein tolerance in portal systemic encephalopathy and showed an increase in tolerance in patients to whom lactulose was given for long periods.

Gauthier (63) reported in 1970 a study of 37 patients with daily doses of 90 to $150 \mathrm{ml} / \mathrm{day}$. He had succes in 27 cases.

Geffroy (64) reported a study of 20 patients. 18 Patients responded well to therapy with lactulose. Mental state and ammonia levels were used as parameters. Geffroy concluded that it was possible to increase protein intake together with lactulose-therapy. In patients responding favourably to therapy, the pH of the faeces fell to 6.0.

James (65) reported a study of patients in which cerebral blood flow and cerebral metabolism were studied in order to evaluate porto-systemic encephalopathy after a 10 day course of lactulose. As a result of therapy five out of the six patients showed clinical improvement. There was a mean increase in cerebral oxygen utilization but no changes in either mean glucose consumption or in mean cerebral blood flow.

Kardel (66) evaluated lactulose treatment in eleven patients, the majority of whom were treated for four weeks. Only three patients improved clinically on lactulose, all of whom showed an improvement in EEG tracings. The improvement occurred within two to five days and withdrawal of the drug was followed by deterioration. One patient who did not improve clinically, nevertheless had 
improved EEG recordings. Blood ammonia was not affected by lactulose in this study. Ho mention of dietary protein was made and blood ammonta was not measured during the fasting state. The author stated that lactulose seened to work best in patients with more severe encephalopathy.

Almici (67) reported a study of 19 cases with advanced hepatic cirrhosis with Ist to 3rd stage coma and grade $A$ to $B$ EEG alterations. Clinical, EEG and blood ammonia normalization was noted in 16 cases. In 5 cases it was also possible to carry out diuretic treatment in order to reduce ascites.

Eisenbury reported in 1974 a study of 14 cases in which 10 were treated succesfully with lactulose (68).

Reikowski treated 36 patients with cirmosis of the 1 iver (69). Virtually all patients responded well to lactulose treatment and ammonia levels fell. Seidlowa reported a study of 14 patients with cirrhosis of the liver (70). The evaluation was carried out according to clinical criteria and EEG examination. It was possible to increase the dietary protein intake and acidification of the faeces accurred regularly. Eleven patients responded well to the therapy.

\subsubsection{Controlled trials}

In the better trials, every effort was made to adequately control variables which right influence the response or assessment of results.

Ma et al (71) conducted a long term trial of lactulose in ten patients with chronic portal systemic encephalopathy. Improvement was assessed by neurological state and EEG. The patients previously required neomycin and protein restriction. Wherever prossible the trial was divided into five phases.

1. Observation in the hospital for one week while the usual regimen of treatment with neomycin and protein restriction was continued.

2. Observation in the hospital for a further three weeks during which lactulose was substituted for neomycin.

3. Observation after discharge from the hospital when treatment with lactu- 
lose was continued.

4. Readmission to the hospital and observations of the effects of withdrawal of lactulose.

5. Reintroduction of lactulose when signs of encephalopathy developed.

Six out of 10 patients had a satisfactory response and were maintained on lactulose for up to twelve months. Two patients falled to respond to either lactulose or neomycin and two patients withdrew from treatment due to intolerance to the drug. Four out of six who had improved on the drug were withdrawn from therapy and deteriorated both on EEG and clinical grounds, but subsequently improved when the drug was reintroduced. Ma indicated that the drug is effective in controlling chronic portal systemic encephalopathy and is a useful substitute for neomycin.

Rorsman (72) and co-authors using lactulose in a long-term study could increase the protein intake in three patients. The response was based on clinical and EEG evidence of improvement following controlled exacerbation of encephalopathy. All three patients had previously been treated with protein restriction but only one had received neomycin. In all cases it was possible to start the trial with a period of protein restriction. If the condition returned to normall an exacerbation was induced by increasing the dietary protein. With protein intake on this higher level, lactulose was started, usually in a dose of $20 \mathrm{ml}$ three times datly. Administration of lactulose produced a regression of the clinical symptoms during increased protein intake as well as a return of the mean frequency of the EEl to about the same stage as before the dietary protein was increased. Withdrawal of lactuliose was associated with encephalopathy. The optimal effect of lactulose was. evident in 10 to 14 days. When the initial trial had been completed the patients were discharged with dietary instructions implying moderate protein restriction and continuation of lactulose. Two patients remained well for more than 2 years, one on a low protein diet, the other on moderate protein restriction. The third died, despite protein restriction and neomycin. 
Siebner (73) found that of twelve patients treated with lactulose eight showed a superior effect with lacturose as compared to broad spectrum antibiotics, while three had equivalent effects. One patient derived no benefit from lactulose.

In 1970 Zeegen et al (74) reported the clinical and biochemical changes associated with lactulase therapy in seven patients with chronic portal systemic encephalopathy and compared the results with a magnesium sulphate solution. Those who responded appeared to have a higher degree of encephalopathy and higher initial blood ammonia levels than the 4 non-responders. Results were assessed in a non-blind manner by a range of clinical and biochemical tests. The tests included EEG, measurement of mental state, blood ammonia level, faecal $\mathrm{pH}$, weight and frequency. The 7 patients had undergone shunt operation. They were initially hospitalized for 7-14 days when a protein intake of 60 to $80 \mathrm{~g} / \mathrm{dlay}$ was started and maintained. Hereafter alternately lactulose or magnesium sulphate was given and in two patients magnesium sulphate was the initial treatment. Magnesium sulphate was used to produce a similar quantity of stools. During the initial control period there was little change in the degree of encephalopathy. Only 3 of the 7 patients derived obvious clinical benefit when given lactulose and deteriorated when transferred to magnesium sulphate. No patients responded to magnesium sulphate. Two of the 4 patients who did not respond to lactulase showed clinical improvement with neomycin and were discharged with this drug. Changes in the lactulose period were paralleled by improvement of EEG tracings. There was also a significant fall in arterial blood ammonia levels in all 3 who responded, but also in 3 of the 4 non-responders. Faecal pH was not related to clinical response and the most acid diarrhoea was produced in 2 non-responding patients. It was concluded that lactulose was of value in certain cases of chronic encephalopathy, and was a useful alternative to neomycin although not always interchangeable.

In 1971 Fung (75) presented a long term study of 11 cases of hepatic encephalopathy treated with lactullose. There was improvement in 9 patients but this 
could be attributed specifically to lactulose alone in only 6 patients. Seven of the 11 patients had evidence of chronic hepatic encephalopathy and were given lactulose on a long-tem basis. Five of these 7 cases had prior neomycin therapy, thus enabling comparison of lactulose with meomycin therapy* sustained long-tem improvement was seen in only 5 of the 7 cases. In these 5 cases, lactulose was more effective than neomycin, since it abolished all evidence of hepatic coma. In the face of a normal protein intake one of the 5 succumbed to bleeding. The conclusion was that lactulose is usefur and effective in the treatment of both acute and chronic encephalopathy and is more effective than neomycin.

In 1971 Imler (76) reported a study of 18 hospitalized cirrhotics with spontaneously appearing and persistent episodes of portal systemic encephalopathy. Only one patient had a surgical portacaval shunt. All patients were first started on a protein-restricted diet before ather treatment was initiated. Lactulose was compared to nemycin, chlortetracyclin ( $1 \mathrm{~g} i . v$.$) or$ Lactobacillus acidophilus. No patient responded in any way to the Lactabacillus acidophilus treatment. Two patients however showed rapid improvement when neomycin was given. Lactulose treatment was first given to 4 cirrhotics at a dose of $50 \mathrm{ml}$ per day, which gave only a slight improvement in one patient. The best response to lactulose occurred in those given $90 \mathrm{ml}$ daily. When administered to 10 patients, 7 showed marked improvement on the basis of clinicall and EEG evidence. When the dose was increased to $135 \mathrm{ml}$ daily to the three patients who did not respond, one showed a slight improvement, but another deteriorated with diarrhoea and hypokaliemia. In seven patients, lactulose treatment was compared with neomycin or chlortetracycline. All patients responded better than with lactulose. The ammonia levels and EEG findings correlated well with clinical improvement. It was not mentioned however whether the treatment was instituted at random and whether the results were evaluated under blind conditions.

Bircher $(1966,1971)(77,78)$ reported a carefully designed within-patient trial with six patients. The 6 patients included in the analysis of the 
results had far adwanced cirrhosis. One patient was an alcoholic, but the origin of the cirrhosis in the others was unknown. Two patients had a surgical portacaval shunt. Of the 17 patients started in the trial, only 6 fullfinled the criteria at the end of the study period [Ccona grade III to IV scale $0-V$ ) within 3 days after withdrawal of neonycin or lactulose with 409 protein a day, no change in state of liver disease during the study, absence of azotemia and uncorrected electrolyte imbalance, absence of gastro-intestinal hemorrinage within one month prior to and during the study, diuretic therapy kept constant]. The investigation in each patient lasted 4 to 5 weeks and was divided into 4 treatment periods:

1) Lactulose

2) Neomycin

3) A laxative (sorbitol or magnesium sulphate)

4) Lactulose + higher protein intake.

The treatment period lasted 7 to 10 days except for the laxative period which had to be teminated earlier because all patients developed coma. Lactulose dosage ranged from 90 to $150 \mathrm{ml} / \mathrm{day}(67 \mathrm{~g} / 100 \mathrm{ml})$. Neomycin was given and waried from $2-8 \mathrm{~g} / \mathrm{day}$. The laxatives were given in doses adjusted to produce the same degree of laxative effect as lactulose. All patients did well on neomycin and protein restriction to $40 \mathrm{~g}$ per day. They also did well on lactulose and no patients showed signs of deterioration when protein intake was increased to between 70 and $100 \mathrm{~g} /$ day in the second lactulose period. Tolerance to increased protein was not tested when neomycin was used. The six patients continued to take lactulose without dietary protein restriction and symptoms of encephalopathy remained well controlled in a11. Two patients discontinued lactulose intake themselves. One of them had to be rehospitallzed in coma, but promptly responded to resumed lactulose treatment. No side effects of long term lactulose treatment could be detected. Five patients died after six weeks to ten months. The causes of death were oesophageal variceal bleeding renal failure, cerebral hemorrhage and unexplained sudden death. Consecutive bacteriological studies of the stools during the whole 
investigation period were available for two patients. It was concluded that there was no correlation between the clinical effect of lactulose and changes in faecal bacterial composition. Bircher concluded from the effects of lactulose and neomycin, that there was no appreciable difference between the therapeutic effects of neamycin and lactulose. The control "laxative" solution (sorbitol or magnesium sulphate) was without effect.

In 1973 Rodgers (79) reported a long-term study of six patients who were originally entered into the study but only three were followed for a year or langer. He used lactulose (50\%) and sorbitol (60\%) in order to compare these drugs in the management of hepatic encephalopathy in a double blind study. Patients were instructed to consume a $50 \mathrm{~g}$ protein diet. During the first year of the study patients were continued treated with one medication for a period of two months and then switched to the other for a similar length of time. During the second year a controlled periad separated treatment periods. EEG, blood ammonia and clinical state were observed. It was cancluded that both lactulose and sorbitol were beneficial in the treatment of hepatic coma. Whether lactulase or sorbitol was superior could however not be cancluded from this study. In contrast to many investigators, Rodgers observed a reduction in stool $\mathrm{pH}$ after sorbitol treatment. It was also difficult to relate clinical state with EEG and blood ammonia levels.

In 1981 Orlandi (80) reported a randomized study in order to compare the course of hepatic encephalopathy in patients treated with neomycin plus magnesium sulphate or with lactulose. One hundred seventy three patients were selected with a diagnosis of cirrhosis. Patients received orally neomycin tablets of $1 \mathrm{~g}$ four times a day and purgation with $30-60 \mathrm{~g}$ of magnesium sulphate orally was achieved in patients with grade I hepatic encephalopathy. Two grams of neomycin four times a day and magnesium sulphate $(30-60 \mathrm{~g})$ were given in grade 2 or 3 of hepatic encephallopathy. Ten to $35 \mathrm{ml}$ of $d 50 \%$ lactulose syrup were given three times per day orally. The aim of the therapy was to induce two bowel movements a day. Mean values of duration of the treatment with neomycin and lactulose were respectively 17.3 and 18.6 days in 
grade 1 and 13.3 and 16.2 days in grades II and II hepatic encephalopathy. Grade I was defined when three or more of the following signs were present:

1. slow or slurred speech,

2. disturbances of memory,

3. abnormalities of behavior and/or mood,

4. abnormalities of gait,

5. asterixis,

6. writing difficulty,

7. abnormal performance of serial subtractions,

8. difficulties in drawing a five poimted star,

9. disturbances in Reitan trailmaking test $A$ en B (81),

10. EEG changes.

Grade II includes major changes of mental state, somnolence and loss of discrimination. Grade III is coma, with inability to test mental state.

Inprovement of the therapy was transition from grade 1 to grade 0 or from grade 2 or 3 to grade 1 or 0 . The outcome was defined as unsatisfactory when transition to a less severe grade did not occur within 14 days. At the time of randomization 114 of the patients exhibited grade I encephalopathy. Fifty two were in grade II and 7 subjects were in grade III. Eighty two received neomycin, 91 lactulose. Forty nine patients with grade I hepatic encephalopathy were allocated to the neamycin group and 65 to the lactulose group. The respective values were 33 and 26 for patients with grade II or III hepatic encephalopathy. Transitions from grade II and III to grade I or 0 showed a difference in favour of neomycin. However the study demonstrated a similar course of the symptoms when patients with grade I hepatic encephalopathy were treated with neomycin sulphate or with lactulose. Improvement in EEG pattern was observed in most patients. Alsa plasma ammonia decreased in the neomycin and lactulose group. Stool pH decreased anly in the lactulose group. The drug of choice in long-term treatment of hepatic encephalopathy should be lactulase because of the benefit risk ratio of neomycin which has many side effects. Although the study was large and excellent in set up, no double blind design 
was used, this however is very difficuit to achieve because of the specific effects of the drugs under investigation.

\subsubsection{Controlled double blind trials}

Simmons (1970) (82).

Twenty six patients with hepatic encephalopathy were selected for the study. All had a history of excessive alcohol consumption and in 16 alcohalic liver disease was comfirmed histolagically. After being accepted into the study, patients were randomly assigned to one of two groups according to the next available code number. The nature of the code was not known to the investigators. One group received lactulase, the control group received a substance similar in flavour and appearance but containing glucose. The duration of the treatment was 10 days. All patients initially received a $40 \mathrm{~g}$ protein diet but after 5 days dietary protein was increased to $60 \mathrm{~g}$ in those patients who were free of encephalopathy. Five patients 3 in the lactulose group and 2 in the glucose grcup) were eliminated from the study, mainly because of complications of their hepatic disease, unrelated to encephalopathy. On the basis of improvement in encephalopathy the lactulose group showed a superior response to the glucose group: a result which was statistically significant. EEG's were not performed. Fasting venous blood arnmonia levels did not change significantly. After 10 days however, the patients receiving lactulose had a mean ammonia level which was significantly lower than patients receiving glucose. This double blind study strongly supports the value of lactulase in the treatment of hepatic encephalopathy.

Brown (1970, 1971) $(83,84)$ reported a long-term double-blind within-patient trial in 20 patients. They were initially hospitalized for a week on a diet containing $20 \mathrm{~g}$ protein per day which was gradually increased until neurological signs of encephalopathy were evident. 9 of the 20 patients were then admitted to a double-blind trial to receive randomly either liactullose or sorbitol for varying periods on an outpatient basis. Of the other 11 pati- 
ents, 3 were uncooperative in taking lactulose and were elliminated from the study. Two had only been under treatment for a few months. Three were mainm tained on a protein restricted diet only and 3 died early, 1 from lymphoma and 2 from acute allcoholic hepatitis. Of the nine patients one did well on sorbitol, the other did well on lactulose only and was discharged on a $100 \mathrm{~g}$ protein diet. The other 7 patients were given alternating periods of lactulose or sorbitol syrup. Five patients responded well to both drugs. Blood ammonia levels were not strikingly reduced and did not always correlate with improvement. The EEG changes, although not impressive, returned to normal. Both lactulose and sorbitol produced a laxative effect which was associated with a fall in faecal pH. Brown concluded that lactulose was effective in outpatient management of hepatic encephalopathy. Sorbitol given as control, often praduced a response but was judged much less effective than lactulose. It is a pity that dietary protein was not kept constant in this study. Germain (1973) (85) performed a double blind study in 18 patients with chronic PSE after portocaval anastomosis in which he compared lactulose and sucrose. Nine of these 18 were randomly selected to have each form of therapy in a simple comparison design. The patients were evaluated before and after 15 days of therapy with $60 \mathrm{ml}$ of lactulose or sucrose daily. Patients in both groups had mild PSE, and only a few patients showed elevations of venous ammonia concentration. EEG's showed mild to moderate changes. The investigators showed that clinical manifestations and blood ammonia were not significantly different in the patients receiving lactulose and in those receiving placebo. However, lactulose had a significant effect on psychometric test abnormalities and on EEG disorders. ATthough there was a reasonably good correlation between the derangement of mental state and the abnormalities of the $E E G$, there was a poor correlation with the other phenomena of the PSE syndrome. The bad results of the administration of lactulose was probably due to the mild grade of PSE and the low dosage.

Elkington (1969) (86) performed a carefully conducted double blind withinpatient trial in 10 patients. The 10 patients studied had received previous 
treatment with neomycin and protein restriction for encephalopathy which was clinically stable at the time of the trial. All had histologically proven cirrhosis. Of these 10 patients 7 were selected for the double blind trial during which they were kept on a constant restricted protein intake. Each patient was used as his own control and the trial was divided into 4 periads.

1. Control period;

2. Treatment with either lactulose or sorbitol at random for 6-27 days;

3. Control period of observation;

4. Treatment period with either sorbitol or lactulase, employing the drug which had not previously been administered.

Sorbitol $70 \mathrm{~g} / 100 \mathrm{ml}$ was presented in a syrup similar in flawour and colour as the lactulose syrup. The mental state was assessed and graded daily according to modified criteria of Parsons-Smith (87) and serial EEG's were interpreted "blindly" at the end of the study. Lactulose therapy resulted in improvement of 5 of the 7 patients studied. In all 5 stool pH and arterial ammonia concentration were reduced by lactulose. Improvement in the EEG occurred in 4. In the other 2 there was no decrease in stool pH or blaod ammonia levels. Overt neurological signs of PSE had been present in only ane of the seven patients at the time of study. This patient, when neomycin was replaced by sorbitol, relapsed into deep coma, but recovered by the repeat administration of neomycin. Lactulose therapy alone in this patient was associated with dramatic improvement in mental state and return to nearly normal blood ammonia levels and EEG. This improvement was maintained during lang term lactulose therapy on a double protein intake. Lactulose was also administered on a long term basis (1-10 months) to seven patients. A1 1 showed satisfactory results enabling neomycin to be discontinued and protein intake to be doubled. Of the 62 serial stool specimens obtained from five patients, results indicate that here was no signifirant alteration in the recoveries of total aerones or anaerobes. These observations suggested that lactulose may be useful in controlling chronic PSE.

Conn (88) performed in 1977 a randomized touble blind clinical trial in which 
he compared neomycin and lactulose in 33 cirrhotic patients with chronic portal systemic encephalopathy. Patients selected for the study were cirrhotic patients with or without portacaval anastomosis who had developed chronic or recurrent PSE. At the time patients entered the protocol, it was required that they were stable, were not azotemic, did not have intercurrent infections and did not receive encephalo-pathogenic medication. Patients renained in the hospital throughout the study. Each patient served as his own control. Because two different drugs were used, a double drug system was devised. Lactulose was paired with placebo tablets identical to neomycin tablets. Neonycin was administered along with sorbitol. Sorbitol however was not a placebo. Another drug like glucose would not have been possiblle since it. would be immediately identified by the absence of cathartic activity. After an initial period of stabilization, control period I was begum. When patients remained well, dietary protein was gradually increased by 5 to $10 \mathrm{~g} /$ day and the control period was extended. During treatment $A$, which continued for at least 10 days the patients received either sorbitol-neomycin or 1actulose placebo. Then control period II was started, which lasted for 10 days or more and was followed by treatment period $B$, during which lactulose-placebo was given. Them control period III was started. The medications were administered randomly by a sealed envelope system. Neomycin was administered in a dosage of $1.5 \mathrm{~g} /$ day and the $1 \mathrm{iquids}$ at $25 \mathrm{ml}$ a day. This dosage was adjusted to induce 3 or more bowel movements. The pH of each stool specimen was measured and dietary protein was kept at a constant level throughout the study. Mental state was assessed at least 3 times daily. A trailmaking test was done and asterixis was recorded. EEG's were performed twice weekly. A PSE index was used as an arbitrary index of therapeutic efficacy. This index was based on the degree of abnormality of each of the various parameters measured e.g. mental state, trailmaking time, EEG, asterixis and arterial ammonia concentration. Thirty three patients satisfied the criteria for inclusion in the study. Twenty nine had alcoholic cirrhosis and 4 had a post-necrotic liver. A porta-caval shunt was performed in 15 of these 33 patients. 18 patients were 
randomly selected to receive 7 actulose and 15 neomycin-sorbitol as treatment A. Patients who completed treatment A were then given the other drug. The authors claimed that lactulose was considered effective in 15 of 18 patients, whereas neomycin-sorbitol was effective in 13 of 15 patients. In the cross-over study, lactulose was considered effective in 26 of 29 patients compared to 24 of 29 with neomycin-sorbitol. Mental state and asterixis were significantly improved by neomycin-sorbitol and by lactulose and deteriorated to pretherapy levels when these treatments were discontinued. EEG recordings improved to an equal degree with lactulose and neamycin-sorbitol. Improvement in trailmaking test time was observed with both neomycin-sorbitol and lactulose, but the differences were not significant. Mean ammonia concentrations were similar after both forms of therapy. In the cross-over comparison of neomycin-sorbitol and lactulose each of the indices of PSE was analyzed. Both neomycin-sorbitol and lactulose however shawed no significant difference of improvement in asterixis and mental state. In the trailnaking test, time to perform the test was significantly reduced by lactulose but not with neomycin and sorbitol. Arterial ammonia levels were reduced by both neomycin and lactulose. The mean grade of EEG abnormality improved significantly with both lactulose and neomycin. The PSE index showed improvement in all patients who received lactulose. Of the 15 patients treated with neamycin-sorbitol 13 improved. In the crass-aver study the PSE index was greater for lactulose than for neomycin-sorbitol. Both therapies reduced stool $\mathrm{pH}$. The authors concluded that both lactulose and nemycin-sorbital are effective in the treatment of chronic portal systemic encephalopathy.

Atterbury (1978) (89) reported a double-blind randonized study in which he compared the efficacy of lactulase with neonycin-sorbital in 15 episodes of acute nitrogenous portal-sytemic encephalopathy. Al1 the patients had underlying cirrhosis. Twenty episodes of acute PSE in ten patients who had suddenly developed acute PSE during the therapy were included in the series. In this study chronic PSE was defined as the state in which recurrent or continuous encephalopathy develops. Acute PSE was defined as the sudden develop- 
ment in a cirrhotic patient of encephalopathy precipitated by nitrogenous substances in the absence of other explanations for encephalopathy. Patients were randomly assigned by sealed envelope technique to recelve neomycinsorbitol or lactulose. Patients selected to receive neonycin-sorbitol $(1.5 \mathrm{~g}$ neomycin and $50 \mathrm{ml}$ syrup every $1-2$ hrs until two bowel movements had been passed). Patients receiving lactulose received $50 \mathrm{ml}$ every $1-2$ hrs until also two bowel movements had been passed. Dietary protein was kept constant at a level of 10-20 $\mathrm{g}$ daily as determined by the house staff. On the initial day of therapy both groups received a cleansing tapwater enema.

Several parameters were used to evaluate improvement and were brought into a PSE index: mental state, NCT (Number Connection Test which is the time in seconds it takes the patient to perform a simple psychametric test), EEG and arterial ammonia concentration. Patients were continued on the regimen to which they were randomized until maximum clinical response had been achieved. Lactulose and neomycin-sorbitol were equally effective in the treatment of acute PSE in this investigation. Both therapeutic programs were successful in more than $80 \%$ of the episodes. The improvement was in both groups demonstrated by a similar reduction of the PSE index. The only difference in results induced by lactulose versus neomycin-sorbitol was in the degree of reduction in stool pH: lactulose reduced the pH more than neonycin-sorbitol. The author concluded that lactulose is an effective alternative to neomycin in the treatment of acute PSE as well as chronic PSE (89).

\subsubsection{Lactulose in acate portal-systemic encephalopathy}

The efficacy of lactulose in the treatment of portal-systemic encephalopathy has been reported by a great number of investigators since it was first used. Although lactulase has primarily been studied in patients with the chronic recurrent form of the disease, a few papers have been published specifically about the treatment of patients with acute PSE. DeMeulenaere (60) reported in 1969 the use of lactulose in five patients with acute PSE (see chapter 
1.4.1.). He concluded that lactulose was useful in acute PSE. The good clinical response was accompanied by a decrease in venous ammonia levels.

Fung (75) (see chapter 1.4.2.) reported eleven cases with evidence of acute hepatic encephalopathy treated with lactulose. There was an improventent of $54.5 \%$ directly attributed to lactulose.

Simmons (82) (see chapter 1.4.3.) performed a controlied investigation of lactulose in the treatment of PSE. Eleven patients received $80 \mathrm{~g}$ of lactulose datly while 10 pattents received $60 \mathrm{~g}$ of glucose as control. Patients receiving lactulose showed significant reduction in both encephalopathy and blood ammonia levels .

Cassi reported a study in which he succesfully treated 5 patients with acute PSE (90).

Fessel (91) reported a controlled study in which lactulase was administered in 24 episodes of acute nitrogenous hepatic coma. The results were compared with 24 retrospectively matched episodes of encephalopathy treated with neomycin. The two groups were similar in type. Lactulose effectively reversed coma in 20 of the 24 episodes. Neomycin was effective in 23 of the 24 episodes. Improvement of arterial ammonia, EEG and other measures of encephalopathy were similar in the two groups. The study demonstrated that lactulose was effective in the treatment of acute PSE.

Atterbury (89) (see chapter 1.4.3.) compared in a double-blind randomized study the efficacy of lactulose with neomycin/sorbitol in 45 episodes of acute PSE. Two thirds of the patients in each group returned to normal mental status and more than $80 \%$ in each group showed at least one grade improvenent in mental state. The only difference in results between those two groups was a reduction in $\mathrm{pH}$ of the stools in the lactulase group. These data suggest that neonycin/sorbitol and lactulose are equally effective in the treatment of acute PSE. 


\subsubsection{Lactulose enemas}

Lactulose is degraded by bacterial enzymes in the intestine. When administered orally it is not degraded until it reaches the lower intestine 1-8 hours later and the beneficial clinical effects of lactulose are seen within 24 to 48 hours. It therefore seemed reasonable that if lactulose was injected directly into the callon by enema the clinical response might be achieved more rapidly. The first report of rectal enemas of lactulose in the treatment of PSE appeared in 1969. In an uncontrolled observation $300 \mathrm{ml}$ of lactullose syrup (200 g and $700 \mathrm{ml}$ water) was administered with a balloon catheter to assure retention of lactulose for at least 20 minutes. Mental state improved very rapidly and sometimes spectacularly. Also there was a marked fall in venous ammonia concentration and improvement in the EEG tracings (60).

Imler (see chapter 1.4.2.) (76) performed a study in patients with lactullose enemas. He reported no succes in their treatment.

Cassi (see chapter 1.4.4.) (90) performed a study in six patients with hepatic coma. One or 2 enema's containing $300 \mathrm{~m}$ of lactulose were administered. Three of the patients awoke within a few hours. The others died.

Kersh (92) performed in 1973 a study in patients with hepatic encephalopathy in four patients in which he administered lactulose by retention enema. A11 patients showed dramatic improvement in clinical grade of coma within 12 hours. Arterial ammonia and cerebrospinal fluid ammonia levels showed a marked decline. The $\mathrm{pH}$ of the stool also decreased. They concluded that clinical and biochemical response occurred much more rapidly than in cases treated with oral lactulose.

Ratnaike (93) studied in 1975 six patients with severe liver failure. In these patients a colonic washout was performed, containing equal papts of lactulose and physiological saline (lactulose $50 \%$ ). Two litres of the solution were administered to each subject by rectal tube over a one hour period. For the state of comparison, in two patients, the lactulose physiological saline washout was preceded by a "control" washout. In one patient the 
control washout was perfomed using phystological salline pH 6.0 and in one patient acetate buffer at $\mathrm{pH} 4.5$, the $\mathrm{pH}$ corresponding to that of the lactulose solution. Estimation of Blood ammonia levels and EEG were performed before and after treatment. In five patients a significant fall was recorded in blood ammonia level as a result of dactulase therapy. In the sixth subject, an enema with buffered physiological saline with pH 4.5 , induced a fall in ammonia, which was not increased by subsequent lactulose solution. Improvement in the EEG, was recorded in all periads where a lactulase colonic washout produced a fall in blood ammonia level. Wan Waes (94) reported in 1979 a study with lactulase enemas during 34 episodes of acute PSE in 18 different patients. All patients had liver cirrhosis, 4 had a porta-caval shunt. Lactulose enemas consisted of lactulose syrup $300 \mathrm{ml}$ diluted with tap water $300 \mathrm{ml}$. The $\mathrm{pH}$ of the solution was 3.85. Enemas containing $1000 \mathrm{ml}$ of a $30 \%$ glucose solution in water ( 8 times) or tap water alone were used as control in 13 episodes. Before the enema, the degree of encephalopathy was evaluated clinically according to criteria of Parsons-Smith (87). Lactulase enemas decreased blood ammonia and reversed clinical and EEG manifestation of encephalopathy in 30 out of 34 episodes of acute portal-systemic encephalopathy in 18 patients with liver cirrhosis. The results became apparent within hours and were suggested to depend on effective acidification of the colon. The authors concluded that lactulose enemas are indicated for prompt control of acute eplsodes of PSE, when oral therapy is not sufficient to control hyperanmonemia.

Conn (95) reported a study with seven patients, all treated with lactulose enemas. He administered one liter enemas that contained $500 \mathrm{mi}$ of lactulose and $500 \mathrm{~m} 1$ of water at 6-hour interwals. There was a good response in 10 of the 14 episodes and nomal mental state was restored within 24 hours. In 3 patients mental state did not normalize. In all 3 patients, impressive reductions in arterial ammonia occurred. 
Table 1: Results of uncontrolled trials of lactulose in the treatment of hepatic coma

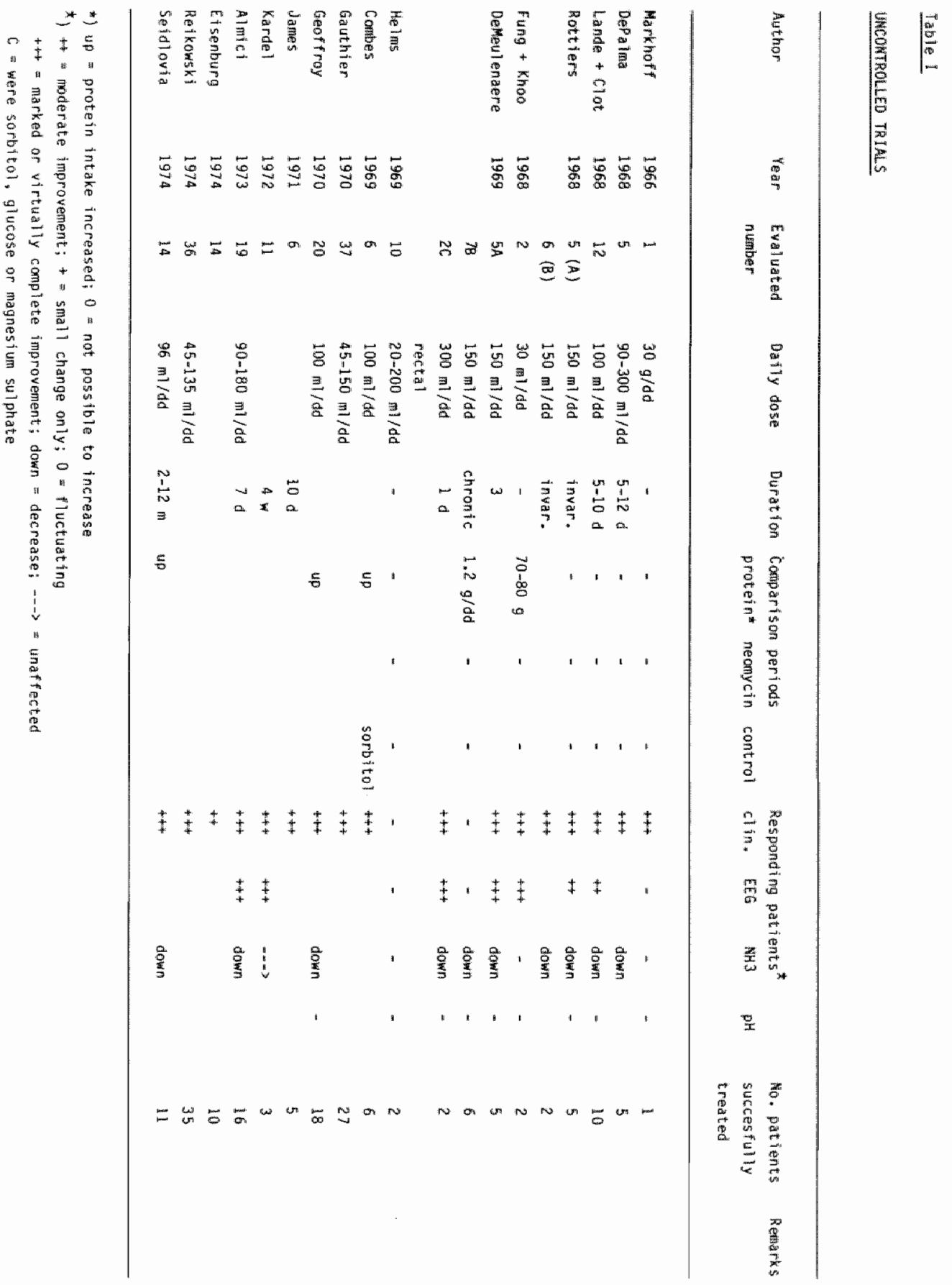


Table II: Results of controlled trials of lactulose in the treatment of hepatic coma

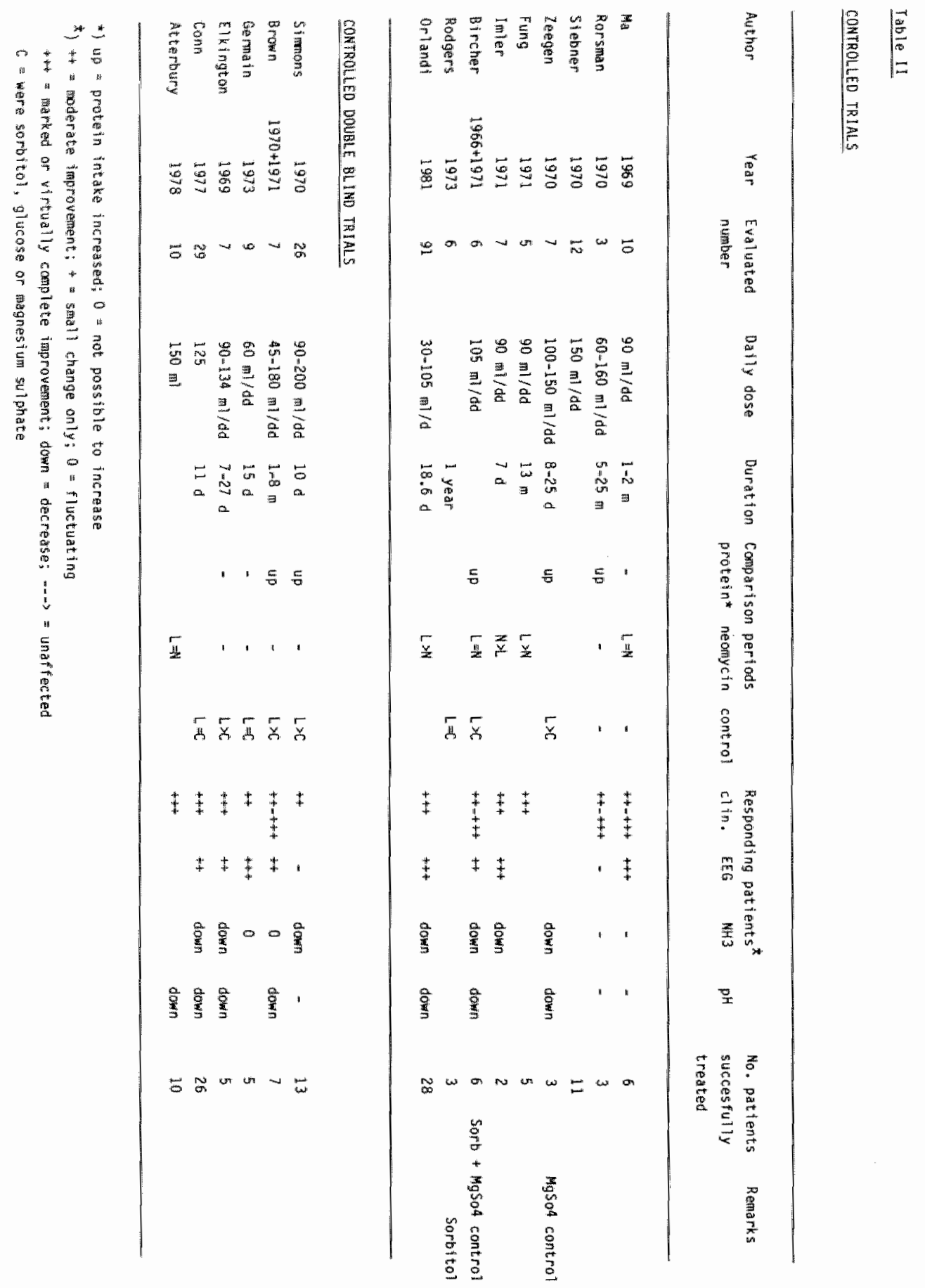




\subsection{Neomycin in hepatic encephalopathy}

\subsubsection{Neonycin: the mode of action and efficacy}

Neomycin is a amino-glycoside antibiotic isolated from a strain of streptomyces fradiae.

The drug is effective against most gram-megative and some gram-positive aerobes, but it has wirtually no effect on the anaerobic flora $(96,97)$. Its activity is not due to a single substance but to a number of active substances entitled the neomycin complex (98). When silen (99) used the drug in dogs, it became apparent that it significantly lowered the ammonia levels in the venous mesenteric blood, even when protein feeding was continued $(100)$

It soon became the drug of choice in the treatment of hepatic encephalopathy $(101,102,100)$ and various investigators claimed beneficial effects $(103,104)$. Its mode of action was claimed to be based on the fact that it reduces the faecal flora. The success of neomycin treatment confirmed the idea that ammonia originated solely from bacteria and that the decrease in plasma ammonia levels occurred due to the anti-microbial properties of neomycin. Daws on however, could not correlate the clinical improvement with bacteriological changes in the stools (101). He concluded also that neornycin certainly did not sterilize the stools and that several species of ammonia producing bacteria remained.

Also in the study of Sabbaj (105) no correlation was found between clinical improvement and bacteriological changes in the faeces. He discovered that although deaminating capacity was common among the faecal bacterial species oral treatment with neomycin ar kanamycin caused no reduction in the numbers of deaminating bacterial species. 


\subsubsection{Uncontrolled and controlled trials}

In 1954 Sherlock (106) introduced oral broad spectrum antibiotics and enema as a basis for treating hepatic coma. In 1955 Silen (99) demonstrated in dogs that ingested neomycin is highly effective in reducing ammonia levels. Fischer (100) reported in 1957 a study of 11 patients to whom neomycin was administered. They had hepatic cirrhosis due to excessive alcohol ingestion. Patients were divided up into two groups. The first group of 8 patients without neurologic manifestations was given a protein diet $110-120 \mathrm{~g}$ and received $12 \mathrm{~g}$ neomycin. The second group consisting of three patients with neurologic manifestations, was given $12 \mathrm{~g}$ of neomycin daily, after control blood ammonia determinations mere obtained. Results indicate that the oral administration of neomycin resulted in a significant decrease in blood ammonia levels in patients with cirrhosis, regardless of the presence or absence of neurologic changes.

In 1957 then Dawson (107) reported a study of 12 patients with acute hepatic coma and 8 patients with chronic hepatic coma, who received neomycin for periods up to ten months. He observed the clinical state, blood ammonia levels and the effect on stool flora. The dosage was 4-10 g daily. Six chronic patients showed pronounced clinical benefit which was associated with a fall in the fasting artertal blood-ammonia level and an improvement in the EEG. One patient relapsed after ten months of treatment. The effect on the stool flora was variable and could not be correlated with the clinical benefit or with the fall in arterial blood ammonium level. Seven out of 12 patients with acute hepatic coma showed initial improvement, but other forms of treatment were used simultaneously.

In 1958 Sumnerskill (108) performed a controlled study with neomycin on six patients. A daily assessinent of the neuropsychiatric state was carried out. In his study he compared neomycin with chlortetracylin and chloramphenicol. Case 1,2 and 3 were of interest, because comparative studies were possible. Neonycin appeared to be more effective than chlortetracyclin, sigmamycin and 
chloramphenicol. The results underline the importance of aral antibiotic therapy and show that neomycin is the most effective of recommended antibiam tics.

In 1958 Fast (109) reported a study of elewen patients with liver disease and hepatic coma. Nine patients had cirrhosis associated with chronic alcoholism. One had cirrhosis of unknown etiology and one had viral hepatitis. Patients were divided into three groups. Group I consisted of two patients with episodic stupor who were studied under the controlled conditions of a metabolic ward. Group II consisted of six patients having progressive hepatic failure, as indicated by elevated serum billirubin concentrations, the presence of ascites and the spontaneous appearance of hepatic coma. Group III consisted of three patients with hepatic coma in whom massive gastrointestinal hemorrhage was the precipitating factor. In group I neonycin was administered and dietary protein gradually increased from 30 to $90 \mathrm{~g}$. No alteration in mental status was noted. Later paromycin and neomycin were given when coma was evident. When given in a dase of $4.0 \mathrm{~g}$ or more daily clinical improvenent resulted within 48 hours. Complete recovery was seen within 4-5 days. In patient 2 severe impending coma occurred during an intake of $90 \mathrm{~g}$ of protein. A dramatic response occurred within 24 hours after administration of $4 \mathrm{~g}$ of paromycin. Arterial ammonia in patient 1 correlated with clinical response. Patients in group II and III were treated with enemata. Sedatives and other drugs known to cause hepatic coma and excess of dietary protein were omitted. Neomycin or paromycin were administered in datly doses of $1 \mathrm{~g}$ or more four times a day. In group II only one patient recovered completely. In group III all three responded to therapy and two recovered completely. One died following recurrent haemorrhage. The authors concluded that neomycin and paromycin orally used were effective therapeutic agents in hepatic coma. In case of hepatic failure associated with hepatic coma antibiotics are recommended, allowing the consumption of normal amounts of protein.

Stormont (110) carried out a study in 1958 in 68 patients and observed 70 episodes of hepatic coma. He used Summerskill's criteria for selection of 
patients. Protein was completely eliminated from the patients' diet. Nitrogenous material in the colon was removed initially by enemas. Neomycin or paronycin was administered oraly in doses of $4-8 \mathrm{~g}$ dally. Chlortetracyclin 2 9 dafly was given to 12 patients. Protein was reinstituted in about $30 \mathrm{~g}$ amounts on the second to fourth day. When improvement accurred, dietary protein intake was gradually tncreased to $60 \mathrm{~g}$ daily, while antibiatics were maintained. If progress continued, antibiotics were gradually decreased and discontinued. Recovery was assumed to mean improvement sufficient for the patient to leave the hospital. Of the 58 episades (excluding the 12 patients receiving chlortetracylin) 34 were treated with paromycin which resulted in 14 recoveries. 24 were treated with neomycin resulting in 9 recoveries. Thus, there was essentially no difference between the various antibiotics used in conjunction with readministration of protein. Comparison with 35 patients treated with complete protein withdrawal and chlortetracyclin also revealed no important difference in improvement and recovery. Stormont concluded that neomycin and paromycin in the treatment of hepatic coma was found equal, if not superior to therapy with chlortetracylin.

Falloon (104) studied 22 patients with a histary and physical findings consistent with alcoholic cirrhosis during 25 episodes of coma. The usual regimen of therapy in these patients included administration of 20 to $40 \mathrm{~g}$ of protein and oral neomycin $12 \mathrm{~g}$ daily. Recovery was assumed ta have occurred when patients were in a stable alert state and could be discharged from the hospital. Of the 22 patients receiving neomycin 11 died but 9 improved prior to death. Of the 25 episodes of coma, recovery was noted in 14 instances. Of the 18 patients receiving protein from the beginning of therapy together with meomycin, seven lived and eleven died, but improwement was noted prior to death in nine of the latter. A decrease in blood ammonia during therapy was obserwed in 16 of the 18 patients in whom it was measured. In 1981 Uribe (111) carried out a randomized double blind comparison of lactose enemas plus placebo tablets versus starch enemas plus neomycin tablets in 18 patients having acute portal systemic encephalopathy. Acute PSE 
was arbitrarily defined as the sudden development of encephalopathy in a cirrhotic patient. Before inclusion in the study patients must have developed an acute episode of PSE within $24 \mathrm{~h}$. Eight patients received a one liter lactose enema of $20 \%$. Simultaneously they received placebo tablets identical to neomycin tablets. Ten patients received 1 I starch enemas (10\%) plus two $1.5 \mathrm{~g}$ neomycin tablets. The following parameters were assessed: mental state, asterixis, EEG, blood ammonia concentration. These parameters were computed in a PSE index. Clinical and biochenical improvement was observed after lactose enemas in 7 of 8 patients and in 7 of 10 patients treated with starch. Both treatments significantly decreased the frequency of asterixis and the level of blood ammonia, and improved EEG. Although this double blind trial was done to demonstrate the effect of lactose, neomycin proved to be an efficacious therapeutic agent for hepatic coma. One should keep in mind however that the beneficial effect of both treatments to a significant extent could have been the consequence of the cleansing effect of both enemas.

In a double blind trial Hirayama (1982) (112) studied 24 patients with advanced chronic 1 iver disease who received $1.2 \mathrm{~g}$ of nicotine hydroxamic acid daily (N.H.A.) and 23 patients who received $1.5 \mathrm{~g}$ of neomycin. Patients receiving N.H.A. showed significant improvement in blood ammonia levels as compared to patients receiving neomycin.

\section{Conclusions}

Several studies have been devised in order to study the effect of lactulose on hepatic coma. The early studies however were not controlled and the data concerning clinical response to therapy were insufficient. However of the 16 uncontrolled trials (table I) in which 217 patients were studied 170 responded wel1 to lactulose treatment (79\%). After 1969 studies became more controlled. A few of these studies compared lactulose with other therapeutic agents like neomycin, broad spectrum antibiotics and laxatives like sorbitol and MgS04. One of these studies performed in 1966 and 1971 by Bircher $(77,78)$ under controlled conditions was of excellent set up and carefully designed. 
of the 56 patients in these studies $39(69 \%)$ responded wel1 to therapy. a few truly objective double blind studtes an the effect of lactulos hepatic coma, have been conducted (table II). Of these studies, the lar was published by simmons and Conn. Of 179 patients entering the tria (52.5\%) responded well to therapy, which is allmost $30 \%$ less than the out of the early studies. It appears as if the better the trial is contral the worse the result is of lactulose treatment of hepatic coma. Althougr last controlled studies were double blind a control group using placebc not included, most likely far ethical reasons. As an outcome of sev studies in which neomycin was administered orally and the ammonta levels decreased, thereby ameloriating the PSE, neomycin was chosen treatment of hepatic coma. Very few controlled studies on neomycin treat have been carried out. Atterbury (89) compared neomycin - sorbitol lactulose and found the drugs equally effective. Neamycin however was together with sorbitol and Brown (83) proved that sorbital is a very alternative for lactulose. Conn (88) carried out a comparable study using neomycin in combination with sorbitol. Orlandi (80) recently condu a controlled study on neomycin therapy. He demonstrated a similar cours the syndrome when patients with grade I hepatic encephalopathy were tre with meonycin and MgSO4 or with lactulose. Results were better with neon in severe hepatic encephalopathy. A control group receiving placebo was included however and the study was not double blind. Although both drugs used worldwide in the treatment of hepatic coma, no double blind contrc study with a placebo group has ever been performed.

\subsubsection{Lactulose and neomycin combined in the treatment of hepatic come}

Both drugs are well accepted in the treatment of hepatic cana and the me nism of action is based on the presumed toxic effect of ammonia and on essentially intestinal arigin of circulating ammonia. According to literature neomycin is known to exert its effect by destraying the ael 
flora and lactulose needs bacteria to break up into several organic acids which lower the intestinal pH and exert a laxative effect due to their asmotic property and to incorporate ammonia into amino acids. Lactulose and neonycin alone have been foumd to be equally effective in the management of PSE (see chapter 1.4) but neomycin is not the first choice because of its side effects (renal toxicity, malabsorption, inner ear deafness). Theoretically there is no need and no expected benefit of using these drugs together. One has suggested that neomycin does not kill all the laxative fermenting bacteria, and therefore that the drugs could potentiate each other. Because of the possible superimposed effects of both drugs Pirotte (113) performed a study in 1974 on nine cirrhotics with chronic PSE. In each patient the study was carried out in three successive periods.

Period 1: First patients were given high doses of lactulose. Three of the subjects also received $2.5 \mathrm{~g}$ neamycin daily orally. The treatments soon brought an improvement in the climical and biological state.

Period 2: Stabilization period.

Period 3: During this period, the patients had complete rest and were kept on a constant diet, identical to that of period 2. Each patient received $15 \mathrm{~g}$ lactulose 3 times a day, then no drug treatment for 5 days. During the next 10 days each patient was given $250 \mathrm{mg}$ neomycin 4 times a day. One day later $45 \mathrm{~g}$ of lactulose was added to neomycin and this double treatment was cont $\mathrm{i}$ nued for 12 days. Pirotte concluded that, used separately, neomycin and lactulose significantly reduce the basal ammonemia to values which were not statistically different from each other, but the association of both drugs lowered the basal ammonemia to values significantly lower than those recorded when the drugs were given alone.

Imler (76) (see chapter 1.4.2.) found in two patients, in whom neither lactulose or neomycin completely restored the mental state, EEG or blood amonia levels, that the combination of both drugs did restore these measures. Conn (95) performed a study in 22 cirrhotics and studied the stool pH of patients receiving the two agents individually and in combination. Based on 
the changes in stool pH it appeared that neamycin has no effect on acidity in one third, partially in the other third but completely inhibits the acidification in the last. He suggested that one might expect optimal action of both agents in about one-third of the number of patients. Hoyumpa (114) suggested in his study that the lactulose splitting bacteria appear to be relatively resistant to neomycin which is why a combination could wark in some cases. As all the authors seem to agree: it is not yet clear whether lactulose should be used alone or in combination with neomycin.

\subsection{Ammania in relation to the hepatic coma syndrome}

There is considerable clinical and experimental evidence that abnormalities in ammonia metabolism are somehow involved in the pathogenesis of hepatic cona $(115,116)$ although a poor correlation between the stage of hepatic encephalopathy and ammonia concentration in blood has also been reported $(117,118,119)$. Reasons for considering ammonia as an important agent in the genesis of hepatic encephalopathy are:

A. Lactulose and some other cathartics, neomycin and some other antibiatics, protein restriction, colon exclusion and other therapeutic measures appear to be of benefit in hepatic coma and all reduce ammonia levels in blood.

B. A great number of investigators have reported a good correlation between plasma ammonia levels and the degree of hepatic encephalopathy $(120,121)$. c. A form of cama can be induced in patients with chronic failure after ammonia loading (122).

Ammonia is generated in the gastrointestinal tract from bacterial and nonbacterial sources $(17,26)$ and in liver, muscle, brain, kidney and erythrocytes $v i$ a the purine nucleotide cycle $(123)$.

Amonia production by muscle only accurs after heavy excercise, but in $10 \%$ of the patients with liwer disease, muscle has been reported to increase arterial ammonia (124). Ammonia in blood, largely derived from the gut is meta- 
bolized in the liwer to urea. The urea then is excreted by the kidney and can be hydrolysed to a certain degree in the gut. When liver function is inpaired, or when portal blood is shunted around the liver into the systemic circulation, muscle may fullfill an important role in homeostasis. In hepatic disease with hyperammonemia, skeletal muscle is able to metabolize part of the arterial ammonia supply $(125,126)$. Ganda (127) claims that the ammonia taken up by muscle is released in the circulation as glutamine which than acts as a non-toxic nitrogen carrier. Imler however suggests that the glutamine release by muscle is not sufficient to explain the total ammonia uptake by muscle (128). Therefore high glutamine content of plasma together with a hypoalanenia in patients with liver disease has been suggested to result not only from the metabolic processes in muscle, but also from processes occurring in kidney, gastrointestinal tract and liver (129).

Ammonia is still present in many hypotheses concerming the genesis of hepatic encephal lopathy.

1. Ammonia can freely enter the brain.

Inside the brain it is thought to be metabolized via the alpha-keto-glutarate-glutamate sequence. As a result depletion may occur of alphaketoglutarate which may result in a decreased operation of the cycle. This results in a fall of high energy phosphate and oxygen consumption. Studies in dogs did show a reduction in many of the tricarboxylic acid cycle substrates intermediates, although results did not differ from a simple sedative or anaesthesia (130). These changes may be secondary rather than primary to coma. In an acute hepatic coma rat model, when rapidly freezing the brain, no major changes occurred in energy substrates $(131,132)$.

Several other hypotheses of ammonia in relation to the hepatic coma syndrome have been mentioned.

2. An acute toxic effect of ammonia on rat brain metabolism has been suggested. Hawkins used the new-freeze blowing technique, which permits freezing of supratentorial brain in rats within $1 \mathrm{sec}$. and without anaesthe- 
sia (133). His study showed no change in brain high energy phosphates ir central cortex and hemispheres and therefore suggested that ammonia toxicity was related, not to a disturbance of brain energy balance but to d drect neuronal effect af ammonia on the brain cells. This suggestion was also put forward in other publications (134) but is difficult to study in wivo.

3. In 1977 Zieve (130) postulated the synergism between mercaptans, ammonia and short chain fatty acids in the production of coma. Ammonia toxicity was enhanced three to four fold by the addition of methanethiol. Similarly, the cona dose of sodium octanoate in the presence of methanethiol was one third the dose required to induce coma by the short chain fatty acid allone.

4. The latest concept, which brings the ammonia tagether with the amino acid neurotransmitter hypothesis of Fischer, has been published by James (135). In his hypothesis he claims that hyperammonemia raises the concentration of neutral amino acids in the brain resulting in changes in neurotransmitter metabolism. Since ammonia stimulates brain-glutamine synthesis, increased outward transport of glutamine occurs at the expense of exchange for plasma neutral amino acids. Because the plasma neutral anfino acid profile is distorted in liver disease, increased transport of neutral amino actds over the blood-brain barrier also results in a distorted pattern in the brain, especially including increased levels of aromatic amino acids. Because these aronatic amino acids are precursors of neurotransmitters, the whole sequence may then result in a distorted neurotransmitter pattern and encephalopathy.

5. For the sake of completeness, the GABA theory should be mentioned which is the only theory, which does not include ammonia. GABA is an innibitory neurotransmitter, which is said to be formed by the anaerobic bacterial action (136) but can probably also be formed in the nucosacel of the intestine. It is degraded in the liver. In acute fulminant hepatic faflure and encephalopathy, gut-derived GABA in plasma crasses an abnor- 
mally pemeable blood-brain barrier and by mediating neural inhibition is claimed to contribute to hepatic encephalopathy. An increased number of GABA receptors in the brain found in liverfailure would then increase the sensitivity of the brain to GABA-ergic neural intibition.

\section{I.7. References}

1. Mossberg, S.M., Ross, G.: Ammonia movenent in the small intestine: preferential transport by the ileum. J. Clin. Invest. 46: 490-498 $(1967)$.

2. Castel1, D.0., Moore, E.W.: Amonia absorption from the human colon. The rale of nonionic diffusion. Gastroenterology 60: $33-42$ (1971).

3. Walser, M., Bodenloos, L.J.: Urea metabolism in man. J. Clin. Invest. 38: $1617-1626(1959)$.

4. Summerskil1, W.H.J., Wolpert, E.: Armonia metabolism in the gut. Am. J. Clin. Nutr. 23: 633-639 (1970).

5. Vince, A., Down, P.F., Morison, J., Twigg, F.d., Wrong, O.M.: Generation of amonia fran non-urea sources in a fecal incubation system. c1 in. Sci. Mo1. Med. 51: 313-322 (1976).

6. Bown, R.L., Gibson, J.A., Fenton, J.C.B., Snedden, W., Clark, M.L., Sladen, G.E.: Armonia and urea transport by the excluded human colon. Clin. Sci. Mol. Med. 48: 279 (1975).

7. Wolpert, E., Philips, S.F., Summerski11, W.H.J.: Transport of urea and ammonia production in the human colon. Lancet 2: 1387 (1971).

8. Gibson, J.A. , Park, N.J., Sladen, G.E., Dawson, A.M.: The role of the colon in urea metabolism in man. Clin. Sci. Mo1. Med. 50: 51-59 (1976).

9. Wrong, D.M., Vince, A.J., Waterlow, J.C.: The origin and bacterial metabolism of faecal anmonia. Falk Symposium 32, 1981, Calon and Nutrition, ed. H. Kasper and H. Goebbel, p. 133-139.

10. Bessman, A.M., Mirick, G.S.: Blood ammonia levels following the ingestion of casein and whole blood. J. C1 in. Invest. 37: 990-998 (1958). 
11. Clarke, U.S., Cruze, K. "Mckissock, P.K., Ozeran, R.S." Diphasic blood amonia curves after feeding protein to nomal dogs and men. Arch. Surg. 78 : $836-843$ (1959).

12. Jores, E.A.: The entigma of hepatic encephalopathy. Postgrad. Med. J. 59 (supp1. 4): 42-54 (1983).

13. Nance, F.C., Kline, D.G.: Eck's fistula encephalopathy in gem-free dogs. Ann. Surg. 174: 856-862 (1971).

14. Matsutaka, H., Aikawa, T., Yamamoto, H., Ischikawa, E.: GTuconeogenesis and amino acid metabolism. III. Uptake of glutamine and output of allanine and ammonia by non-hepatic splanchnic organs of fasted rats and their metabolic significance. J. Biochem. 74: 1019-1029 (1973)

15. Scha1m, S.W., Van der Mey, T.: Hyperammonemic coma after hepatectony in germ-free rats. Gastroenterology 77: $231-234$ (1979).

16. Warren, K.S., Newton, W.L.: Portal and peripheral blaod ammonia concentrations in germ-free and conventional guinee pigs. Am. J. Physiol. 197: 717-720 (1959).

17. Weber, F.L., Veach, G.: The importance of the small intestine in gut anmonium production in the fasting dag. Gastroenterology 37: 235-240 (1979).

18. Felig, P., Wahren, d., Karl, I., Cerasit, E., Luft, R., Kipnis, D.M.: Giutamine and glutamate metabolism in nomal and diabetic subjects. Diabetes 22: 573-576 (1973).

19. Pinkus, L.M., Windinueller, H.G.: Phosphate dependent glutaminase of small intestine: Locallization and role in intestinal glutamine metabo1ism. Arch. Biochem. Biophys. 182: 506-517 (1977).

20. Neptune, E.M. Jr.: Respiration and oxidation of various substrates by ileum in vitro. An. J. Physio1. 209: 329-332 (1965).

21. Addae, S.K., Lotspeich, W.D.: Relation between glutamine utilization and production in metabolic acidosis. Am. J. Physiol. 215: 269-277 (1968). 
22. Elwyn, D.H.s Parikh, H.C., Shoemaker, W.C.: Amino acid novenents between gut, liver and periphery in unaesthetized dogs. Am. J. Physiol. 215: $1260-1275$ (1968).

23. Wolf, J.E., Bergman, E.M., Williams, H.H.: Net metabolism of plasma amino acids by 7 iver and portal drained viscera of fed sheep. Am. J. Physiol. 223: 438-446 (1972).

24. Windmueller, H.G., Spaeth, A.B.C.: Uptake and metabolism of plasma glutamine by the sma11 intestine. d. Biol. Chem. 249: 5070-5079 (1974).

25. Watford, M., Lund, P., Krebs, H.A.: Isolation and metabolic characteristics of rat and chicken enterocytes. J. Biochem. 178: 589-596 (1979).

26. Windmueller, H.G.: Glutamine utilization by the small intestine. In: Meister A: Advances in enzymology, vol. 53, 1982, Wiley, New York, pp. 201-237 (1982).

27. Windnueller, H.G., Spaeth, A.: Respiratory fuels and nitrogen metabo$1 \mathrm{ism}$ in vivo in small intestine of fed rats. J. Biol. Chem. 255: $107-112(1980)$.

28. Windmueller, H.G., Spaeth, A.E.: Intestinal metabolism of glutamine and glutamate from the lumen as campared to glutamine fram blood. Arch. Biochem. Biophys. 171: 662-672 (1975).

29. Hanson, P.J., Parson, D.S.: Metabolism and transport of glutamine and glucose in vascularly perfused small intestine of rat. Blochem. J. 166: $509-519$ (1977).

30. Anderson, N.G., Hanson, P.J.: Arteriovenous differences for amino acids across control and acid secreting rat stanach in vivo. J. Biochem. 210: 451-455 (1983).

31. Uchiyama, C., Mori, M., Tatibaum, M.: Subcellular localization and properties of $n^{\prime \prime}$ acetyl glutamate synthese in rat snall intestinal mucosa. J. Biochem. (Tokyo) 89: 1777-1786 (1981). 
32. Wakabayash, Y., Hensler, J.G., Jones, M.E.: Pyroline-5-carboxylate synthesis from glutamate by rat intestinal mucosa: subcellular localization and temperature stability. J. Biol. Chem. 258: 3878-3882 (1983).

33. Wakabayashi, Y., Jones, M.E.: Pyroline-5-carboxylate synthesis fron glutamic by rat intestinal mucasa. J. Biol. Chem. 258: 3865-3872 (1983).

34. Hensler, J.G., Jones, M.E.: Ornithine synthesis from glutamate in rat small intestinal mucosa. Arch. Biochem. Biophys. 219: 186-197 (1982).

35. Herzfeld, A., Raper, S.M.: Enzymes of ornithine metabolism in adult and developing rat intestine. Biochim. Biophys. Acta 428: 600-610 (1976).

36. Windmueller, H.G., Spaeth, A.E.: Source and fate of circulating citrulline. Am. M. Physiol. 241: E473-E480 (1981).

37. Windmueller, H.G., Spaeth, A.E. : Identification of ketone bodies and glutamine as the major respiratory fuels in vivo for postabsorptive rat sma11 intestine. J. Bio1. Chem. 253:69-76 (1978).

38. Tanaka, F.: Experiments and clinical studies on digestion, absorption and utilization of 1actulose. Bu17. Kobe Med. Col1. 212: 328-338 (1962).

39. Hoffman, K., Mosse1, D.A.A., Korus, W. and Kamer van de, J.: Untersuchungen uber die Wirkungsweise der Lactulase (Bèta-Galactosido-Fructose). Klin. Wochschr. 42: 126-130 (1964).

40. Liem, K.S.: Biochamical report on the absorption of lacturose. N.V. Philips, Duphar. Clinical Research Department, Weesp, Dec. 1966. Report no. 5/56874. Project Report A $71-42$ on file. Merrel-National Laboratories, Cincimatti, OH 45215 .

41. Gary, L., Simon, M.P., Sherwood, L. and Gorbach, M. D.: Intestinal microflora. Med. C1 in. North Am. 66 (3): 557-572 (1982).

42. Bircher, J., Müller, J., Guggenheim, P. and Haemmerli, U.P.: Treatment of chronic portal systemic encephalopathy with lactulose. Lancet 1: 890-892 (1966). 
43. Flock, M.H., Katz, J. and Conn, H. O.: Unpublished data cited by Elkington et al, 1969. Vide Supra.

44. Zeeger, R., Drinkwater, J.E., Fenton, J.C.B., Vince, A. and Dawson, A.M.: Some observations on the effects of treatment with lactulose with chronic hepatic encephalopathy. Quant. J. Med. 39: 245-263 (1970).

45. Conn, H.O. and Flock, M.H.: Effects of lactulose and lactobaclllus acidophilus on the fecal flora. An. J. Clin. Nutr. 23: 1588-1594 (1970).

46. Vince, A., Zeeger, R., Drinkwater, J.E., O'Grady, F. and Dawson, A.M.: The effect of lactulose on the faecal flora of patients with hepatic encephalopathy. J. Med. Microbio1. 7: 163-168 (1974).

47. Summerski11, W.H.J., Aoyagi, F. and Evans, W.D.: Ammonia in the upper gastrointestinal tract of man: Quantitations and relationships. Gut 7: 497-501 (1966).

48. Caste11, P.D. and Moore, E.W.: Ammonia absorption from the human colon: the role of non-ionic diffusion. C1in. Res. 16:528-532 (1968).

49. Bircher, J., Haemmer1 i, U.P., Trabert, E., Largiacker, F., Mocetti, T.: The mechanism of action of lactulose in portal-systemic encephalopathy. Mon-ionic diffusion of ammonia in the canine colon. Rev. Fr. Etud. Cl in. Bĭol. 16: 352-357 (1971).

50. Elkington, S.G., Flock, M.H. and Conn, H.0.: Lactulose in the treatment of chronic portal-systemic encephalopathy. A double-blind clinical tria1. N. Eng1. J. Med. 281: 408-412 (1969).

51. Bown, R.L., Gibson, J.A., Sladen, G.E., Hicks, B. and Dawson, A.M.: Effects of lactulose and other laxatives on ileal and colonic pH as measured by a radiotelemetry device. Gut 15: 999-1004 (1974).

52. Agostini, L., Down, P.F., Murison, J. and Wrong, D.M." Faecal ammonia and pH during lactulose administration in man: camparison with other cathartics. Gut 13: 859-866 (1972). 
32. Wakabayashi, Y. Hensler, J.G., Jones, M.E.: Pyroline-5-carboxylate synthesis from glutanate by rat intestinal mucosa: subcellular lacalization and temperature stability. J. Biol. Chem. 258: 3878-3882 (1983).

33. Wakabayashi, Y., Jones, M.E.: Pyroline-5-carboxylate synthesis from glutamic by rat intestinal mucosa. J. Biol. Chem. 258: 3865-3872 (1983).

34. Hensler, J.G., Jones, M.E.: Ornithine synthesis from glutamate in rat small intestinal mucosa. Arch. Biochem. Biophys. 219: 186-197 (1982).

35. Herzfeld, A., Raper, S.M. : Enzymes of ornithine metabolism in adult and developing rat intestine. Biochim. Biophys. Acta 428: 600-610 (1976).

36. Windmueller, H.G., Spaeth, A.E.: Source and fate of circulating citrul1ine. An. J. Physiol. 241: E473-E480 (1981).

37. Windmueller, H.G., Spaeth, A.E.: Identification of ketone bodies and glutamine as the inajor respiratory fuels in vivo for postabsorptive rat small intestine. J. Biol. Chem. 253: 69-76 (1978).

38. Tanaka, F.: Experiments and clinical studies on digestion, absorption and utilization of lactulose. Bu11. Kobe Med. Col1. 212: 328-338 (1962).

39. Hoffman, K., Mosse1, D.A.A., Korus, W. and Kamer van de, J.: Untersuchungen uber die Wirkungsweise der Lactulose (Bèta-Galactosido-Fructose). K1 in. Wochschr. 42: 126-130 (1964).

40. Liem, K.S.: Biochenical report on the absorption of lactulose. N.V. Philips, Duphar. C1 inical Research Department, Weesp, Dec. 1966. Report no. 5/56874. Project Report A 71-42 on file. Merrel-National Laboratories, Cincinatti, OH 45215.

41. Gary, L., Simon, M.P., Sherwood, L. and Gorbach, M.D.: Intestinal microflora. Med. Clin. North Am. 66 (3): 557-572 (1982).

42. Bircher, J., Müller, J., Guggenheim, P. and Haemmerli, U.P.: Treatment of chronic portal systemic encephalopathy with lactulose. Lancet 1:
$890-892(1966)$. 
43. Flock, M.H., Katz, J. and Conn, H.O.: Unpublished data clted by Elkington et a1, 1969. Vide Supra.

44. Zeeger, R., Drinkwater, J.E., Fenton, J.C.B., Vince, A. and Dawson, A.M.: Some observations on the effects of treatment with lactulose with chronic hepatic encephalopathy. Quant. J. Med. 39: 245-263 (1970).

45. Conn, H.O. and Flack, M.H.: Effects of lactulose and lactobacillus acidophilus on the fecal flora. Am. J. Clin. Nutr. 23: 1588-1594 (1970).

46. Vince, A., Zeeger, R., Drinkwater, J.E., 0'Grady, F. and Dawson, A.M.: The effect of lactulose on the faecal flora of patients with hepatic encephal opathy. J. Med. Microbiol. 7: 163-168 (1974).

47. Summerski11, W.H.J., Aoyagi, F. and Evans, W.D.: Armonia in the upper gastrointestinal tract of man: Quantitations and relationships. Gut 7 : 497-501 (1966).

48. Caste11, P.D. and Moore, E.W.: Ammonia absorption from the human colon: the role of nom-ionic diffusion. Clin. Res. 16:528-532 (1968).

49. Bircher, J., Haemmer1 i, U.P., Trabert, E., Largiacker, F., Mocetti, T.: The mechanism of action of lactulose in portal-systemic encephalopathy. Non-ionic diffusion of anmonia in the canine colon. Rev. Fr. Etud. Clin. Binol. 16: $352-357$ (1971).

50. Elkington, S.G., Flock, M.H. and Conn, H.O.: Lactulose in the treatunent of chronic portal-systemic encephalopathy. A double-blind clinical trial. N. Engl. J. Med. 281: 408-412 (1969).

51. Bown, R.L., Gibson, J.A., STaden, G.E., Hicks, B. and Dawson, A.M.: Effects of lactulose and other laxatives on ileal and colonic pH as measured by a radiotelametry device. Gut 15: 999-1004 (1974).

52. Agostini, L., Down, P.F., Murison, J. and Wrong, 0.M.: Faecal ammonia and pH during lactulose administration in man: camparison with other cathartics. Gut 13: 859-866 (1972). 
53. Vince, A., Killingley, M. and Wrong, 0.M.: Effect of lactulose on amonia production in a fecal incubation system. Gastroenterology 74: $544-549(1978)$.

54. Bennet, A., Eley, K.G.: Intestinal pH and propulsion: an explanation of diarrhea in lactase deficiency and laxation by lactulose. J. Pham. Phamacol. 28: 192-195 (1976).

55. Markhoff. N.G.: Portal-systemic encephalopathy treated with 1actulose. Lancet II (letter): 281 (1966).

56. Paima de, M., Disanto, $V$. and Ferrarese, S.: Clinical trials on the prophylactic treatment of porta-systemic encephalopathy with lactulose. Puylia Chir. II supp1. 6 (III): 1507-1518 (1968).

57. Lande, M. and clot, C1.: Un correcteur des métabolisnes bactériens du colon: traitement moderne des encéphalopathies porta-caves. Sem. Thérapeutique $44: 672-674(1968)$.

58. Rottiers, R., Egmond van, J., Verbruggen, R., Dierick, G., Vermeulen, A., Groote de, J., Standaert, L. and Deneulenaere, L.: Cirrhosis, hyperammonemia and lactulose. Gastroenterology 11: 123 (1968)

59. Fung, W.P. and Khoo, 0.T.: Treatment of chronic encephalopathy with lactullose. Med. J. Austr. 4: 160-163 (1968).

60. Demeulenaere, L., Rottiers, R., Egmond van, J., Lacrès, R., Dierick, G. and Verbruggen, R.: Lactulose treatment of spontaneous or induced paroxysinal hyperammonemia and of chronic hyperarmonentia in the cirrhotic patient. Translation fram: Problènes de réanimation (5e série): $855-868(1969)$.

61. Helms, M. and Beck, K.: Treatment of chronic portal-systemic encephalapathy with lactulose in ten patients with cirrhosis of the liver. Symposium on lactulose, Baden bei Wien, Austria, Sept. 8, 1969.

62. Combes, B., Walker, C.0. and Polter, D.: Long-term treatment in chronic portal-systemic encephalpathy. Symposium on lactulose, Baden bei Wien, Austria, Sept. 8, 1969 (1969). 
63. Gauthier, M.M.A., Camatte, R., Renacle, J., Mathieu, G. et Torrent, M.: Tratement des encëphalopathies hépatiques chroniques par le lactulose. Arch. Franc Mal. Appar. Dig. 59: 521 (1970).

64. Geffroy, Y., Segrestin, M. et Geffroy, P.Y. (1970): Interet de 1actulose dans le traitement de l'encéphalopathy porto-cave chronique (a propos de 20 observations thérapeutiques). Extrait de thérapeutique. Semaine des Hôpitaux, 46e année no. 9, nov. 1970, p. 897-901.

65. James, J.M. and Garassini, M.: Effect of lactulose on cerebral metabo$1 \mathrm{ism}$ in patients with chronic partosystemic encephalopathy. Gut 12: $702-704$ (1971).

66. Kardel, T., Zander 01 sen, P., Stigsby, B. and Tonnesen, K.: Hepatic encephalopathy evaluated by autamatic period analysis of the electroencephalogram during lactulose treatment. Acta Med. Scand. 192: 493-498 (1972).

67. Almici, C., Inzoli, M.R., Poloni, A.E. and Zambruni, A.: 11 lattulosio nella terapia dell'encefalopatia porto-sistamica. Minerva medica $64:$ 4596-4603 (1973).

68. Eisenburg, J., Grunst, H.J. and Hol1, J.: Effect of lactulose on blood ammonia levels in patients with chronic cirrhosis, encephalopathy and after portacaval shunt operation. In: Imler, M., Szam, J. (eds.): Recent Progress in annonia metabolism, Werlag Gerhard Witzstrock, Baden-Baden, Brussels, 1974, p. 138-187 (1974).

69. Reikowski, H., Reikowski, J. and Moting, D.: Effect of lactulose longterm treatment on increased ammonla levels in the blood and serum plenol values in 36 patient with cirrhosis of the 1iver. In: Imler, M., Szam, J. (eds.): Recent Progress in ammonia metabolism, Verlag Gerhard Witzstrock, Baden-Baden, Brusse1s, 1974, p. 174-177 (1974).

70. Seidlova, V.: Lactulose in the treatment of chronic portal-systemic encephalopathy. Cest. Gastroenterology Vyz 28: 201-207 (1974).

71. Ma, M.H., McKod, J.G. and Blackburn, C.R.B.: Long-term treatment of portal-systemic encephalopathy with lactulose. Aust. Ann. Med. 18: $117-123(1969)$. 
72. Rorsman, G. and Suly, 1.: Lactulose treatment of chronic hepatopartal encephalopathy. Acta Med. Scand. 187: 337-346 (1970).

73. Siebner, H., Missmaht, H.P.: The treatment of hepatoportal encephalopathy with Tactulose. Ger. Med. Mon. 15: 529-533 (1970).

74. Zeegen, R., Drinkwater, J.E., Fenton, J.C.B., Vince, A. and Dawson, A.M.: Some observations on the effects of treatment with lactulose on patients with chronic hepatic encephalopathy. Quart. J. Med. 154: $245-263(1970)$.

75. Fung, W.P. and Khoo, O.T.: Lactulose in the treatment of acute and chronic hepatic encephalopathy. Singapore Med. J. 12 (3): 176-180 (1971).

76. Imler, M., Kurtz, D., Bockel, R. et Stahl, J.: Etude comparative du traitement de l'encêphalopathy porto-cave par le lactulase, les bacillles lactiques et les antiobiotiques. Therapeutique 47: 237-248 (1971).

77. Bircher, J., Müller, J., Guggenheim, P. and Haemmerli, U.P.: Treatment of chronic portal sytemic encephalopathy with lactulose. Lancet 1: 890 (1966).

78. Bircher, J., Haemmer1i, U.P. and Scollo-Lavizzari, G.: Treatment of chronic portal systemic encephalopathy with lactulose. Am. J. Med. 51: 148-159 (1971).

79. Rodgers, J.B., Kiley, J.E. and Balint, J.A.: Comparison of results of long-term treatment of chronic hepatic encephalopathy with lactulose and sorbitol. Am. J. Gastroenterol. 60; 459-465 (1973).

80. Orlandi, F., Freddara, U., Camdelaresi, M.T., Morettini, A., Corazza, G.R., Simone, A.T., Dohilla, G. and Cavallini, G.: Comparison between neomycin and lactulose in 173 patients with hepatic encephalopathy. Dig. Dis. Sci 26:498-506 (1981).

81. Reitan, R.M.: Validity of the trail making test as an indicator of organic brain damage. Percept. Motor. Skil1 8: 271-276 (19??).

82. Simmons, F., Goldstein, A. and Boyle, J.: A controlled clinical trial of lactulose in hepatic encephalopathy. Gastroenterology 59 (6): 827-832 (1970). 
83. Brom, H., Trey, G. and McDemott, W.W.: Encephalopathy after portacaval shunting managed with lactulose. Am. J. Surg. 119: 132-137 $(1970)$.

84. Brown, H., Trey, C. and McDemott, W.: Lactulose treatment of hepatic encephalopathy in outpatients. Arch. Surg. 102: 25-27 (1971).

85. Germain, L., Frexinos, J., Louis, A. and Ribet, A.: Etude en double aveugle du lactulose chez 18 malades atteints d'encëphalopathy hêpatique chronique après shumt porto-cave. Arch. Fr. Mal. App. Dig. 62: $293-302$ (1973).

86. Elkington, S.G., Floch, M.H. and Conn, H.O.: Lactulase in the treatment of chronic portal-systenic encephalopathy. N. Engl. J. Med. 281: 408-412 (1969).

87. Parsons-Smith, B.G., Summerski11, W.H.J., Dawson, A.M., Sherlock, S.: The electroencephalograph in Iiver disease. Lancet II: 867-871 (1957).

88. Conn, H.0., Leevy, C.M., V1ahcevic, Z.R., Rodgers, J.B., Maddrey, W.C., Seeff, L. and Levy, L.L.: Comparison of lactulose and neamycin in the treatment of chronic portal-systemic encephalopathy. Gastroenterology 4: $573-582$ (1977).

89. Atterbury, C.E., Maddrey, W.C. and Conn, H.D.: Neonycin-sorbitol and lactulose in the treatment of acute portal-systemic encephalopathy. Dig. Dis. 23: 398-406 (1978).

90. Cassi, E., Sala, E., Beretta, R., Columbo, A., Cova, L., Ezechiêl, S., Malacco, Massarotti, G., Pagani, C.: Treatment of chronic portalsystenic encephalopathy with lactulase. Clin. Ter. 63: 531-556 (1972).

91. Fessel, J.M. and Conn, H.O.: Lactulose in the treatment of acute hepatic encephalopathy. Arm. J. Med. Sci. 266: 103-109 (1973).

92. Kersh, E., Rifkin, H. and Bronx, F.: Lactulose enemas. Ann. Int. Med. 78: $81-84(1973)$.

93. Ratnaike, R.N., Hicks, E.P. and Hislop, J.C.: The rectal administration of lactulose. Aust. N.Z.J. Med. 5: 137-140 (1975). 
94. Waes van, L., Egnond van, J. and Deneulenaere, L.: Emergency treatment of portal-systemic encephalopathy with lactulose enemas. A controlled study. Acta Clin. Belg. 34: 122-129 (1979).

95. Conn, H.O. and Lieberthal, M.M.: The hepatic coma syndrome and lactulose. Willians Wilkins Co., Baltimore, 1979.

96. Imler, M., Peter, P., Schl tenger, J.L., Lavillaureux, J. and Stah1, J.: L'Ammoniogénêse intestinal du rat nomal. Méd. Chir. Dig. 4: 15-20 $(1975)$.

97. Walter, A.M. and Hellmeyer, L.: Antibiotika-Fibeli, Antibiotika und Chemotherapie. Georg Thiene Verlag, Stuttgart (1976).

98. Rinehart, K.L., Argoudel is, A.D., Goss, W.A., Sohler, A. and Schaffner, S.P.: Chemistry of the neamycins. V. Differentiation of the neomycin complex. Identity of framycetin and neamycin $B$. compounds obtained from methyl neobiosaminide B. J. Am. Chen. Soc 82: 3938-3947 (1960).

99. Silen, W., Harper, H.A., Mawdsley, D.L. and Weinrich, W.L.: Effect of antibacterial agents on amnonia production within the intestine. Proc. Soc. Exp. Bïol. 88: 138-140 (1955).

100. Fischer, C.J., Faloon, H.M.: Blood ammonia levels in hepatic cirrhosis: Their control by the oral administration of neamycin. N. Engl. J. Med. 256: $1030-1035(1957)$.

101. Dawson, A.M., McLaren, J., Sherlock, S.: Neomycin in the treatment of hepatic cana. Lancet 2: 1263-1268 (1957).

102. Summerski11, W.H.J.: Hepatic cona in liver failure and gastro-intestinal haemorrhage treated with neanycin. Br. Med. J. 29: 1322-1325 $(1953)$.

103. Stomont, J.M., Machie, J.E. and Davidson, C.S.: abservations on antibiatics in the treatment of hepatic cana and on factors contributing to prognosis. N. Engl. J. Med. 259: 1145-1150 (1958).

104. Faloon, W.W. and Fischer, C.J.: Clinical experience with the use of neomycin in hepatic coma. Arch. Intern. Med. 103: 43-53 (1959). 
105. Sabbaj, J., Sutter, V.L., Finegold, S.M.: Urease and deanthase activities of faecal bacteria in hepatic cona. Antimicrob. Agents chemotherapy: $181-185(1970)$.

106. Sherlock, S., White, L.P., Phear, E.A.: Portal-systemic encephalopathy; neurologic complications in liver disease. Lancet II: 453-457 (1954).

107. Dawson, A.M., McLaren, J., Sherlock, S.: Neomycin in the treatment of hepatic coma. Lancet II: $1263-1268$ (1957).

108. Summerskil1, W.H.J.: Hepatic coma in liver failure and gastrointestinal henorrhage treated with neanycin. Br. Med. J. 29: 1322-1325 (1958).

109. Fast, R., Wolfe, S.J., Stomont, J.M., Davidson, C.: Antibiotic therapy in the management of hepatic cama. Arch. Int. Med. 101: 467-475 (1958).

110. Stomont, J.M., Mackie, J.E., Davidson, C.S.: Obserwations on antibiotics in the treatment of hepatic coma and on factors contributing to prognosis. N. Engl. J. Med. 259: 1145-1150 (1958).

11. Uribe, M., Berthier, J.M., Lewis, H., Mista, J.M., Sierra, J.G., Carcia-Ramos, G., Acosta, J.R., Dehesa, M.: Lactose enemas plus placebo tablets vs neanycin tablets plus starch enemas in acute portal systemic encephal opathy.

Gastroenterology 81: 101-106 (1981).

112. Hirayama, C., Ichida, F., Takahashil, Y., Koizumi, T., Sato, S., Kosaka, J., Wakui, K., Shimada, Y., Yoshibai, A., Hattori, N., Doya, T., Takino, T., Takedo, H.: A controlled clinical trial of nicotinohydrosamic acid and neamycin in advanced chronic liver disease. Digestion 25: $115-123(1982)$.

113. Pirotte, J., Guffers, J.M., Devos, J.: Comparative studly of basal arterial amonemia and of orally-induced hyperamonemia in chronic portal systenic encephalopathy, treated with neomycin, lactulase and an association of neanycin and 1actulose. Digestion 10: 435-444 (19..???)

114. Hoyumpa, A.M., Desmond, P., Avant, G., Roberts, R.K., Schenker, S.: Hepatic encephalopathy. Gastroenterology 76: 184-185 (1979). 
115. White, L.P., Phear, E.A., Sumerskill, W.H.J. and Sherlock, S.: Amonia tolerance in liver disease. Observations based on catheterization of the hepatic veins. J. Clin. Invest. 34: 158-168 (1955).

116. Schwartz, R., Phillips, G.B., Gaburda, Jr.G.J. and Davidson, G.S.: Blood ammonia and electrolytes in hepatic coma. J. Lab. Clin. Med. 42: 499-508 (1953).

117. Sherlock, S., Summershil1, W.H.J., White, L. and Phear, E.A.: Portalsystemic encephalopathy - Neurological camplications of liver disease. Lancet 2 i: $453-457$ (1954).

118. Phear, E.A., Sherlock, S. and Summerski11, W.H.J.: B1ood ammonia levels in liver disease and hepatic coma. Lancet i: 836-847 (1955).

119. Laidlaw, J., Read, A.E. and Sherlock, S.: Morphine tolerance in hepatic cirrhosis. Gastroenterology 40: 389-395 (1961).

120. McDermott, W.V. and Adams, R.P.: Episodic stupor associated with eck fistulas in the human with particular reference to the metabolism of ammonia. J. C7 in. Invest. 44: 1-9 (1954).

121. McDermott, W.V.: The role of ammonia intoxication in hepatic cana. Bu11. N.Y. Acad. Med. 34: 352-368 (1958).

122. Walka, C.0. and Schenka, S.: Pathogenesis of hepatic encephalopathy with special reference to the role of ammonia. Am. J. clin. Nutr. 23: $619-633(1970)$.

123. Löwenstein, J.M.: Ammonia production in muscle and other tissues. The purine nucleotide cycle. Physiol. Rev. 52: 382-414 (1972).

124. Dawson, A.M.C.: Regulation of blood ammonia. Gut 19: 504-509 (1978).

125. Bessman, S.P. and Bradely, J.E.: Uptake of amonia by inuscle. Its implication in ammaniagenic cona. N. Engl. J. Med. 253: 1143-1147 (1955).

126. Staht, J.: Studies of the b7ood ammonia in liver disease. Its diagnostic, prognostic and therapeutic significance. Ann. Int. Med. 58: 1-24 (1963). 
127. Ganda, O.P. and Ruderman, N.B.: Muscie nitrogen metabolism in chronic hepatic insufficiency. Metabolism 25: 427-435 (1976).

128. Imler, M., Schlienger, J.L. and Frick, A.: Comparitive study of amonia and glutanine levels in blood and cerebrospinal fluid in hepatic ancephalopathy. In: Aminosäuren, Anmoniak und hepatische Encephalopathie, Wewalka, F. and Dragosics, B. (eds.), G. Fischer Werlag, Stuttgart, New York, p. 105-118 (1978).

129. Imler, M., Schlienger, J.L., Frick, A., Stan1, A., Chabier, G.: Study of muscular glutanine and alanine release in cirrhotics with hyperamonewia and in ammonium infused rats. In: Aninosäuren und Ammoniak Stofwechsel bei Leberinsufficienz, Holm, E. (ed.), Verlag Gerhard, Witzstrock, Baden-Baden, Köln, New York, p. 33-39 (1982).

130. Zieve, L., Nicoloff, D. and Doizaki, W.M.: Effect of total hepatectany on selected cerebral substrates and enzymes of the glycolytic pathway and Krebs-cycle. Surgery 78: 414-423 (1975).

131. Biebuyck, J., Funovics, J., Dedrick, D.F. e.a.: Neurachemistry of hepatic cana. Alterations in putative neurotransmitter amino-acids. In: Artificial liver support, ed. R. Williams and J.M. Murray, Lyon, London. Pitman Medical, p. 51-57 (1975).

132. Veech, R.L., Harris, R.L., Veloso, E. e.a.: Freeze blowing: A new technique for the study of brain in wivo. Blochem. Phannacol. 20: $183-188$ (1973).

133. Hawkins, R.A., Miller, A.L., Nielsen, R.C., Veech, R.L.: Acute action of ammonia on rat brain metabolism in vitro. Biochem. J.: 134: 1001$1008(1973)$.

134. Wei1-Malherbe, H.: The metabolism of ammonia in brain in consciousness and the chamical environment of the brain. 25th Ross. Pedilat. Res. Congress 1958 , p. 50-57.

135. James, J.H., Jeppsson, B., Ziparo, V. and Fischer, J.E.: Hyperammonemia, pllasma amino acid imbalance and blood-brain amino acid transport: a unified therapy of portal-systemic encephalopathy. Lancet II: 772$775,1979$. 
136. Jones, E.A., Schafer, D.F., Ferenci, P., Pappas, C.: The GABA hypothesis of the pathogenesis of hepatic encephalopathy: current status. Yale J. Biol. Med. 57: $301-316(1984)$. 


\section{II.1. Introduction}

Ammonia is claimed to contribute to hepatic encephalopiathy. The presumptive etiological role has served as the base of many therapeutic measures. Most ammonia in the body is claimed to originate in the gut as a result of degradation of urea, protein and amino acids by bacteria $(1,2,3)$. Urea is considered to be the main source of ammonia because large amounts $1 \pm 7 \mathrm{~g} /$ day) are degraded in the body (1), apparently as a result of the activity of the intestinal flora. Doubts about the contribution of urea to colonic ammonia production have risen however because the human colonic mucosa is impermeable to urea (4) and only small amounts of urea reach the colon from the ileum (5). Studies by Wrong (6) al so show that endogenous urea is not, as been generally assumed, the major source of faecal ammonia. They confirm earlier studies that faecal ammonia and total nitrogen is in close equilibrium. Recent studies suggest that an important site of ammonia production must be the intestinal wall itself because germ-free dogs became hyperamnonatic after porta-caval shunt (7).

Matsutaka (1973) (8) discovered in rats that this gut ammonia production was glutamine dependent. He suggested that the nitrogen of glutamine and other amino acids catabolized were converted into alanine and ammonia. This production of ammonia had to be non-bacterial since he studied germ-free rats and as much ammonia and alanine accumulated in the perfusate as in experiments with conventional rats.

Windmuller and Spaeth $(1974)(9,10)$ have identified the small intestine as 
the site of this glutamine utilization where glutamine contributes significantly to the respiratory fuel of the intestimal mucosa. Weber (11) quantitated the armonia released into the portal vein in dogs and demonstrated that the production of ammonita by jejunum and ileum was of equal magnitude as in the colon. This production could be accounted for by uptake of glutamine from arterial blood.

One of the therapeutic measures to reduce ammonia levels is the administrathon of neonycin and lactulose. Explanations, that the effects of neomycin and lactulose are achieved by their action on bacterial colon flora are conflicting. Neomycin lowers ammonia levels in the portal vein presumably by elimination of the aerobic flora (12). Such an effect of neomycin on ammonia levels is difficult to understand since the aerobic flora represents only a small fraction of the total flora in the intestine. Moreover, clinical state and blood ammonia do not always correlate with the observed alterations in flora induced by neomycin (13). Lactulose has been claimed to influence ammonia metabolism and absorption in the colon by a decrease of the luminal pH (14), leading to an osmotic diarmoea (15) and provision of a carbon and energy source to assimilate ammonia by bacteria (16). However the mechanism by which lactulose might provide assimilation of ammonia by bacteria was not really elucidated. Whether lactulose and nemycin act directly on non-bacterial ammonia metabolism has never been subject to study. Little evidence exists to suggest that there are sources of gut ammonia production not attributable to bacteriat metabolism within the colon. These considerations prompted us to study amino-acid and ammonia metabolism in the small and targe Intestine with particular interest for the metabolism of glutamine, alanine, anmonia and glutamic acid, and the effect of lactulose and neomycin. As a first approach to this problem, in vitro studies were carried out with fragnents of small and large intestine. The productiom of ammionia was quantitated after addition of glutamine to the medium, and the influence of neomycin and lactulose on this ammonia production was studied. 


\subsection{Material and Methods}

Rats.

Specified pathogen free (SPF) rats were obtained from the centralized experimental animal facilities of the University of Limburg.

Male Wistar rats were used weighing $250-300 \mathrm{gr}$. Rats were kept at $21^{\circ} \mathrm{C}$ and allowed free access to water and rat chow (formula SRM Al20 Hope Farms, Woerden). Fasted rats were deprived of food for 24 hours before operation. Operations were perfarmed between 8.00 am and 10.00 anm.

\section{Reagents.}

Enzymes: Crystalline glutaminase (L-Glutamine-Amidohydrolase EC. 3.5.1.2.) was a product of Sigma U.S.A. The following were products of Boehringer Mannheim, Mannheim: Glutamate dehydrogenase $[L-g l u t a m a t e: ~ M A D(P)$ oxidoreductase (deaminating), EC. 1.4.1.3], type II in 50\% glycerol from beef liver (specific activity $120 \mathrm{U} / \mathrm{mg}$ ); L-alanine dehydrogenase (L-alanine: NAD oxidoreductase) deaminating EC. 1.4.1.1. (specific activity $30 \mathrm{U} / \mathrm{mg}$ ). Lactulose (Duphalac) was abtained from Duphar (Weesp, the Netherlands) and contained $667 \mathrm{mg}$ lactulose/ml. Neonycin sulphate was obtained from Lundbeck (Amsterdam, The Netherlands).

\section{Incubation procedures.}

Through an abdominal incision the small and large intestine were removed. Small and large intestine were rinsed with icecold saline to remove luminal contents and apened. Longitudinal sections of gut approximately $1 \mathrm{~cm}$ in length were obtained weighing $35-40 \mathrm{mg}$ wet weight. The intestinal pieces, cut along the mesenteric border were transferred to Erienmeyer flasks containing $2 \mathrm{ml}$ of icecold krebs-Ringer buffer.

Tissue was then transferred to a fresh medium $\left(38.5^{\circ} \mathrm{y}\right.$ with and without glutamine $(10 \mathrm{mM})$, and with and without lactulose or neomycim, incubated for 90 min in a shaking water bath at 60 cycles per minute (Grants Instruments, 
London) and kept under carbogen atmosphere. After incubation, the tissue was frozen in liquid nitrogen and homogenized with a tissue grinder (size $002 z$ Firma kontes van dortmersen. The Netherlands). Medium and homogenates were deproteinfized with perchloracid.

\section{Determination of metabolites.}

Ammonia was determined according to the method of Da Fonseca-Wollheim (17). Alanine, glutamine and glutamic acid were measured in the incubation media and tissue homogenates by an enzymatic micromethod using a centrifugal analyser (Cobas Bio, Hoffman La Roche). We followed the method of Williamson (18) for alanine, of E. Bernt (19) for glutamic acid and of E. Lund (20) for glutanine.

Lactate dehydrogenase was determined in the medium after centrifugation at $7000 \times \mathrm{g}$ for 2 min in an Eppendorf microfuge. Total lactate dehydrogenase (LDH) cantent of the tissue was measured after complete lysis, which could be obtained by homogenization of the tissue with a ultra-turrax, 3 times for 7 sec on ice and subsequently by sonification for $40 \mathrm{sec}$, with intervals for 5 sec, amplitude 12 microns (Sonicator type ultrasonic desintegrator 100 watt mode], NV Beun - de Ronde - HVL ). Lactate dehydragenase was measured with a Boehringer test kit based on the method of Wroblewski and La Due (23).

\section{Interassay variations.}

In order to standardize our amino acid determinations a standard curve was prepared in the same way as aur tissue and medium and frozen at $-70^{\circ}$. Four standards were measured together with all samples in order to correct all our measurements for interassay variations. Interassay variations of the amino acid measurements were obtained by measuring four standard aliquots on the same day under the same conditions as the samples, during the whole experiment.

- Alanine. The following standard concentrations were used: $16.5-33.0$ 82.7 and $165 \mu \mathrm{mol} / \mathrm{L}(\mathrm{n}=15)$. The observed results were respectively 16.4 - 
$33.0-82.9$ and $164.9 \mathrm{mmol} / \mathrm{L}$.

Coefficients of variation (CV), expressed as a percentage of the mean were respectively $3.1 \%-4.7 \%-2.9 \%$ and $3.5 \%$.

- Glutamic acid. The following standard concentrations were used: $16.6-32.3$

$-65.0-131.3$ and $250 \mu$ mol/L $(n=8)$. The observed results were respectively $18.3-31.6-63.0-130.0$ and $250.0 \mu \mathrm{mol} / \mathrm{L}$.

CV: $9.4 \%-2.2 \%-1.4 \%-1.0 \%$ and $0.7 \%$.

- Ammonia. The following standard concentrations were used: $50.0-100.0$ 200.0 and $300.0 \mu m 01 / L(n=20)$. The observed results were respectively 51.5

$-102-200$ and 301 umol/L.

$C V: 6.5 \%-4.4 \%-2.9 \%$ and $1.8 \%$.

\section{Intra-assay variations.}

Intra-assay variations of the amino acid measurements were obtained by measuring 10 aliquots of these standards on the same day, under the same conditions. This procedure was repeated on three different days.

The intra-assay variations of alanine, glutamic acid and ammonia are respectively $2.7 \%-0.5 \%$ and $0.9 \%$. The minimum detection level of each al anine, glutamic acid, glutamine and ammonia in medium and tissue is $0.5 \mathrm{nmol} / \mathrm{mg}$ tissue.

The mean analytical recovery of alanine, glutamic acid and ammonia after 30 min and 60 min incubations with and without glutamine 10 mm and with and without lactulose and neomycin were for alanine, glutamic acid and ammonia respectively $100 \%-99.5 \%$ and $99.8 \%$.

\section{3. Results}

\section{Linearity in time and weight.}

In order to test the Tinearity of the production of ammonia in the test system, incubations were performed during increasing time periods with 
and without addition of glutamine. In fig. 1 the results of small and large intestine respectively are represented.

\section{AMMONIA PRODUCTION \\ in conventional rats}

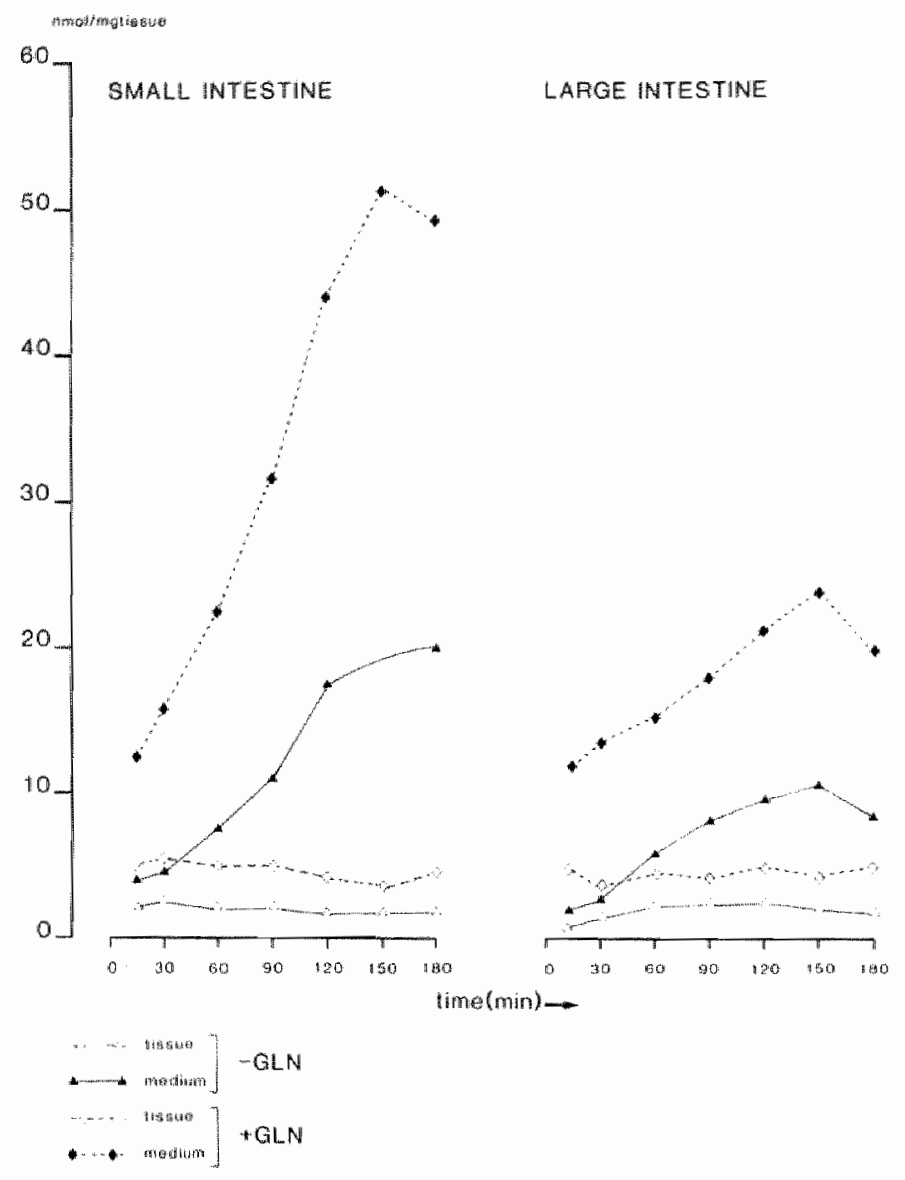

Figure 1: Armonia production in the small and large intestine as measured in incubation medium and tissue after different times of incubation intervals $(0-180$ min. $)$.

Incubations were performed with and without giutamine (10mM). Results are the mean of the triplicates and expressed in nmol/mg tissue wet weight $W . W . *$

Production of ammonia in the incubation medium was linear until 150 min, thereafter production of ammonia declined suggesting that wiability of tissue pieces decreased. The concentration of ammonia in tissue homogenates did not 
increase substantially. To test the possibility that diffusion of $0_{2}$ and substrate might be rate limiting for ammonia production, segments of bowel were incubated with weights increasing from 20-200 mg (fig. 2 ).

\section{AMMONIA PRODUCTION \\ in conventional rats}

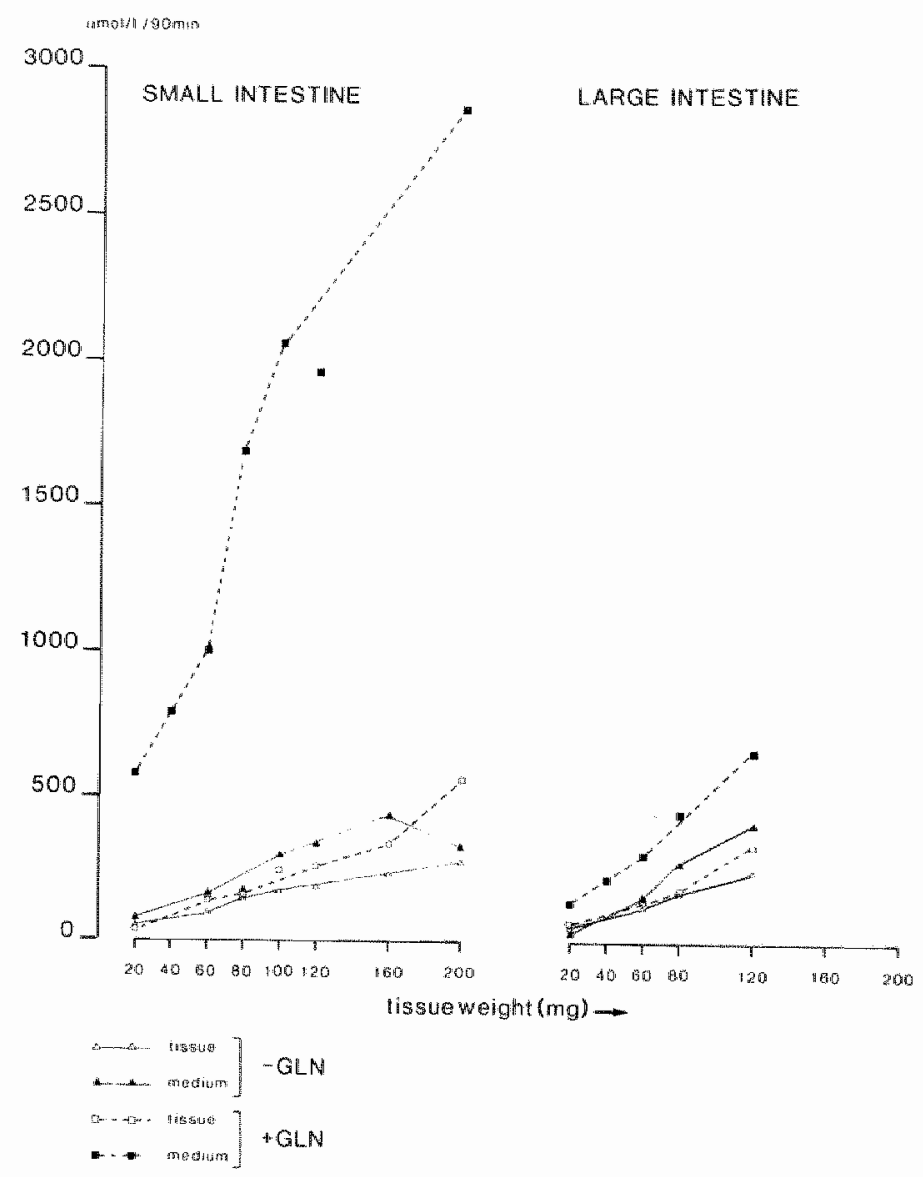

Figure 2: Ammonia production in slices of small and large intestine of different weight after $90 \mathrm{~min}$. of incubation. Ammonila was measured in tissue and medium. The tissues were incubated in media with and without glutamime $(10 \mathrm{mM})$. Results are the mean of the triplicates and expressed in $\mu$ mol/L/90min. 
Aminionia production prowed to be proportional to weight under these circumstances.

Ammonia and amino-acid release by small and large intestine and the influence of feeding and fasting.

Small and large intestine both from fasted and fed rats were capable to generate significant amounts of amnonia, alanine and glutamate in vitro in the presence and absence of glutamine (tabel I and $\mathbb{I})$.

Table I

\begin{tabular}{|c|c|c|c|c|}
\hline & Antononta & Alanine & Glutamine & Giv tamate \\
\hline & Smal intesti & (fiasted state & - glutamine) & \\
\hline Medilum & $10.19 \pm 1.03$ & $10.40 \pm 1.0$ & $<2.5$ & $5.19 \pm 0.84$ \\
\hline \multirow[t]{2}{*}{ Tissue } & $2.13 \pm 0.38$ & $2.42+0.24$ & $<2.5$ & $1.55 \pm 0.09$ \\
\hline & Smal intest 1 & Ifasted state & + glutamine lonv & \\
\hline Med ium: & $35.40 \pm 3.76$ & $24.70 \pm 1.25$ & $448.30 \pm 19.9$ & $12.56 \pm 2.53$ \\
\hline \multirow[t]{2}{*}{ Tissue } & $4.21 \pm 0.15$ & $2.75 \pm 0.22$ & $14.28 \pm 2.0$ & $2.68 \pm 0.22$ \\
\hline & Large intesti & (fasted state & - glutarine) & \\
\hline Med tur & $3.84 \pm 0.42$ & $2.47 \div 0.3$ & $<2.5$ & $1.47 \pm 0.14$ \\
\hline \multirow[t]{2}{*}{ Tissue } & $2.58 \pm 0.10$ & $1.27 \pm 0.4$ & $<2.5$ & $1.76 \pm 0.20$ \\
\hline & Large intesti & (fasted state & + glutamine 10 mM & \\
\hline Medi unt & $15.20 \pm 1.07$ & $6.94+0.5$ & $448.3 \pm 19.2$ & $6.26 \pm 1.07$ \\
\hline Tissue & $5.35 \pm 0.53$ & $1.48 \pm 0.16$ & $16.9 \pm 2.22$ & $3.15 \pm 0.35$ \\
\hline
\end{tabular}

Table 1: Anmonia, alanine, glutamate and glutamine concentrations in small and large intestine (fasted state) of conventional rats after incubations ( $90 \mathrm{~min}$.). The mean of the concentrations were measured in tissue and medium $(n=7$, mean \pm SEM). Glutamine in the incubation medium was 10mM. Results are expressed in nmol/mg tissue w.W.190min. 


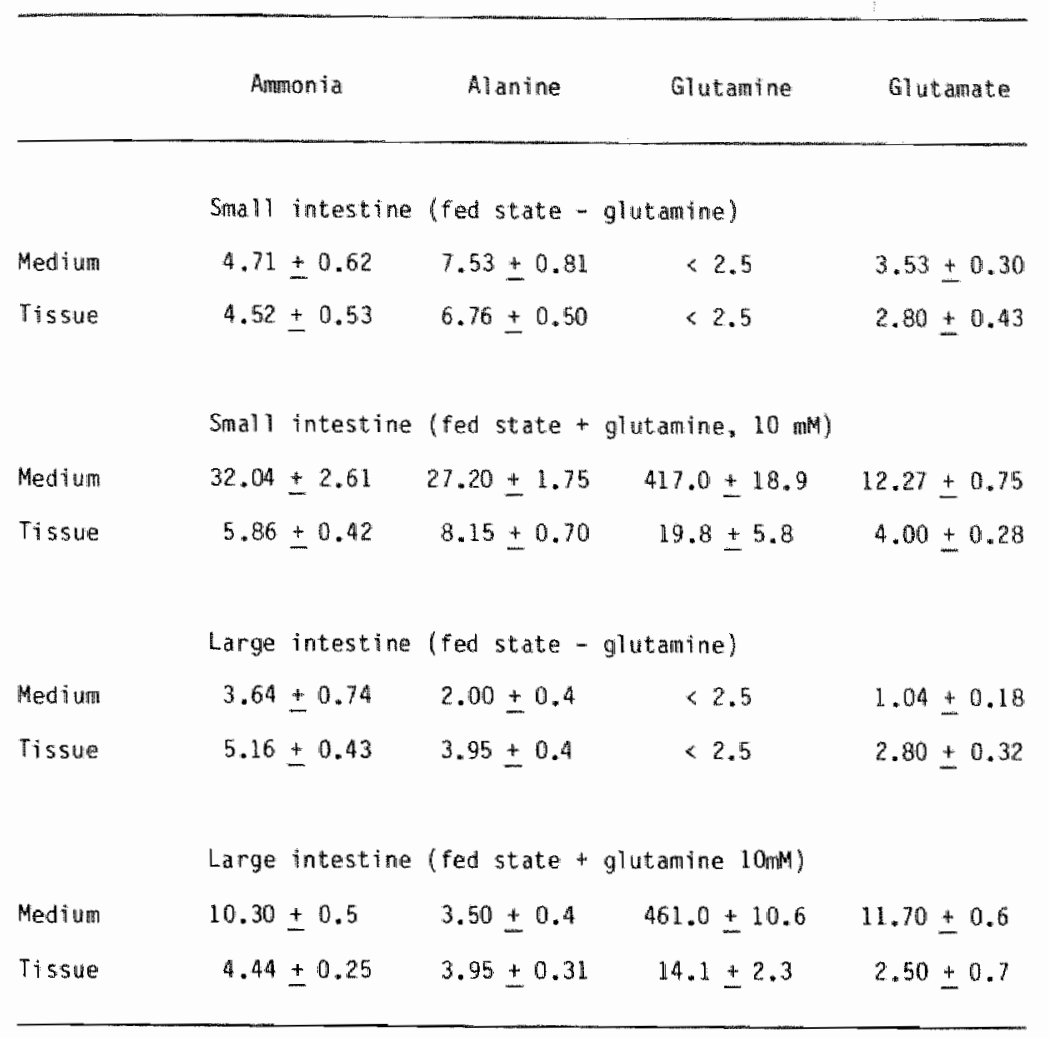

Table II: Ammonia, alanine, glutamate and glutamine concentrations in small and large intestine (fed state) of conventional rats after incubations (90 min.). The mean of the concentrations were measured in tissue and medium $(n=7$, mean $\pm S E M)$. Glutamine in the incubation medium was $10 \mathrm{mM}$. Results are expressed in nmol/mg tissue W.W. gomin.

In the fed state, without addition of glutamine, small intestine produces an equal amount of ammonia per unit weight when compared to the colon (table II). More allanine and glutamate was released by the small intestine than by the colon. Addition of glutamine $(10 \mathrm{mM})$ increased the production of ammonia, alanine, glutamate in small and large intestine. More alanine, glutamate and ammonia was released by the small intestinal segments than by the colon segments. 
Ammonia, glutamate and alanine were produced by small and large intestine in amounts which accounted roughly for the decrease in glutamine. No significant differences were noted when pieces of intestine were obtained from fed or fasted rats.

In order to estimate the damage to the fragments of bowel after 90 minutes of incubation upon exposure to lactulose, lactate was detemined in tissue homogenates and proved not to increase when lactulose was added. In addition lactate dehydrogenase (LDH) release during incubation was detemined and expressed as percentage of total cellular LDH content. It can be seen in table III that there is a sma 11 leakage of LDH into the medium during 60 min of incubation.

\section{Table III}

\begin{tabular}{lll} 
Smail & $15.6 \pm 2.6 \%$ & Large \\
Intestine & & Intestine \\
\hline
\end{tabular}

Table 11I: Lactate dehydrogenase (LDH) measurements in the medium of smal1 and large intestine. After 60 min of incubation expressed as percentage of the total LDH contents of the tissue prior to incubation $(n=3$, mean \pm SEM).

\section{The effect of lactulose on ammonia production in witro.}

Incubations were performed with lactulose in the medium in concentration ranging from $5-25 \%(W / V)$. Ammonia production by the small intestine decreased significantiy when lactulose was added to the medium (fig. 3 ). 


\section{AMMONIA PRODUGTION}

in conventional rats

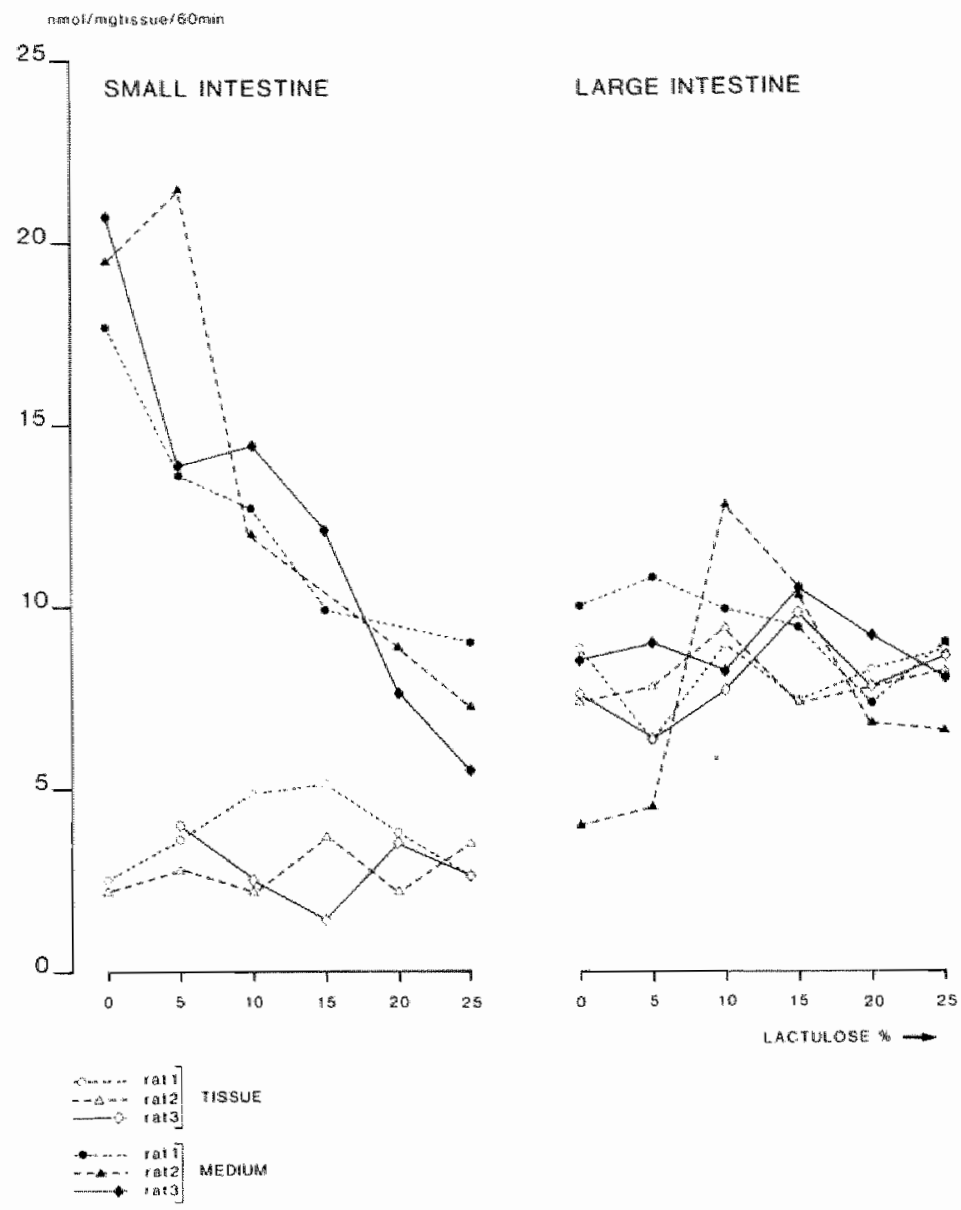

Eigure 3: Ammonia production of smail and large intestine of three rats after $60 \mathrm{~min}$. of incubation in medium with increasing concentrations of lactulose. Ammonia was measured in the medium and in the tissue. The tissues were incubated in media with glutamine $(10 \mathrm{mM})$. Data are expressed in nmol/mg tissue W.W. $/ 60 \mathrm{~min}$.

This decrease was already significant $(p<0.002)$ at the lowest concentration of lactulose $(5 \%)$. Ammonia production in the small intestine decreased to less than $40 \%$ of control values when $25 \%$ of lactulose was added to the medium. Ammonia concentrations in homogenates of small and large intestime did not exhibit a significant decrease when lactulose was added, nor did lactulose inhibit ammonia production in the colon. 
Glutamic acid production decreased in medium of small ( $p<0.025)$ and large intestine $(p<0.02)(f i g .4)$.

\section{GLUTAMIC ACID PRODUCTION}

in conventional rats

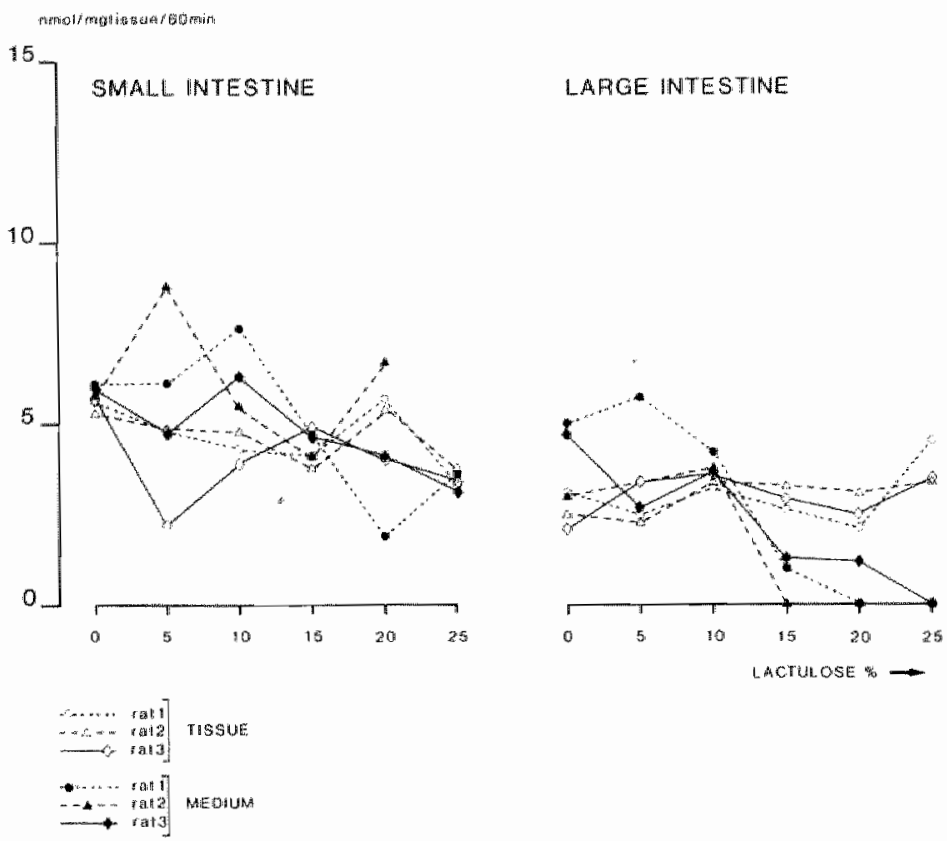

Figure 4: Glutamic acid production of the small and large intestine of three rats after $60 \mathrm{~min}$. of incubation in medium with increasing concentrations of lactulose. Glutamic acid was measured in the medium and in the tissue. The tissues were incubated in medium with glutamine (10mM). Data are expressed as nmol/mg tissuew.W./60min.

After addition of lactulose alanine production decreased in the medium and homogenate of the $i l$ eum $(p<0.001$ and $p<0.001$ resp.) and not in the colon (fig. 5) (non-paranetric test used). 


\section{ALANINE PRODUCTION \\ in conventional rats}

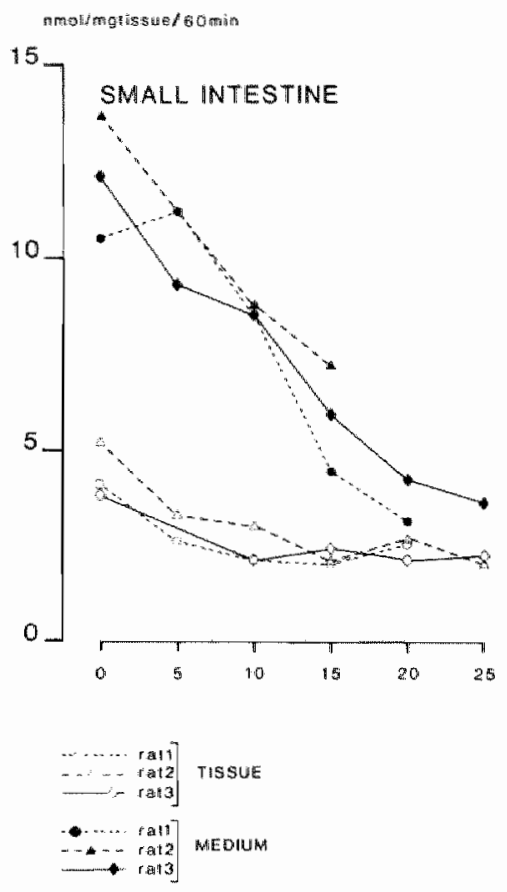

LARGE INTESTINE

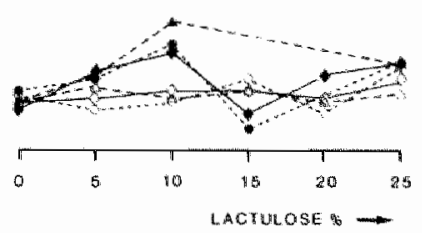

Figure 5: Alanine production of small and iarge intestine of three rats after $60 \mathrm{~min}$. of incubation in medium with increasing concentrations of lactulose.

Alanine was measured in the medium and in the tissue. The tissues were incubated in media with glutamine (10mM). Data are expressed in nmol/mg tissue W.W. 160 min.

The effect of neomycin on ammonia production in vitro.

To study the effects of neomycin on non-bacterial ammonia production, small 1 and Varge intestine were incubated with increasing concentrations of neomyclin (8.1 $\mu M-814 \mu M)$. Neomycin achieved a reduction of the ammonia concentration in homogenate of small intestine but not in the incubation medium. No substantial effect was observed on ammonia production in the large intestine. The concentrations of alanine and glutamate in medium or homogenate of small and large intestine were not significantly affected by neomycin under these circumstances. 


\subsection{Discussion}

The results indeate that small and large intestine exhibit a substantial capacity to metabolize glutamine in vitro. The degradation of glutamine is most likely not mediated by bacterial actiwity because the preparation of the tissue pieces elimimates most of the gut flora. Results therefore are in accordance with the literature where it has been demonstrated by several investigators that the gutwall can take up glutamine $(9,11)$.

Windmueller investigated glutamine metabolism in a preparation of perfused rat intestine and found that the glutamine nitrogen taken up by the intestine could be accoumted for $33 \%$ by alanine production, for $23 \%$ by ammonia production and small amounts by proline and citrulline production. Metabolism by small and large intestine was not investigated separately however. In contrast to the in vitro studies of Matsutaka (8) in which tissue pieces of 200 mg were used, our studies showed a net increase in alanine production after addition of glutamine to the incubation medium. Our results may be more representative for the in vivo situation where glutamine uptake in the gut especially yiellds alanine and ammonia. Hanson (21) used perfused rat jejunum and found increased allanine production when animals had fasted. We did not conflym this in our study because no significant differences in alanime production could be detected in normally fed and fasted animals. It is noteworthy that the small bowel took up more glutamine than the large bowel and released more alanine, ammonia and glutamic acid into the medium (the finding that less glutamine was taken up by colon than by small bowel is consistent with the observation that colonic tissue has a lower glutaminase activity than small bowel (22)). This is contrary to what one would expect if metabolism of these substances would be mainly bacterially mediated, because small bowel contains $\log 2$ to 3 less bacteria.

Similarily it is striking that lactulose significantly decreases ammonia production in the small bowel and not in the colan. It thereby decreases release of alanine and glutamate. This suggests that in this in vitro study, 
lactulose effectively decreases ammonia production in the smald bowel through interference with intemediary metabolism. Since $2.5 \%$ lactulose increases the osmolarity of the medium with 130 mosmol one should consider the possibility that this mechanism is solely due to hyperosmolarity. Therefore, in this model we incubated sorbitol, mannitol and polyethyleen glyool with the sane osmolarity. At an osmolarity of 130 mosmol no decreasing effect was noted with these substances, although lactulase inhibited ammonia for $25 \%$. Whth an osmolarity of $518 \mathrm{~m} .0 \mathrm{sm}$ all substances decreased ammonia but much less still than lactulose.

Most if not all theories regarding the effect of lactulose on ammonia production have focused on bacterial amnonia production $(13,14,15,16)$. The results of our study do not exclude this mechanism but suggest an important role for lactulose in decreasing gut production of ammonia, alanine and glutamate by influencing intermediary metabolism in the small bowel. Neonycin decreases the concentration of ammonia in tissue hamogenates of the ileum and not in the colon. No influences of neomycin on ammonia, alanine and glutamate release into the incubation medium could be noted. Interpretation of these data is difficult but, with the exception of decreased ammonia levels in small intestine homogenates, these data do not suggest a role for neomycin in decreasing metabolic ammonia generation in the gut wall. These data justify further in vivo studies in animal models to establish the role of bacterial flora and gut wall in ammonia generation and the influence of lactulose and neomycin. In addition, the rolle of the different parts of the gutwall in ammonia metabolism should be specified.

\subsection{References}

1. Walser, M. and Bodenloos, L.J.: Urea metabolism in man. J. Clin. Invest. 38 : 1617 (1959).

2. Wolpert, E., Philips, S.F. and Summerski11, W.H.d.: Ammonia production in the human colon. N. Engl. J. Med. 283: 159-164 (1970). 
3. Philips, G.B., Schwartz, R., Gabuzda, G.J. and Dawidson, C.S.: The syndrome of impending hepatic coma in patients with cirrhosis of the liver given certain nitrogenous substances. N. Engl. A. Med. 247: $239-246(1952)$.

4. Wolpert, E., Phillips, S.F. and Summerskill, H.H.J.: Transport of urea and ammonia production in the human colon. Lancet 2: 1387-1390 (1971).

5. Gibson, J.A., Park, N.J., Sladen, G.E. e.a.: The role of the colon in urea metabolism in man. Clin. Sci. Mol. Med. 50: 51-59 (1976).

6. Wrong, O.M., Vince, A.J. and Waterlow, J.C.: The origin and bacterial metabolism of faecal anmonia. Falk Symposium 32, may 1981: Col on and Nutrition, p. 133-139, Ed. H. Kasper and H. Goebe11.

7. Nance, Fr.C. and K1 ine, F.C.: Eck's fistula encephalopathy in germ-free dogs. Ann. Surg. 174: 856-861 (1971).

8. Matsutaka, H., Aikawa, F., Yamamoto, H. and Ishikawa, E.: Gluconeogenesis and amino-acid metabolism. III. Uptake of glutamine and output of alanine and ammonia by non-hepatic splanchnic organs of fasted rats and their metabolic significance. J. Biochem. 74: 1019-1029 (1973).

9. Windmueller, H.G. and Spaeth, A.E.: Uptake and metabolism of plasma glutamin by the small intestine. J. Biol. Chem. 249 (16): 5070-5080 $(1974)$.

10. Windmueller, H.G. and Spaeth, A.E.: Intestinal metabolism of glutamine and glutamate from the 1 umen as compared to glutamine from blood. Arch. Biochem. Biophys. 17: 662-672 (1975).

11. Weber, F.L. and Veach, G.L.: The importance of the small intestine in gut ammonia production in the fasting dog. Gastroenterology $77: 235-240$
(1979).

12. Imler, M., Peter, B., Schlienger, J.L., Lavillanrieux, J. and Stahl, J.: L'ammoniogénèse intestinale du rat noma7. Méd. Chir. Dig. 4: 15-20
(1975).

13. Dawson, A.M., Mclaren, J. and Sherlock, S.: Neomycin in the treatment of hepatic coma. Lancet, dec. 21 p. 1263 (1957). 
14. Bown, R.L., Gibson, J.A., Sladen, G.E. e.a.: Effects of lactulose and other laxatives on ileal and colonic pH as measured by a radiotelemetry try device. Gut 15: 999-1004 (1974).

15. Bircher, J., Muller, J., Guggenheim, P. e.a.: Treatment of chronic portal systemic encephalpathy with lactulose. Lancet 1: 890-893 (1966).

16. Vince, A., Killingley, B.S.C. and Wrong, O.M.: Effect of lactulose on ammonia production in a fecal incubation system. Gastroenterology 74: $544-549$ (1978).

17. Da Fonseca-Wollheim, F., Bergmeyer, H.U., Gutman, J.: Ammoniak. In: Methoden der enzymatischen Analyse. Band I und II, p. 1850-1853, Verlag Chemie, Weinheim (1974).

18. Williamson, D.H.: L-Alanin Bestimmung mit Alanin-Dehydrogenase. I $n$ : Methoden der Enzymatischen Analyse, ed. H.U. Bergmeyer, Band I and II, p. 1724-1726, Verlag Chemie Weinheim (1974).

19. Bernt, E., Bergmeyer, H.U.: L-Glutamat. UW-Test mit Glutamat-Dehydrogenase und NAD. In: Methoden der Enzymatischen Analyse, ed. H.U. Bergmeyer, Band I and II, p. 1749-1753, Verlag Chemie Weilnheim (1974).

20. Lund, P.: Bestimmung mit Glutaminase und Gl utamat-Dehydrogenase. I $n$ : Methoden der Enzymatischen Analyse, ed. H.V. Bergmeyer, Band I and II, p. 1767-1769, Verlag Chemie Weinheim (1974).

21. Hanson, P.J. and Parsons, 0.S.: Metabolism and transport of glutamine and glucose in vasculary perfused small intestine rat. J. Biochem. 166: 509-519 (1977).

22. Pinkus, L.M., Windmueller, H.G.: Phosphate-dependent glutamine of small intestine: localization and role in intestinal glutamine metabolism. Arch. Biochem. Biophys. 182: 506-517 (1977).

23. Wroblewski, F., La Due, J.S.: Lactate dehydrogenase activity in blood. proc. Soc. Exp. Biol. Med. 90: 210-215 (1955). 
METABOLIC CHARACTERISTICS OF VILLOUS AND CRYPT ENTEROCYTES OF CONVENTIONAL AND GERM-FREE RATS AND THE INFLUENCE OF NEOMYCIN AND LACTULOSE

\section{III.1. Introduction}

In recent years considerable progress has been made to identify the small intestine as an important site of glutamine utilisation, thereby contributing significantly to the respiratory fuel of the intestinal mucosa. According to Windmueller and Spaeth $(1,2)$ ammonia, alanine, citrulline and proline are the main nitrogenous products derived from glutamine. However, these studies were carried out with an isolated perfused preparation and the site of ammonia production could not be identified. Watford and Lund (3) indicated in their studies with chicken enterocytes that of the added substrates glutamine, glucose and glutamate were the preferred fuels of respiration in the enterocyte. Presumably the enterocytes were mainly derived from the villous compartment and no information about the relative contribution of crypt epithelial cells to glutamine metabolism was obtained. Whether lactulose and neomycin influenced glutamine metabolism and ammonia production in villous and/or crypt epithelium has never been the subject of study. In chapter II we nave suggested that lactulose and possibly neomycin are capable of inhibiting the glutamine dependent ammonia production. The exact site of this process was not identified. Therefore we investigated the ammonia production of villous and crypt cells and the influence of lactulose and neomycin on this ammonia production. 


\section{III.2. Material and methods}

Rats.

Specific pathogen free (SPF) male and germ-free Wistar rats weighing approximately 250-300 $g$ were obtained from the centralized experimental animal facilities of the University Biomedical Center, Mastricht. Rats were kept at $21^{\circ} \mathrm{C}$ and allowed free access to water and rat chow fformula SRM A120, Hope Farms, woerden, The Netherlands). All experiments reported were carried out with cells from normally fed rats. Germ-free experiments were done under sterile conditions. Cultures of medium were performed before and after the experiments and no bacteria were present.

\section{Isolation of villous and crypt cells.}

Male Wistar rats were used for the isolation of villous and crypt cells. Small intestine was freshly removed during ether anaesthesia and the lumen was flushed with $150 \mathrm{ml}$ of ice-cold saline. Further work was done at $0-4^{\circ} \mathrm{C}$. Cells were prepared in principle according to the vibration technique of Harrison \& Webster (4) as described by Iemhoff et al (5) and Halsman et al (16). In short four $15 \mathrm{cra}$ pieces of everted intestine were attached to the metal rods with surgical silk. The rods were exposed to longitudinal vibration following attachment to a vibromixer (type El Chemap, Mannedorf, Switzerland). The intestine was first vibrated $(100 \mathrm{~Hz} 2 \mathrm{~mm}$ amplitude) for 1 minute in saline to remove mucus and adhering material followed by 12 minutes of vibration in isolation medium containing $0.15 \mathrm{M} \mathrm{NaCl}, 5 \mathrm{MM}$ EDTA, $10 \mathrm{~m}$ M TrisHC7, $\mathrm{pH} 7.4$ in order to release upper villous cells. Before harvesting the crypts, the intestine was wibrated for another $18 \mathrm{~min}$ to remove lower villus. This suspension was discarded. Then by the insufflation of air into the space between intestine and metal rod the pieces of intestine were dilated to expose the crypts better to the medium. By wibration for another 30 min, crypt cells could be released. Upper villous and crypt cell suspensions are centrifuged for 1 min at $300 \times 9$ (Iemhoff et al, 5). Cells were 
then washed three times and centrifugated for 1 min $300 \times 9$ with a buffer contalning: $128 \mathrm{mH} \mathrm{NaCl}, 4.7 \mathrm{mH} \mathrm{KCl}, 20.2 \mathrm{mH}^{\mathrm{M}} \mathrm{NaHCO}_{3}, 0.4 \mathrm{mM} \mathrm{NaH} \mathrm{PO}_{4} \mathrm{H}_{2} 0,0.33$

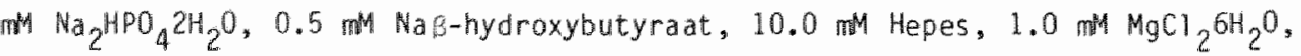
$1.3 \mathrm{mM} \mathrm{CaCT} 26 \mathrm{H}_{2} \mathrm{O}$ equilibrated with $\mathrm{O}_{2} / \mathrm{CO}_{2}(95: 5 \mathrm{v} / \mathrm{v})$. Then $10 \mathrm{mM}$ glucose and bovine serum albumin (BSA) $1 \mathrm{~g} / 1$ was added. The same buffer was used for the incubation procedure. A11 isolation and incubation procedures were carried out with plastic material, thus minimizing cell rupture. During isolation, only a small percentage of the cells is damaged, as judged by leakage of soluble enzymes and measurements of protein and DNA synthesis (lemhoff et al, 5; de Jonge et al, 7). Moreover both axygen consumption rate (measured polaro graphically as reported in ref. 7) and the rate of glucose utilization in villous and crypt cells are wirtually constant during 30 min of incubation under our experimental conditions $(5,7$ and H.R. de Jonge: unpublished observations).

\section{Reagents.}

Crystalline glutaminase L-glutanine amidohydrolase, EC 3.5.1.2. (grade V) was abtained from Sigma U.S.A.. The following were products of Boehringer Mannheim:

- Glutamate dehydrogenase (L-glutamate; NAD(P) axidoreductase (deaminating), EC 1.4.1.3.) in 50\% glycerol, from beef liver (specific activity 120 $\mathrm{U} / \mathrm{mg})$;

- L-alanine dehydragenase from Bacillus subtilis (L-alanine: NAD oxidoreductase (deaminating), EC 1.4.1.1.). Specific activity: circ. 30 U/mg;

- B-Nicotinamide-adenine dinucleotide; NAD free acid, grade 1, 100\%;

- Adenosine-5 -diphosphate (ADP) dísodium salt;

- B-Nicotinamide-adenine dinucleotide phosphate, reduced (NADPH, tetrasodium sa1t, $98 \%$;

- a-Ketoglutaric acid, crystallized free acid $98 \%$

- Lactulose (Duphatac) was obtained from Duphar (Weesp) and contained 667 mg 1 actulose $/ \mathrm{ml}$; 
- Neomycin sulphate was obtained fram Lundbeck. Amsterdam, The Netherlands.

\section{Incubation procedure.}

Cells were suspended in buffer (DNA content $50 \mathrm{pg} / \mathrm{ml}$ final concentration) with and without the addition of Jactulose $2.5 \%$, lactulose $10 \% \mathrm{~W} / \mathrm{N}$ or neomycin $81.4 \mathrm{MM}$ and $814 \mathrm{kM}$. Two $\mathrm{mi}$ cell suspension was incubated with and without glutamine $10 \mathrm{~mm}$ at $37^{\circ} \mathrm{C}$ for 0 and $30 \mathrm{~min}$. During the incubations the suspensions were gassed with $\mathrm{O}_{2} / \mathrm{CO}_{2}(95: 5 \mathrm{v} / \mathrm{V})$. Incubations were stopped by the addition of 200 ul perchloric acid (PCA) $60 \%(\mathrm{w} / \mathrm{v})$ and directly frozen at $-75^{\circ} \mathrm{C}$. Metabolite analyses were carried out following neutralization of P.C.A. with $\mathrm{KOH}$ and removal of the insoluble $\mathrm{KCLO}_{3}$ by centrifugation.

\section{Determination of metabolites.}

Ammonia mas determined according to the method of Dafonseca (8). Alanine, glutamine and glutamic acid were measured in the neutralized supernatant by an enzymatic micromethod using a centrifugal analyser (Cobas-Bio, Hoffmann La Roche). For the concentrations of the solutions used, the preparations of the samples and the enzymatic assay we followed the methods of Williamson for alanine (9), of E. Bernt for glutamate (10) and of Lund for glutamine (11). DNA content in villous and crypt suspensions were determined according to Burton (12).

Lactate dehydrogenase (LDH) was determined in the cell medium after centrifugation of the cell suspensions at $300 \times \mathrm{g}$ for $5 \mathrm{~min}$. Total lactate dehydrogenase content of the willous and crypt cells was measured after complete lysis which could be performed by sonification for $40 \mathrm{sec}$ (with intervals for $5 \mathrm{sec}$ ) on ice [Sonicator type U1trasonic desintegrator 100 watt model (NN Beun - de Ronde, H.V.L.) amplitude 12 microns]. It was measured with a Boehringer test kit based on the method of Wroblewski (13). 
82.7 and 165.0 wnol/L $(n=15)$. The observed results were respectively $15.4-$ $32.4-81.5$ and 162.0 umol/L. Coefficients of variation (CV) were respectively $3.5-3.0-2.5$ and $2.6 \%$.

- Glutamic acid. The following standard concentrations were used: $16.6-32.3$

$-65.0-131.3$ and $33.3 .3 \mu m o l / L(n=8)$. The observed results were respect vely $18.3-35.5-67.9-130.4$ and 336.0 umol/L. CV were respectively: 9.4 $-5.1-4.9-3.4$ and $0.7 \%$

- Amnonia curve. The following standard concentrations were used: 50.0 $100.0-200.0$ and $300.0 \mu m 01 / L(n=20)$. The observed results were respectively $51.5-102.0-200.0$ and 301.0 pmol/L. CV were respectively $6.5 \%$ $4.4 \%-2.9 \%$ and $1.8 \%$.

- DNA curve. The following standard concentrations were used: 3.0 - 6.0 $15.0-22.5-30.0-45.0-60.0 \mathrm{~kg} / \mathrm{ml}$. The observed results were respectively $3.1-6.0-14.7-22.4-30.8-44.7$ and $59.7 \mu \mathrm{g} / \mathrm{ml}$.

\section{Intra-assay variations.}

Intra-assay variations of alanine, glutamic acid and ammonia are respectively $2.7 \%-0.5 \%$ and $0.9 \%$. The minimum detection level of alanine, glutamic acid, glutamine and ammonia in villous and crypt cells of the T30 and To analysis is $10 \mu \mathrm{mol} / \mathrm{L}$.

The analytical mean recovery of alanine, glutamic acid and ammonia after 60 min and 30 min incubations with and without glutamine $10 \mathrm{mM}$ and with and without lactulose and neomycin were for alanine, glutamic acid and ammonia respectively $100 \%-99.5 \%$ and $99.8 \%$.

\section{III.3. Results}

Ammonia and amino acid release by villous and crypt cells of conventional and gierm-free rats.

Villous and crypt cells of small intestine of conventional and germ-free rats 


\section{AMIMONIA PRODUCTION}

in conventional rats

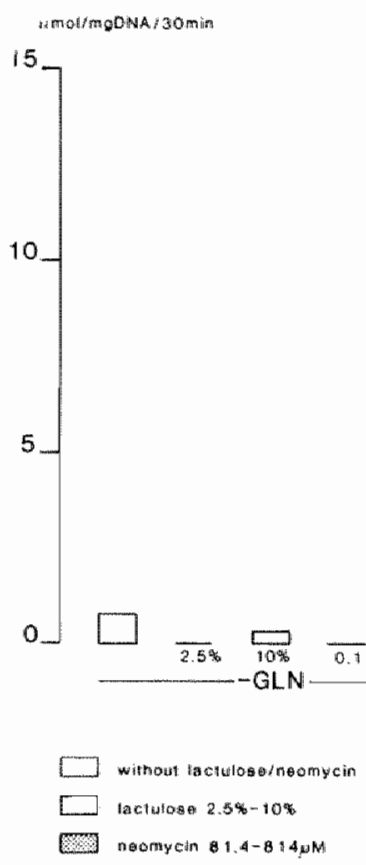

Figure 1: Ammonia production in villous cells of conventional rats incubated in Krebs Ringer buffer ( \pm glutamine $10 \mathrm{~m}(\mathrm{~N})$ with and without lactulose $(2.5 \%-10 \% W / W)$ and neomycin $(81.4, M M$ and $814 \mu M)$ added. DNA content of each sample $50 \mu \mathrm{g} / \mathrm{ml}$. Results are the mean of the duplicates and expressed in umol/mg DNA/30min. Cells were harvested from a batch of 4 rats.

were capable of generating a measurable amount of amrnonia when incubated for 30 min in vitro. This production was greatly increased when glutamine was added to the medium (fig. $1,2,3$ and 4 ). Concomitant with this ammonia production, alanine and glutamic acid were produced by both villous and crypt cells of conventional and germ-free rats (table II and III). In conventional rats more glutamine dependent ammonia was produced by villous cells in comparison to crypt cells (expressed per $\mu \mathrm{mol} / \mathrm{mg}$ DNA protein). In the germ-free state production was of equal magnitude. Glutamic production of villous and crypt 
cells in the conventional pats was almost similar. Glutamic acid production however was roughly twice as much in the crypt cells of germ-free if compared to the villous cell production. More alanine was produced in villous cells of conventional rats than in the crypt celis. Alanine production of villous and crypt cells was the same however.

\section{AMMONIA PRODUCTION}

in conventional rats

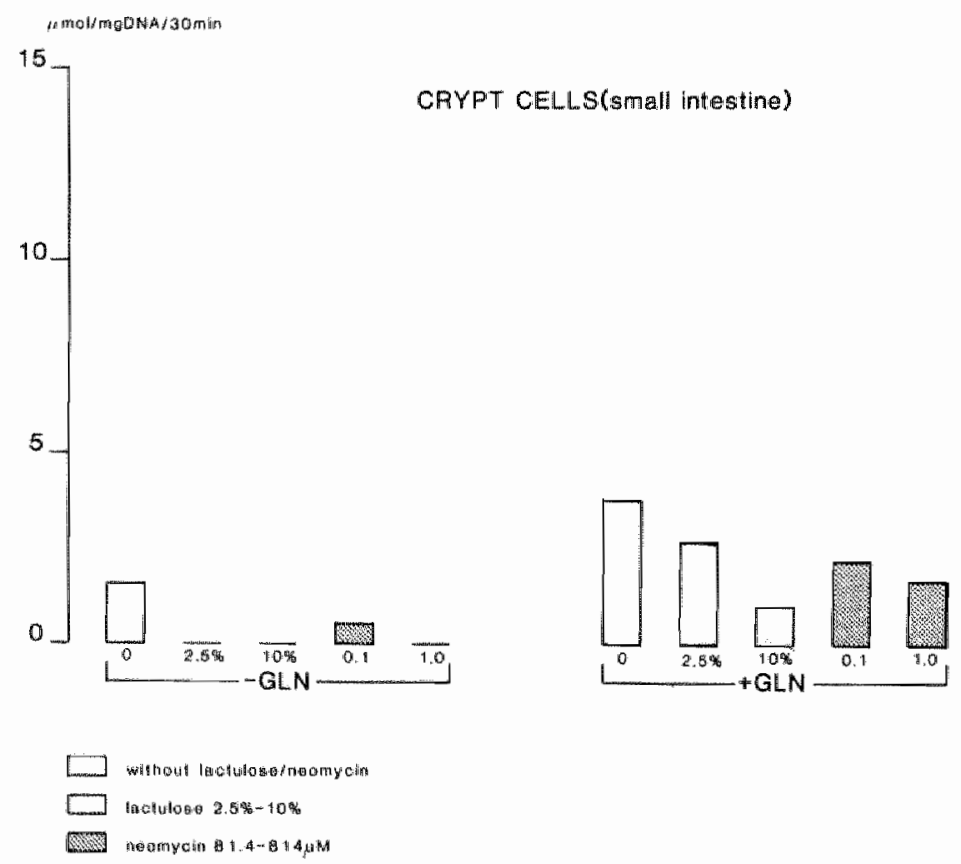

Figure 2: Ammonia production in crypt cells of conventional rats incubated in Krebs Ringer buffer $( \pm g l u t a m i n e ~ 10 \mathrm{mM})$ with and without lactulose

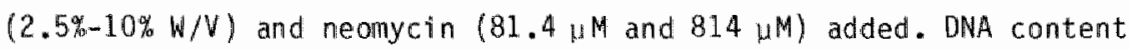
of each sample $50 \mathrm{Hg} / \mathrm{ml}$. Results are the mean of the duplicates and expressed in umol/mg DNA/30min. Cells were harvested from a batch of 4 rats. 
citrulline and ornithine were not detectable as a product of glutamine metabolism under the present experimental conditions.

\section{AMMONIA PRODUCTION}

in germ free rats

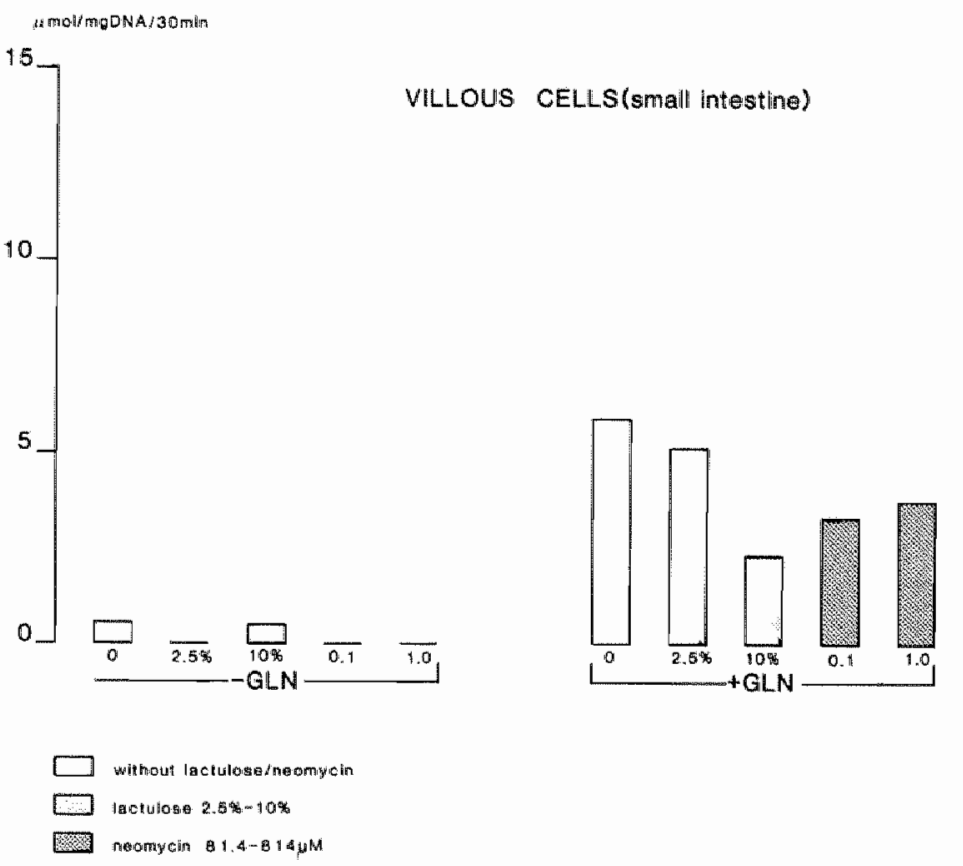

Figure 3: Ammonia production in villous cells of germ-free rats incubated in Krebs Ringer buffer $( \pm$ glutamine $10 \mathrm{mM})$ with and without lactulose $(2.5 \%-10 \% \mathrm{~W} / \mathrm{V})$ and neomycin $(81.4 \mu \mathrm{M}$ and $814 \mu \mathrm{M})$ added. DNA content of each sample $50 \mu \mathrm{g} / \mathrm{ml}$. Results are the mean of the duplicates and expressed in umolng ONA/30min. Cells were harvested from a batch of 4 rats. 


\section{AMMONIA PRODUCTION}

in germ free rats

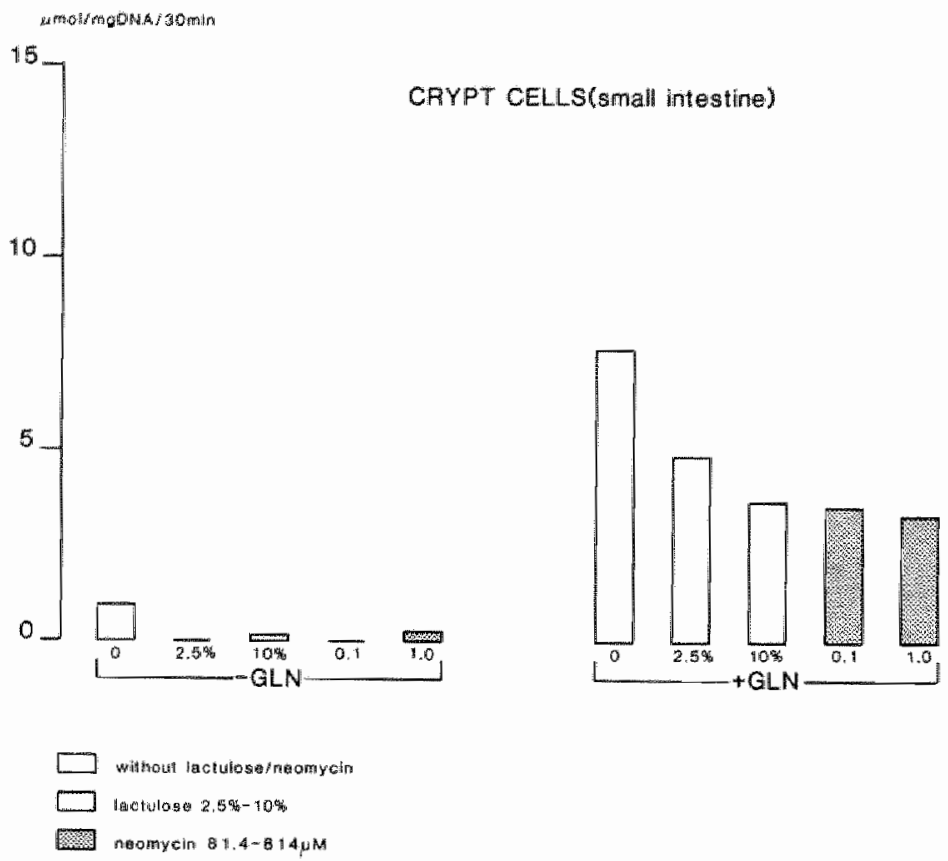

Figure 4: Ammonia production in crypt cells of germ-free rats incubated in Krebs Ringer buffer ( \pm glutamine $10 \mathrm{mM}$ ) with and without liactulose $(2.5 \%-10 \% W / V)$ and neomycin $(81.4 \mu M$ and $814 \mu M)$ added. DNA content of each sample $50 \mathrm{ug} / \mathrm{mll}$. Results are the mean of the duplicates and expressed in $\mu m 01 / \mathrm{mg}$ DNA/30min. Cells were harvested from a batch of 4 rats.

In order to estimate the viability of the mucosa cells after 30 min. of incubation, lactate dehydrogenase (LDH) release during incubation was determined and expressed as percentage of total cellular LDH content. It can be appreciated in Table 1 that there is a small leakage of LDH into the medium during 30 min of incubation but this release does not exceed $20 \%$ of the original content in villous and crypt cells. Lactulose (2.5\%) and neomycin (81.4 HM) apparently caused only a slight increase of this LDH release. In contrast, a higher level of lactulose (10\%) presumably through its effect on the osmolarity of the medium, leads to a more substantial leakage of LDH, 
amounting to about $40 \%$ in the germ-free experiments.

\section{Table I}

\begin{tabular}{|c|c|c|c|c|}
\hline Buffer & Lactulose & Lactulose & Ne onyycin & Neonycin \\
\hline without & $2.5 \%$ & $10 \%$ & $81.4 .1 . \mathrm{M}$ & 814 uM \\
\hline \multicolumn{5}{|l|}{ Lact/Neo } \\
\hline$-\quad+$ & - & + & - & + \\
\hline
\end{tabular}

\begin{tabular}{lrrrrrrrrrr} 
Conventional rat & & & & & & & & & \\
Villious cells & 6 & 7 & 12 & 12 & 20 & 16 & 16 & 16 & 10 & 10 \\
Crypt cells & 14 & 21 & 18 & 20 & 26 & 21 & - & - & 15 & 20 \\
\hline
\end{tabular}

\begin{tabular}{lllllllllll} 
Germ-free rat & & & & & & & & & \\
Willows cells & 20 & 20 & 26 & 25 & 38 & 39 & 29 & 27 & 23 & 24 \\
Crypt cells & 15 & 19 & & 27 & 41 & 32 & - & - & - & - \\
\hline
\end{tabular}

+ w with glutamine

- = without glutamine

Table I: Lactate dehydrogenase (LDH) measurements in the medium after 30 min of incubation expressed as percentage of the LDH content of the cells prior to incubation. Experiments were done with and without glutamine $10 \mathrm{mM}$ added.

The effect of lactulose on ammonia production in vitro.

In order to study the effects of lactulose on this glutamine dependent ammonia production by the mucosa cells, lactulose was added to the medium in two different concentrations $(2.5 \%$ and $10 \% \mathrm{~W} / \mathrm{V})$.

Lactulose decreased the ammonia production in villous and crypt cells of conventional rats already at a concentration of $2.5 \%$ (fig. 1 and fig. 2 ). The decrease was more dramatic at $10 \%$. Lactulose also decreased the ammonia production in the willous and crypt cells of the germ-free rats $(3,4)$. 
The glutamic acid concentration already decreased at a concentration of $2.5 \%$ and even more so at a concentration of $10 \%$ in villous and crypt cells of conventional rats. Alanine production was decreased in conventional and germfree rats in both the villous and crypt cells at a concentration of $10 \%$ (table II and III).

\section{Table II}

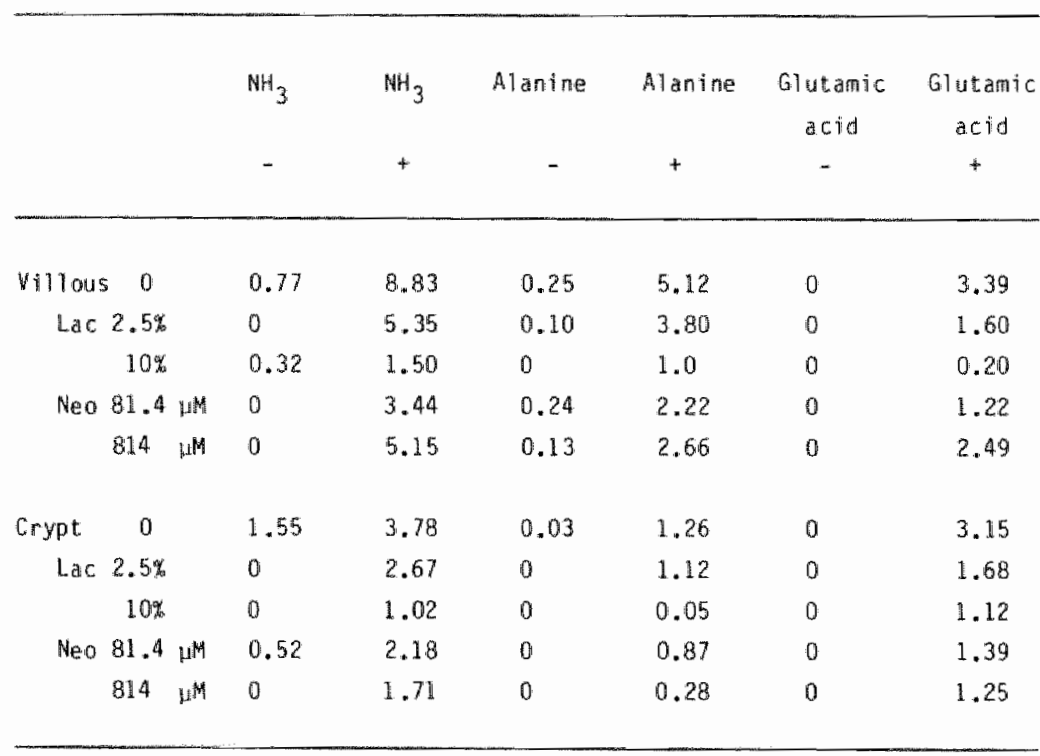

* with glutamine

- wthout glutamina

Table II: Ammonia, alanine and glutamic acid production of conventional rats incubated in Krebs-Ringer buffer (glutamine $10 \mathrm{mM}$ ) for $30 \mathrm{~min}$ with and whout lactulose $(2.5 \%-10 \% W / V)$ and neomycin $(81.4 \mu M$ and $814 \mathrm{\mu M}$ ) added. DNA content of each sample was $50 \mathrm{\mu g} / \mathrm{ml}$. Results are the mean of the duplicate experiments and expressed in $\mu m 0 l / m g$ DNA/30 min. Intestinal cells harvested from 4 rats were pooled prior to each experiment. 


\begin{tabular}{|c|c|c|c|c|c|c|c|}
\hline & & ${ }^{N H_{3}}$ & $\begin{array}{l}\mathrm{NH}_{3} \\
+ \\
+\end{array}$ & Alantine & $\begin{array}{c}\text { Alanine } \\
+\end{array}$ & $\begin{array}{l}\text { Blutamic } \\
\text { acid }\end{array}$ & $\begin{array}{c}\text { Glutamic } \\
\text { acid } \\
+\end{array}$ \\
\hline Villows & $s 0$ & 0.54 & 5.89 & 0.43 & 4.09 & 0 & 1.49 \\
\hline Lac & $2.5 \%$ & 0 & 5.14 & 0.11 & 3.66 & 0 & 0.92 \\
\hline & $10 \%$ & 0.48 & 2.30 & 0 & 1.60 & 0 & 0.60 \\
\hline \multirow[t]{2}{*}{ Neo } & $81.4 \mu^{M}$ & 0 & $3_{m} 27$ & 0.34 & 1.63 & 0 & 1.63 \\
\hline & $814 \quad M$ & 0 & 3.76 & 0 & 2.34 & 0 & 1.48 \\
\hline Crypt & 0 & 0.95 & 7.63 & 0.42 & 2.84 & 0 & 5.49 \\
\hline Lac & $2.5 \%$ & 0 & 4.85 & 0 & 2.27 & 0 & 2.57 \\
\hline & $10 \%$ & 0.14 & 3.66 & 0 & 1.15 & 0 & 3.32 \\
\hline \multirow[t]{2}{*}{ Neo } & $81.4 \mathrm{MH}$ & 0 & 3.53 & 0.32 & 2.45 & 0 & 0.49 \\
\hline & 814 药 & 0.22 & 3.27 & 0 & 2.25 & 0 & 0.67 \\
\hline
\end{tabular}

* = with glutamine

- without glutamine

Table III: Ammonia, alanine and glutamic acid production of germ-free rats incubated in Krebs-Ringer buffer (glutamine $10 \mathrm{mM}$ ) for $30 \mathrm{~min}$ with and without lactulose $(2.5 \%-10 \% \mathrm{~W} / \mathrm{V})$ and neomycin $(81.4 \mu \mathrm{M}$ and $814 \mu M)$ added. DNA content of each sample was $50 \mu \mathrm{g} / \mathrm{ml}$. Results are the mean of the duplicate experiments and expressed in unol/mg DNA/30 min. Intestinal cells harvested from 4 rats were pooled prior to each experiment.

The effect of neomycin on ammonia production in vitro.

In order to investigate whether neomycin was capable of inhibiting this non-bacterial ammonia production, both villous and crypt cells of conventional and germ-free rats were incubated with neomycin added in two different concentrations $(81.4 \mu \mathrm{M}$ and $814 \mu \mathrm{M})$. Neomycin decreased the ammonia production in villous and crypt cells of conventional and germ-free rats at both concentrations (fig. 1, 2, 3 and 4). The decrease was almost $50 \%$ in the crypt 
cells of the conventional and germ-free rats at a concentration of $814 \mathrm{M}$. Glutamic acid production was decreased in both concentrations of neomycin in willous and crypt cells of conventional and in the crypt cells of the germfree rats. Alanine production was decreased by neomycin in the villous cells of conventional and germ-free rats, in the crypt ceils of conventional rats, but not in the crypt cells of the germ-free rats.

\section{III.4. Discussion}

Results indicate that the mucosal cells of the small intestine may account for a substantial part of the glutamine degradation in the gut. This degradation occurs both in villous and crypt cells and appears to be of non-bacterial origin, since these mucosal cells and the preparation isolated by the vibration procedure are virtually sterile (14). Moreower germ-free rats were likewise capable of generating ammonia in their mucosa cells. In conventional rats more ammonia was formed in the villous cells then in the crypt cells. In the germ-free state however crypt and villous cells showed an almost equal production rate of ammonia. Whem the production by villous and crypt cells is added together, and when the total number of crypt and villous cells isolated from conventional and germ-free rats are considered to be approximately equal (as shown by DNA content) the production capacity of ammonia is roughiy equal in enterocytes of conventional and germ-free rats. As Watford (3) and Hanson (15) concluded, the carbon skeleton of alanine can be provided by degradation of glutamine or glutamate to pyruvate and this has its significance in clearing the blood of excessive glutamine or glutamate. The uptake of glutamate by the liver is too slow to clear the high content of glutamate in the blood. Clearing of glutamate is necessary because a high concentration can be toxic to the brain (16). No citrulline and ornithine could be detected. Results are in accordance with the study by Watford (15) who also could not detect citrulline, but are in contrast to the findings of 
Windmueller. Failure to detect these amino acids may be due to a very low rate of synthesis in the mucosa cells. Ross (17) reparted the synthesis of ornithine or citrulline from glutamate in homogenates of mucosa from rat small intestine. The rate was 31.8 mol/90 min/g fresh weight of tissue which is low enough to explain our failure to detect citrulline. In contrast to the literature, where neomyc in and lactulose are supposed to exert their influence on hepatic coma by interfering with the bacterial flora, our results do suggest an additional effect on intemediary metabolism. Both neomycin and lactulose were capable of inhibiting the non-bacterial ammonia production together with inhibition of the praduction of alanine and glutamic acid.

Weber (18) determined the contribution of jejunum and ileum to portal ammia relative to the colon in his study with dogs. He concluded that when expressed per total intestinal segment, jejunum and ileum released 28 and $22 \%$ of gut ammonia and the colon 50\% into the venous blood. Amrnomia released by the jejunum and ileum could be largely accounted for by the metabolism of glutamine, but in the colon for 50\%. Taking our results and the results of Weber into account it is most likely that besides their possible action on the fhora, lactulose and neamycin decrease ammonia by interfering with intemediary metabolism. The exact mode of action or the site where their action takes place is, at this moment, only speculative.

\subsection{References}

1. Windmueller, H.G., Spaeth, A.E.: Uptake and metabolism of plasma glutamine by the small intestine. J. Biol. Chem. 249: 5070-5079 (1974).

2. Windmuelier, H.G., Spaeth, A.E.: Intestinal metabol ism of glutamine and glutamate from the lumen as compared to glutamine from blood. Arch. Biochem. Biophys. 171: 662-672 (1975).

3. Watford, M., Lund, P. and Krebs, H.A.: Isolation and metabolic characteristics of rat and chicken enterocytes. Biachem. J. 178* 589-596 (1979). 
4. Harrison, 0.D. and Webster, H.L.: The preparation of 1 solated intestinal crypt cells. Exp. Cell Res. 55: 257-260 (1969).

5. lemhoff, W.G.J., Berg van den, J.W.O., Pijpen de, A.M. and Holsman, H.C.: Metabolic aspects of cells from rat small intestinal epithelium. Biochem. Biophys. Acta 215 (2): 229-241 (1970).

6. Hulsmann, H.C., Berg van den, J.W.O. and Jonge de, H.R.: Isolation of intestinal mucosa cells. In: Methods in Enzymology (Fleischer, S. and Packer, L., eds.). Academic Press, New York, vol. 32 (part 2), p. 665-673 (1977).

7. Jonge de, H.R.: Toxity of tetracycline in rat small intestinal epithe1 ium and liver. Biochem. Phanmacol. 22 (2): 2659-2677 (1973).

8. Da Fonseca-Wollheim, H.U., Bergmeyer, F. and Gutman, H.U.: Ammoniak. In: Methoden der Enzymatische Analyse, ed. H.U. Bergmeyer. Band I, II, p. 1850-1853, Verlag Chemie, Weinheim (1974).

9. Williamson, D.H.: L-Alanin. Bestimung mit alanin-dehydrogenase. In: Methoden der Enzymatischer Analyse, ed. H.U. Bergmeyer, Band I and II, p. 1724-1726, Verlag Chemie, Keinheim (1974).

10. Bernt, E., Bergmeyer, H.U.: L-Glutamat. U.V.-Test mit Gl utamat-dehydrogenase und NAD. In: Methoden der Enzymatischen Analyse, ed. H.U. Bergmeyer, Band I and II, p. 1749-1753, Kerlag Chemie, Weinheim (1974).

11. Lund, P.: Bestirmung mit GTutaminase und GTutamat Dehydrogenase. In: Methoden der enzymatischen Analyse, ed. H.U. Bergmeyer, Band I and II, p. 1767-1769, Ver1ag Chemie, Weinheim (1974).

12. Burton, $K_{.}$: A study of the conditions and mechanisms of the diphanylamine reaction for the calorimetric estimation of deoxyribonucleic acid. Biochem. J. 62: $315-323$ (1956).

13. Wroblewski, F. and La Due, J.S.: Lactate dehydrogenase activity in b1ood. Proc. Soc. Exp. Biol. Med. 90: 210-215 (1955).

14. Jonge de, H.R.: Unpublished observations, Rotterdam. 
15. Hanson, P.J. and Parsons, D.S.: Metabolism and transport of glutamine and glucose in vascularly perfused small intestine rat. Blochem. $\mathrm{J}$. 166: $509-519(1977)$.

16. 01ney, 3.W.: Excitotoxic amino-acid research application and safety implications. In: Glutamic acid. Adv. Biochem. Physiol. Eds. L.J. Filer Jr., S. Garattini, M.R. Kare, W.A. Reynolds and R.d. Wurtman, Raven Press, New York, 1979, p. 287.

17. Ross, G., Dunn, D.A., Jones, M.E.: Ornithine synthesis from glutamate in rat intestinal mucosa homogenates: evidence for the reduction of glutamate to $\gamma$-giutamyl-semialdehyde. Biochim. Biophys. Acta 85: 140-147 (1978).

18. Weber, F.L. and Veach, G.: The importance of the small intestine in gut ammonium production in the fasting dog. Gastroenterology 37: 235-240 (1979). 


\section{INTESTINE.}

IV.1. Introduction

Neomycin is an aminoglycoside antibiotic isolated from a strain of streptomyces fradiae. Oral treatment with nemycin reduces the number of aerobic gram negative rods and gram positive cocci in the intestine. It has become part of standard treatment for hepatic encephalopathy where it has beneficial effects on mental state, supposedly by the ability of neomycin to lower plasma amonia levels. Efforts to explain the effects of meanycin by its action on bacterial intestinal flora, fail to convince because clinical state and blood ammonia levels do not correlate well with the observed alterations in faecal flora (1). Whether the effect of neomycin is only achieved by a reduction of the Enterobacteriaceae is still questionable because the aerobic flora represents only a minor fraction of the total intestinal flora.

Concomitantiy it became apparent that neomycin has significant effects on intestinal function $(2,3,4,5)$. It reduces intestinal absorption $(6,7)$ and decreases the level of a variety of intestinal enzymes $(4,8)$. In the present study, we wanted to evaluate changes in the morphology of the intestinal wall in the rat and the reactivity of certain mucosal enzyme systems in the course of neomycin treatment, in order to reveal a possible mechanism of neomycin in the treatment of hepatic cona on the mucosa.

Several possible ways in which the drug exerts its influence on the mucosa, include:

I. Interference with intracellutar mucosal enzyme systems.

II. Interference with absorption. 
III. Disturbance of the symbiotic relationship between bacterial flora and mucosa.

IV. A combination of these mechanisms.

In an endeavour to separate the effect of neomycin on gutwall mucosa from its effect on the gut, mediated by its action on the intestinal fiora, gem-free rats and conventional rats were included in the study.

Several histochemical enzyme reactions were selected, each more or less representative for a specific function of the cel. To investigate whether transport function by the brush border was affected, alkaline phosphatase (A.Ph) was chosen as a marker enzyme. Lysosomal distribution was observed with acid-phosphatase (Ac.Ph). Interference with transport-function in the enteracyte was recorded by changes of the aspecific esterase staining (AE). The oxidative capacity of the cell was evaluated by changes in the NAD tetrazoliumreductase (NADHtr) and succinate dehydrogenase staining (SDH).

\section{IV.2. Material and methods}

Specific pathogen free (SPF) male Wistar rats weighing $250-300$ g were used for all experiments, and were allowed free access to water and food. Germfree animalis were housed in plastic isolators. Air was filtered with bacterial filters (Miller Filters, Millipore, U.S.A.). Environmental conditions were kept constant. Entries of supplies and removal of waste products were carried out under strict aseptic conditions. Control cultures were perfomed weekly and on the day of termination of the experiment in the germ-free group. The diet consisted of special labaratory chow (formula SRM-A120 Hopefarms, Woerden, NL) for germ-free and conventional animals. All animals were kilied by aortic exsanguination on the seventh day after daily ingestion of $500 \mathrm{mg}$ nearnycine or placebo. Before sacrifice, each rat was operated under ether anaesthesia. Operations were perfarmed between $8.00 \mathrm{a} . \mathrm{m}$. and 1.00 p.m. After an abdominal incision the proximal $(14 \mathrm{~cm}$ from the pylorus) and distal 
segments (10 $\mathrm{cm}$ from the lleocoecal junction) of the small intestine and segments of the colon were removed, fixed or frozen on to microtone plugs. Tissue segnents were prepared for histochenical reaction on $\mathrm{AlPh}$, ACPh, $\mathrm{AE}$, SOH, NADHtr and for hamatoxyline-eosine (HE) staining. For AE, Est, HE, AlPh and AcPh specimens were first fixed in Holt's fixation fluid (10) for 24 hours and subsequently stored in Holt"s storage medium for 48 hours. Specimens, including those for NADHtr and SDH were immersed in Freon at melting temperature. Fixed and unfixed blacks were cut with a cryostat microtome at sections of $10 \mathrm{um}$. Per experiment we used six germ-free ( 3 treated +3 controls) and six conventional ( 3 treated +3 controls) animals. Three experiments were carried out.

\section{IV.3. Results}

Small intestine of conventional and germ-free rats, treated with placebo.

In the HE staining of nomal rats a well developed lamina propria was seen, containing numerous lymphocytes, reticuloendothelial cells and plasma cells. Villi were well formed and regular in outline. The columnar epithelium is continuous with that of the crypt. In germ-free animals the lamina propria is poorly developed with relatively few cells in its interstices; crypts are shallow and villi are long and slender.

AlPh activity was localized at the brush border zone and juxtaapical portion of the epithelial cells in germ-free rats (fig. 1) and in conventional rats. Staining was prominent near the top and basis of the villus and negative in the crypt.

AcPh activity was high in villus epithelfum and crypt celis and azodye was distributed throughout the cytoplasm of reacting cells in conventional and germ-free rats (fig. 2). A clear staining reaction was noted along the brush border of the epithelial cells of the villi. A granular distribution was observed in the apical portion of these cells. 


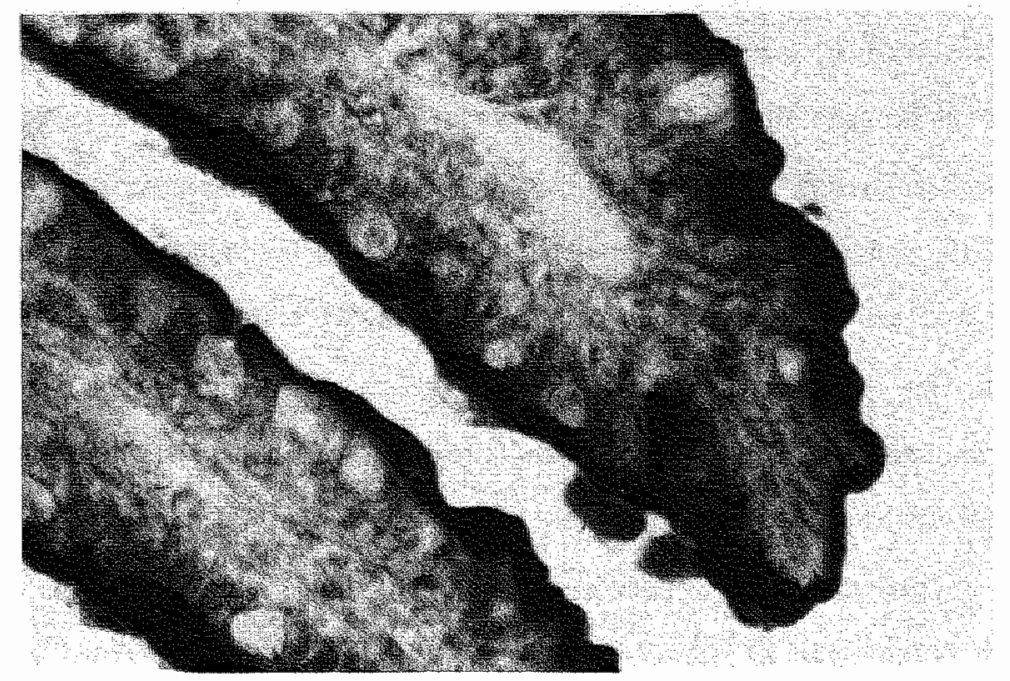

Figure 1: Alkaline phosphatase staining of the small intestine of a germ-free rat.

Continuous brush border zone.

Magnification $2340 \times$.

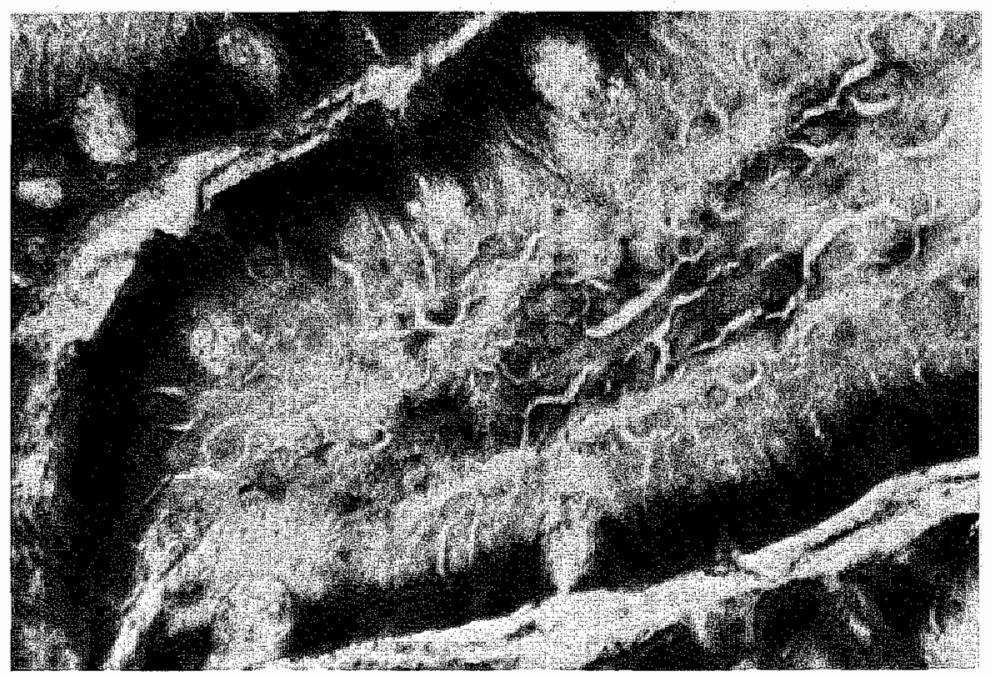

Figure 2: Acid phosphatase staining of a conventional rat. Activity in the apical region of the enterocytes.

Magnification $2340 x$. 
The reaction product after application of the AE reaction was distributed evenly throughout the cytoplasm of the epithelial cells. Staining reaction of the enterocytes along the basis and top of the villus was strong. Crypt surface cells reacted well in contrast to the cells in the bottom of the crypt. The epithelial cytoplasm of the basis and top of the villus reacted strongly in the NADHtr reaction. Crypt cells, both superficially and deeply situated reacted well. Granules were seen along the apical border of the enterocytes. In the SOH staining the collumar cells of both the villus top and basis, crypt surface and bottom reacted strongly in germ-free and conventional rats (fig. 3 ).

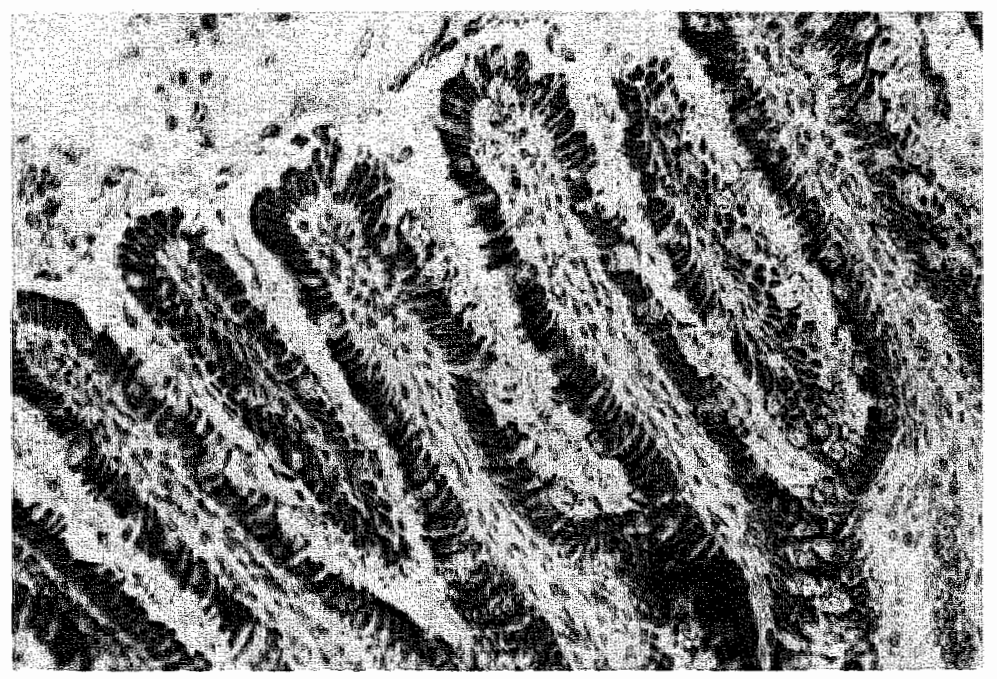

Figure 3: Succinate dehydrogenase staining of the small intestime of a germfree rat. Even distribution of enzyme reaction product. Magnification $1560 \times$.

Large intestine of conventional and germ-free rats treated with placebo.

The staining reactions in the surface epithelium revealed clear columnar cells with thin striated borders and some goblet cells. The lamina propria of the large intestine as in the small intestine contains abundant diffuse lymphatic tissue. No clear $\mathrm{A} 1 \mathrm{Ph}$ reaction was noted in the crypts of the large 
intestine. Epithelial cells of the crypts reacted well in the AcPh staining reaction. A strong reaction was noted in the crypt surface with the NADHtr, SDH and AE reaction. Crypt bottom reacted moderately with the NADtr and SDH reaction in contrast to a strong reaction with the $A E$ staining.

Conventional and germ-free animals treated with neomycin.

The colon and proximal small intestine of untreated normal or germ-free animals did not show appreciable difference in staining activity with the comparable parts of animals treated with nemycin. Histologic alterations were characteristic in the rats treated with neomycin and found prominent in the distal part of the small intestine in germ-free and conventional rats (table I and II). In germ-free animals villi were widely spaced, mare stubby and more irregular in outline than in untreated animals. The mucosal lining of the top of most of the villi was discontinuous. The total number of goblet cells showed an increase of approximately 50\%. The top of the villi of normal rats was also irregular in outlime. Alkaline phosphatase showed a change in staining pattern along the surface border of the top of the willus of both germ-free (fig. 4) and conwentional rats.

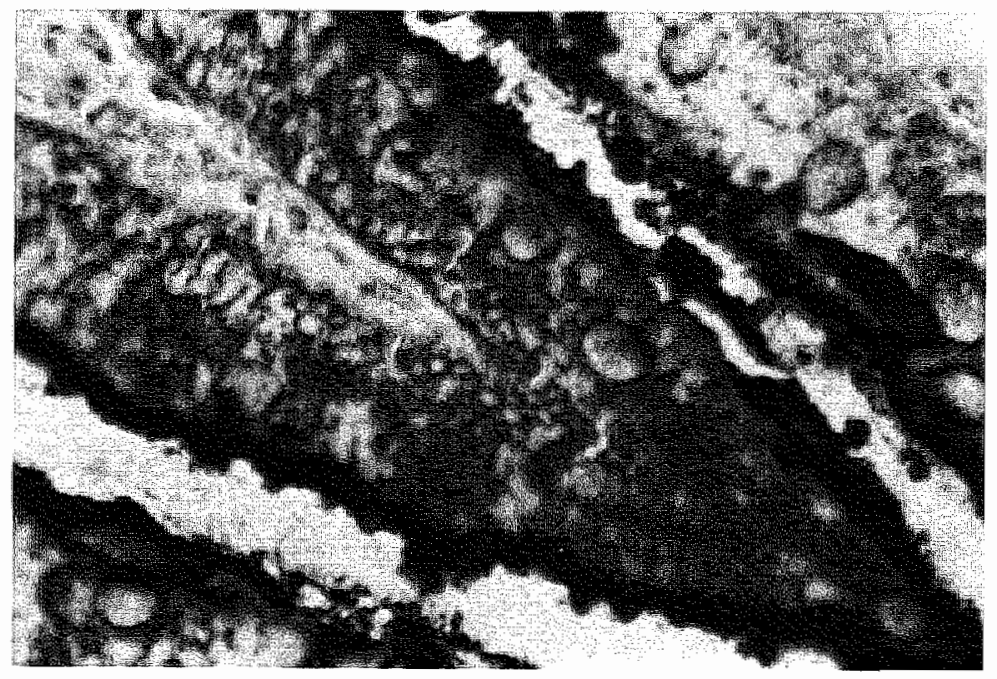

Figure 4: Alkaline phosphatase staining of the small intestine of a germ-free rat treated with neomycin. Disrupted and irregular brush border zone. Magnification $2340 \mathrm{x}$. 
$\mathrm{T} a \mathrm{bla}$

\begin{tabular}{|c|c|c|c|c|}
\hline $\begin{array}{l}\text { Alkaline } \\
\text { phosphatase }\end{array}$ & $\begin{array}{c}\text { Acid } \\
\text { phospinatase }\end{array}$ & $\begin{array}{c}\text { M.M.D. } \\
\text { tetrazol fum }\end{array}$ & $\begin{array}{c}\text { Succimate } \\
\text { dehydrogenase }\end{array}$ & $\begin{array}{l}\text { Aspecific } \\
\text { estemase }\end{array}$ \\
\hline & & reductase & & \\
\hline
\end{tabular}

NH+ N N N N N N N N N N N

Teum villus top

$+4+4+4$

$++1=$

$4+4$

$+t+$

Ileulir vi? lus bases

$4+4$

$+4$

$+4+$

$+4$

$+4$

\section{Il eum crypt surface}

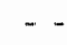

$++$

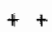

$+4$

$+$

Illeum crypt bottom

$-$

$++$

$++$

$4+4$

t- +-

\section{Colon crypt surface}

$-\cdots$

$++$

$+4+4$

$++4+$

$++4$

\section{Colon crypt bottan}

$+4$

$$
\begin{aligned}
& \text { Chassification } \\
& ++ \text { strong staining } \\
& +=\text { well staining } \\
& +-=\text { moderate } \\
& -=\text { negative }
\end{aligned}
$$$$
N=\text { normal rat }
$$$$
N+\text { = normal rat + neonycin }
$$

Table I: The presence of several enzymes in different regions of gut epithelium. 
Table II

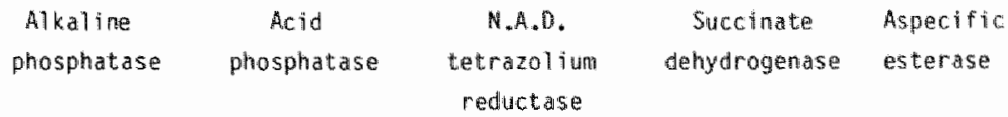

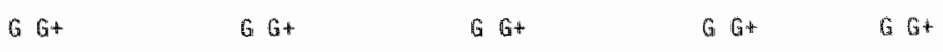

I1 eutm vị 1 lus top

$+\div-$

$++4$

$+++$

+t+ + t-

$+4+$

Il eum villus bases

$+1-$

$+4$

top to

$+4$

$+t+1$

I Hewn crypt surface

$+$

$4+$

+t. -

$+$

leum crypt bottom

- - + + +

$+$

$++4$

$+-+$

Colon crypt surfiace

- - -

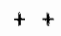

$+++4$

$+4+$

$+4+k$

Colon crypt botton

- +

$+$

$+$

$+4+$

Table II: The presence of several enzymes in different regions of gut epithe1ium. 
Staining activity was markedly reduced along the whole surface area. Enterocytes in the small intestine of germ-free and conventional rats after neomycin treatment reacted moderately with AcPH staining. An extensive increase in the number of goblet celis was seen along the whole border of the epithelium, which became most prominent towards the top. Activity lining the brush border was not present anymore. Granular activity was decreased and changes in distribution were seen (fig. 5). After the AE reaction, no difference in staining activity was noted in the neomycin treated animals if compared with the non-treated (table I and II).

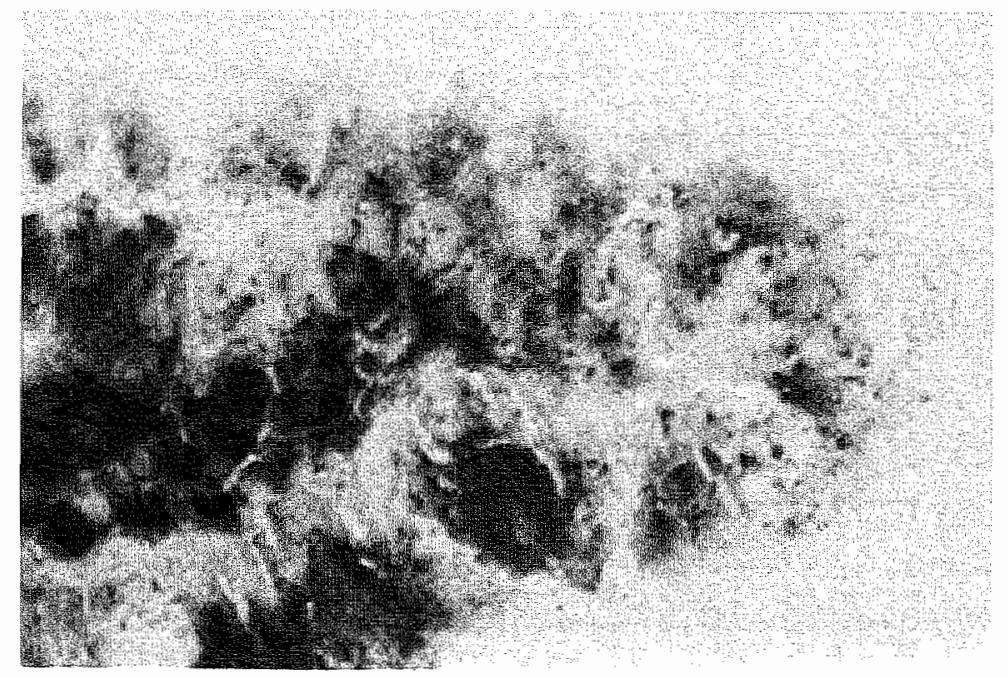

Figure 5: Actd phosphatase staining of a conventional rat treated with neomycin. Decreased activity in the apical region of enterocytes. Coarse granular distribution of actiwity throughout the cells. High activity in the stroma. Magnification $2340 \mathrm{x}$.

The NAOHtr reaction showed in both germ-free and conventional treated rats a decrease in staining reaction along the villi. This decrease was most prominent around the basis of the villi (table $\mathbb{I}$ and $\mathbb{I}$ ). No change in staining reaction could be observed in the crypts of the animals. An extensive decrease of staining activity in the SDH reaction was noted along the villi of 
the small intestine of germ-free (fig. 6) and conventional treated rats. This was most prominent along the basis of the villil.

The bottom of the crypt reacted strongly.

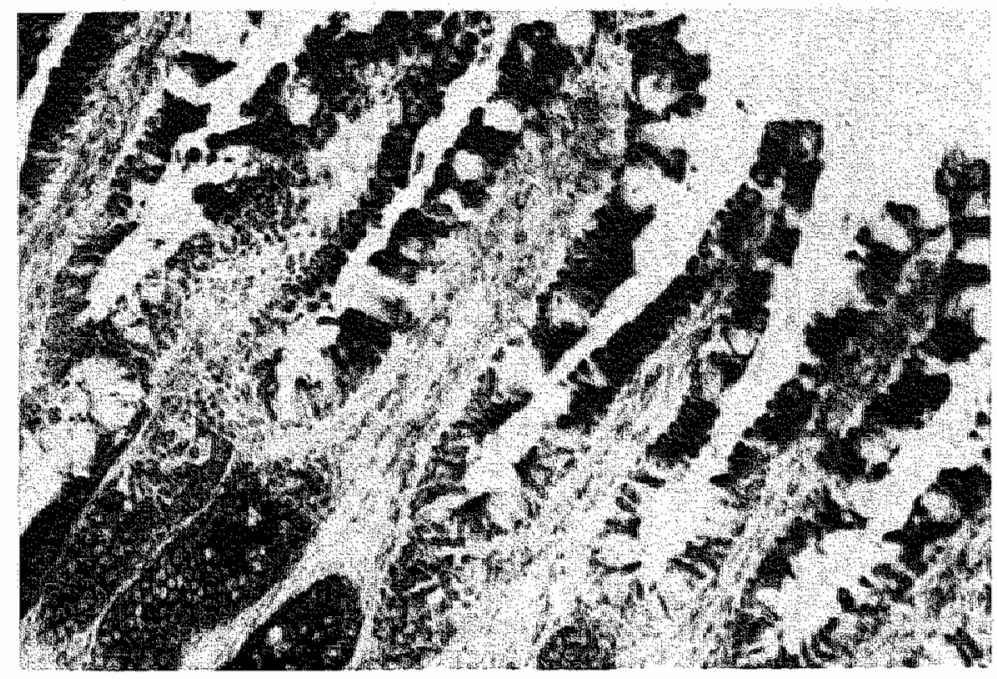

Figure 6: Succinate dehydrogenase staining of the small intestine of a germfree rat treated with neonycin. Basal parts of the villus show decreased activity. Magnification $1560 \mathrm{x}$.

\section{IV.4. Discussion}

In addition to a antimicrobial activity against the aerobic flora neomycin induces malabsorption and enzyme reduction. It is not clear whether there is a causal relation between these phenomena or that they are mutually independent $(8,11)$. Examination of the small and large intestine provided a possible clue for actions of nemycin, that are not mediated via the gut flora. In agreement with earlier reports $(12,13)$ we have shown morphological changes following orally administered neomycin recognizable with light microscopy. Neomycin decreased both in conventional and germ-free rats the activity of NADHtr, SDH, AlPh and ACPh in the small intestine. In contrast to the study of Khoury (14) with mice who demonstrated a decrease in staining reaction of 
AE and Mabtr levels in the proximal small intestine and not in the distal intestine, we noted decrease in staining actiwity of NADHtr in the distal part. No change in activity of AE was abserved in our study. Schiraldi (15) described a decrease in reactivity of AlPh and SDH, which we could confirm in the small bowel of neomycin treated germ-free and conventional rats. This study indicates that neomycin is capable of decreasing the concentration of certain enzyme systems in conventional and germ-free rats. It suggests that neomycin has a direct effect on mucosal enzyme systems in the small intestine apart from its action on gut flora because the morphologic alterations after neomycin treatment are similar in nomal and germ-free animals. Consequently no evidence in support of the third hypothesis, as referred to in the introduction, has been found. The first stage of the action of neomycin could occur at the enterocyte brush border. AlPh is attached to the membrane (17). Since AlPh reaction was decreased in this study, this finding correlates with the hypothesis that neomycin possibly exerts an action via interference with absorption. Neomycin is also likely to interfere with the intracellular metabolism of enteracytes as is shown by the results of AcPh, SDH and NADHtr reactions. As these enzymes promote reactions of a completely different nature, it appears that neomycin exerts a nom-specific influence on their activity. In view of the fact (18) that neomycin disturbs protein synthesis in bacteria by binding to microsomal subunit 30 s, this would support the posslbility fomulated in the first hypothesis, that neonycin interferes with intracellular mucosal enzyme systems, for instance by inhibition of their synthesis. It can not be concluded from our study that neomycin acts differently on villous epthelium and crypt epithelium. We have no explanation why the colon did not show a difference in staining activity after neomycin treatment. Mare precise ultrastructural studies are necessary to investigate the interaction of neomycin with the intestinal brush border. The effect on intracelluiar or membrane bound enzymes needs to be investigated by more basic biochemical study.

The results of this study indicate that explanations for the beneficial 
effects of nemycin, for instance on mental state in liver disease, should not only include the antimicrobial action of neomycin but also its potential influence on absorption and possibly, on intracellular metabolism in the mucosa.

\section{IV.5. References}

1. Dawson, A.M.: Neomycine in the treatment of hepatic coma. Lancet IT: $1263-1268$ (1957).

2. Jacobson, E.D., Chodos, R.B., Faloon, W.W.: An experimental malabsorption syndrome induced by neomycin. Am. J. Med. 28: 524-533 (1960).

3. Faloon, W.W., Fisher, C.J., Duggan, K.C.: Dccurrence of a sprue like syndrome during neomycin therapy. Am. Soc. Clin. Invest. 37: 893 (1958).

4. Hayman, H., Fisher, C.J., Duggan, K.C. et al.: Effect of fat-poor diet upon neomycin malabsorption. Gastroenterology 47: 161-165 (1964).

5. Jacobson, E.D., Hibbs, S., Faloon, W.W.: Effect of adrenal steroids and of gluten upon malabsorption induced by neomycin. Am. J. Clin. Nutr. 10: $325-331(1962)$.

6. Faloon, W.W., Paes, I.C., Woolfolk, D., Nankin, H., Wallace, K., Haro, E.N.: Effect of neomycin and kanamycin upon intestinal absorption. Ann. NY. Acad. Sci. 132: 879-887 (1966).

7. Gordon, S.J., Haro, E.N., Paes, I.C., Faloon, W.W.: Studies of malabsorption and calcium excretion induced by neomycin sulphate. J. Am. Med. Ass. 204: 127 (1968).

8. Dobbins, W.0., Herrero, B.A., Mansbach, C.M., Rollins, E.L.: Neomycin induced malabsorption. Clin. Res. 15: 231 (1967).

9. Loyda, 2., Gossray, R., Schiebler, T.H.: Enzym-histochemischer methode. Springer-Verlag, Berlin, Heidelberg, New York (1976). 
10. Holt, S.J. Hobbiger, E.E., Pawan, G.L.: Preserwation of integrety of rat tissues for eytochemical staining purposes. J. Biophys. Biochen. cytol. 7: 383 (1960).

11. Paes, I.C., Searl, P., Rubert, M.W., Faloon, W.W.: Intestinal lactase deficiency and saccharide malaborption during oral neomycin administration. Gastroenterology 53 (1): $49-58$ (1967).

12. Sma11, M.D., Follen, V., Abrams, G., Bledsoe, F., Norris, H.T., Sprinz, H.: High doses of neomycin sulphate and the absorption of glucose and xylose from the rat small intestine. Am. J. Dig. Dis. 11 (12): 923 $(1966)$.

13. Waitzova, D. Kubat, K., Melicharova, M., Koldovsky, 0.: The effect of neomycin on the absorption of glucose from the small intestine and on morphology of the intestinal mucosa in infant and adult rats in vitro. Physiol. Bohemosiow. 20: 11-20 (1971).

14. Khoury, K.A., Floch, M.H., Herskovic, T.: Effects of neonycin and penicillin administration on mucosal proliferation of the mouse small intestine. J. Eur. Med. 129: 1063 (1969).

15. Schiraldi, 0., Marono, R., Grimaldi, M., Capurso, A.: Quadro isto-enzymatico del tenue in ratti trattati con antibiotica. Arch. Ital Anat. Istol. Pat. 37: 180 (1963).

16. Dittmer, J.C., Douglas, M.G.: Quantitative determination of phasphoinasitides. Ann. NY. Acad. Sci. 165: 515-525 (1969).

17. Low, M.G., Zilversmit, D.B.: Role of phosphatidylinositol in attachment of alkaline phosphatase ta membranes. Biachemistry 19: 3913-3918 $(1980)$

18. Weisblum, D., Davis, J.: Antibiotic inhibitors of the bacterial ribosome. Bacterial. Reviews 32: 493-528 (1968). 
Chapter $V$

THE EFFECT OF INTESTINAL FLORA MODULATION ON AMMONIA PRODUCTION IN THE RAT INTESTINE

\section{V.1. Introduction}

It has been $c l a i m e d$ that a considerable amount of ammonia is generated in the colon and that most body ammonia originates in the gut from hydrolysis of urea by bacterial ureases $(1,2)$ and a smaller fraction from bacterial metabo$1 \mathrm{ism}$ of other nitrogenous substances in dietary residues, desquamated epithe1 ial cel1s and endogenous secretions $(3,4)$. Approximately 15-30\% of the total urea pool i.e. about $7.4 \mathrm{~g} \mathrm{(1)} \mathrm{is} \mathrm{hydrolysed} \mathrm{and} \mathrm{the} \mathrm{main} \mathrm{source} \mathrm{of} \mathrm{urease} \mathrm{in}$ the colon is of bacterial origin. Urea enters the colon by passive diffusion (5). Many intestinal organisms like Bacteroides spp, bifidobacteria, clostridia 5pp, Proteus spp and Klebsiella spp excrete urease, others 7 ike Escherichia coli do not split urea so that ammonia produced by these organisms must. be derived from deamination of substances other than urea. Many species will produce ammonia by both mechanisms. $0^{\prime} \mathrm{Grady}(7)$ showed that the most active of the intestinal organisms in the production of ammonia were Gram-negative aerobic rods c.q. E. coll, Klebsiella spp, Proteus spp and Pseudomonas spp. In nomal heal thy persons the ammonia generated in the gut is chiefly confined to the portal circulation, but in hepatic disease the liver fails to metabolize ammonia or collateral circulation exists so that ammonia enters the general circulation. This is claimed by some authors to result in chronic or recurrent neuropsychiatric disorders and ultimately in hepatic coma $(8,9)$. Therefore a rational therapy of hepatic coma is the inhibition of ammonia production in the gut by interfering with the intestinal flora. Neonycin and lactulose are now both generally accepted in the therapy for hepatic coma and 
are believed to reduce blood ammonia levels by the ir influence on the intestinal flora. Nenycin is manly active against the Enterobacteriaceae $(10,11)$ and reduces ammonia levels (12). Lactulose in a faecal incubation system influences the faecal flora by lowering the $p H$ and stimulates incorporation of ammonia into bacterial protein (13). In wivo this would result in lowering blood ammonia lewels. The question whether the effect of neamycin is only achieved by a reduction of the number of Enterobacteriaceae in the intestinal tract is still not solved because alterations of patient flora do not correlate with clinical improvement (14) and the aerobic flora represents only a minor fraction of the total intestinal flora. The largest part of ammonia has been clatined to be generated in the colan by hydrolysis of urea. This is difficult to explain because the colon is relatively impermeable to urea (15) and very little urea is entering it (16). This study was undertaken to quantitate the contribution of the aerobic and anaerobic intestinal flora in ammonia production. The quantitation of ammonia was done by selectively decontaminating conventional animals and by colonizing germ-free rats with a defined aerobic, anaerobic or mixed (aerobic + anaerobic) flora. Amnonia concentration was measured in the portal vein after occlusion of veins from the stomach and the spleen in conventional, germ-free and gnotobiotic rats. In addition, ammonia production in the effluent of small and large intestine of conventional, selectively decontaminated and germ-free animals was measured.

\section{V.2. Material and methods}

Animals.

For these studies specific pathogen free (SPF) male Wistar rats (250-300 g) were obtained from the centralized experimental animal facilities (CPV) of the University of Limburg (RL). During the experiments the animals were allowed free access to water and food. Environmental conditions were kept 
constant. The diet consisted of special sterilized rat chow (formula SRM-A120 Hopefarms, Woerden, NL). Germ-free and gnotobiotic aninals were housed in plastic isolators with filtered sterile air (Miller-filters, Millipore, U.S.A.). Entries of supplies and removal of waste products were carried out under strict aseptic conditions.

\section{Gnotobiatic and selectively decontaminated rats.}

From the coecum contents of SPF rats of the barpier-sustained breeding unit of the CPV of the RL, the most predominant bacterial species were isolated and after purification cultured. Gnotobiotic rats were prepared by colonizing groups of germ-free rats housed in separate isolators with several species. The gnotobiotic rats with a facultative aerobic flora (GAF) received appraximately $10^{8}$ collony forming units (CFU) by mouth of both Escherichia coli and Streptococcus faecium. The gnotabiotic rats with an obligatary anaerobic flora (GAnF) received each $10^{9}$ CFU suspended in anaerobic transport medium of each of the following species: Clostridium perfringens, Clostridium inocuum, an unidentified clostridium, Bacteroides ruminiculum, Bacteroides fragilis, Lactobacillus acidophilus, and an unidentified Peptostreptococcus and Bifidobacterium. The gnotobiotic rats with a mixed facultative aerobic and obligate anaerobic flara (GMF) were prepared by receiving two days after the aerobic species also the anaerobic species by the oral route.

Physiological parameters were used to assess the nomalisation of the gastrointestinal tract of the three different groups of gnotobiatic rats and the influence of serective decontamination. This includes total counts of facultative aerobic and obligatory anaerobic bacteria in the coecum (table $1-A)$, concentrations of volatile fatty acids (VFA) (table 1-B), absence of betaaspartylglycine in the faeces and the relative coecum weight (table $1-A)$. Selective decontamination was carried out by adding antibfotics to the drinking water: $200 \mathrm{mg}$ trimethoprim and $1000 \mathrm{mg}$ sulfadiazine (Tribrissen ${ }^{R}$ powder, Wellcome, Englandy, $100 \mathrm{mg}$ colistine and $0.7 \mathrm{ml}$ HCl per liter. in order to remove the Enterobacteriaceae. 


\begin{tabular}{|c|c|c|c|c|}
\hline & $\begin{array}{c}\text { serobes } \\
\text { coecum lumen }\end{array}$ & $\begin{array}{l}\text { anderobes } \\
\text { coecum Iumen }\end{array}$ & R.C.W. & $\begin{array}{r}\text { B-aspartyl } \\
\text { glycine }\end{array}$ \\
\hline Converitional rats & $7.76 \pm 0.74$ & $9.36 \pm 0.27$ & 1 & $-\infty$ \\
\hline Germ-free rats & -- & $m-$ & 5 & $+4+$ \\
\hline GAF & $9.36+0.12$ & $-\cdots$ & 4 & $4+$ \\
\hline GAnF & $-\infty$ & $10.34 \pm 0.10$ & 2 & $-\infty-$ \\
\hline Gate & $9.20 \pm 0.11$ & $10.90 \pm 0.39$ & $\mathbb{1}$ & $-\infty$ \\
\hline $\begin{array}{c}\text { Selective decont. } \\
\text { (-aerobe) }\end{array}$ & $7.83 \pm 0.60$ & $9.55 \pm 0.38$ & $\mathbb{1}$ & -- \\
\hline $\begin{array}{l}\text { Sulliective decont. } \\
\text { (-anderab) }\end{array}$ & $8.59+0.49$ & $-\cdots$ & 2 & +4 \\
\hline
\end{tabular}

Table I-A: Total number of aerobic and anaerobic bacteria (1og CFU/O faeces $\pm S D$ ) in coecum lumen, the rellative coecum weight (RCW) and B-aspartylglycine in conventional, germ-free, selectively decontaminated rats (without enterobacteriaceae or without anaerobic flora) and gnotobiotic rats [colonized with either an aerobic (GAF), anaerobic (GAnF) or mixed flora (GMF)].

Control cultures from the faeces were done weekly until the bacteriological results were satisfactory. Totally decontaminated animals received drinking water containing trimethoprim $200 \mathrm{mg}$ and surfadiazine $1000 \mathrm{mg}$, $135 \mathrm{mg}$ colistine, $250 \mathrm{mg}$ amphotericine-B, $250 \mathrm{mg}$ ampicilline, $1000 \mathrm{mg}$ metronidazole and $50 \mathrm{~g}$ sucrose per liter. The rats were housed in laminar flow units and the animals received sterile rat chow. Cages were changed daily and were sterilised with the bedding before use. The animals were handled with sterile 9 loves. 
Table I*8

\begin{tabular}{|c|c|c|c|c|c|c|c|c|}
\hline & $c_{2}$ & $\mathrm{C}_{3}$ & $1 \mathrm{C}_{4}$ & $C_{4}$ & $10_{5}$ & $\mathrm{C}_{5}$ & ${ }^{16} 6$ & $\mathrm{c}_{6}$ \\
\hline \multicolumn{9}{|c|}{ Conventional rats } \\
\hline $\begin{array}{l}\mathbb{C C} \\
\mathbb{C C}\end{array}$ & $\begin{array}{l}239 \pm 17 \\
170 \pm 75\end{array}$ & $\begin{array}{l}37 \pm 6 \\
34 \pm 6\end{array}$ & $\begin{array}{l}2 \pm 1 \\
2 \pm 1\end{array}$ & $\begin{array}{l}122+23 \\
106 \div 39\end{array}$ & $\begin{array}{l}2 \pm 0.3 \\
1 \pm 0.2\end{array}$ & $14 \div 1$ & 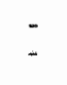 & $\begin{array}{l}14 \div 2 \\
10 \pm 3\end{array}$ \\
\hline \multicolumn{9}{|c|}{ Selectively decontamimated rats (- Enterobacteriaceae) } \\
\hline $\begin{array}{l}60 \\
10\end{array}$ & $\begin{array}{r}159 \pm 65 \\
87 \pm 49\end{array}$ & $\begin{array}{l}28+5 \\
12 \pm 6\end{array}$ & $\begin{array}{l}4 \pm 0.2 \\
1 \pm 1\end{array}$ & $\begin{array}{r}111 \pm 14 \\
45 \pm 23\end{array}$ & $3 \pm 1$ & $\begin{array}{r}13 \pm 2 \\
4 \pm 2\end{array}$ & - & $12 \pm 1$ \\
\hline \multicolumn{9}{|c|}{ Selectively decontaminated rats (- anaerobic flora) } \\
\hline $\begin{array}{l}\text { CC } \\
\text { IC }\end{array}$ & $\begin{array}{l}24 \pm 11 \\
44 \pm 23\end{array}$ & - & - & - & - & - & - & - \\
\hline
\end{tabular}

Gnotobiotic rats (t) anaerobic flora)

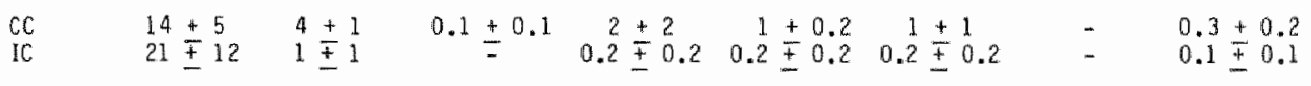

Gnotobiatic rat's (+ aerobic flora)

\begin{tabular}{|c|c|c|c|c|c|c|c|}
\hline $\mathrm{CC}$ & $12+2$ & - & - & - & - & $\sim$ & - \\
\hline IC & $14 \pm 9$ & - & - & - & - & - & - \\
\hline
\end{tabular}

Gmotobiotic rats (aerobic + anaerobic flora)

\begin{tabular}{|c|c|c|c|c|c|c|c|c|}
\hline $\mathrm{CC}$ & $33+23$ & $1+1$ & 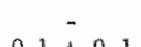 & $2+1$ & $0.3 \pm 1$ & $1+1$ & - & $1+1$ \\
\hline IC & $52 \pm 19$ & $1 \pm 0.2$ & $0.1 \pm 0.1$ & $2 \pm 1$ & $=$ & $0.4 \pm 1$ & - & $1 \pm 0.1$ \\
\hline
\end{tabular}

$C C=$ colon conterits

IC $=$ ileal contents

$\mathrm{C}_{2}=$ acetic acid

$\mathrm{C}_{3}^{2}=$ propiontc acid

$\mathrm{LC}_{4}=\$ \mathrm{sia-butyric}$ acio

$c_{4}^{4}=$ butyric acid

$I_{5}=$ iso-valeric acid
$C_{5}=$ valeric acid
$I_{6}=$ iso-capronic acid
$C_{6}=$ capronic ateid

Table I-B: Volatile fatty acid (VFA) concentrations in mol/L of conventional, selectively decontaminated rats (without enterobacteriaceae or without anaerabic flora) and gnotobiatic rats [colonized with either an aerobic, anaerobic, or mixed (anaerobic + aerobic) flora]. 


\section{Volatile fatty acid analysis.}

The volatile fatty acids (VFA) were measured in the faeces by gas liquid chromatography (GLC). The GLC-system consisted of a Packard Becker 433 gaschromatograph equipped with dual column system and flame ionisation detectors in conjunction with a digital processor. The glass columns were conditioned overnight in the oven at $175^{\circ} \mathrm{C}$ with a carrier gas flow of 20 $\mathrm{ml} / \mathrm{min}$. The next day, 7 doses of 5,11 of $0.1 \% \mathrm{v} / \mathrm{v}$ formic acid in water were injected. During operation the injector temperature was $100^{\circ} \mathrm{C}$ and the detector temperature $200^{\circ} \mathrm{C}$. The oven temperature was programed to $110^{\circ} \mathrm{C}-190^{\circ} \mathrm{C}$ with increments of $20^{\circ} \mathrm{C} / \mathrm{min}$. This temperature programme was started $90 \mathrm{sec}$ after injection of the sample and the final temperature was sustained for 5 min. Faeces was diluted 1:10 in anaerobic dilution fluid. These samples were prepared for gaschromatography by applying $1.9 \mathrm{ml}$ of the sample spiked with $0.1 \mathrm{ml}$ of a $200 \mathrm{~mm}$ stock solution of heptanoic acid, which was used as an internal standard, on to $1 \mathrm{ml}$ of cationexchangle resin ( $\mathrm{AG} 50 \mathrm{~W}-X_{2}, 200-400$ mesh, hydrogen form, washed in water) packed on glasswool in a pasteur pipette. The sample was allowed to drain through the resin and the resin was than washed twice with $1 \mathrm{ml}$ of $0.1 \% \mathrm{v} / \mathrm{w}$ formic acid in water. All fluid draining from the pipette was collected in a test tube and 1 uldirectly injected into the gaschromatograph for analysis of VFA. The minimum detection level of each VFA $\left(\mathrm{C}_{2}-\mathrm{C}_{6}\right)$ is $0.2 \mathrm{mmol} / \mathrm{L}$ and the coefficient of variation is $1.5 \%$.

\section{Detection of B-aspartylglycine.}

By using a turrax mixer one part of faeces was thoroughly mixed with 3 parts of water. The homogenized samples were centrifugated at $2000 \times g$ for at least $30 \mathrm{~min}$. The supernatants were freeze dried at $-70^{\circ} \mathrm{C}$ and stared at $-25^{\circ} \mathrm{C}$ unti? analysis. The determination of $\beta$-aspartylglycine was performed by highvoltage paper electrophoresis. Electrophoresis was performed at $\mathrm{pH} 3.5$ (pyridine/acetic acid/water, 1:10:89 by volume) for one hour at 3000 $\mathrm{V}$ with a high voltage electrophoresis equipment (MK41, Locarte Company, London, UKK). Whatman 3 MM chromatagraphy paper $(46 \times 57 \mathrm{~cm})$ was used and samples of 5 to 50 
\#1 were applied $1.5 \mathrm{~cm}$ apart at a distance of $12 \mathrm{~cm}$ from the rimargin of the paper that is to be immersed in the anode buffer compartment. Generally, 80 ul of a $25 \%$ solution of faecal supernatants was applied. Xylene Cyanol FF was added to a reference mixture of amino acids as a coloumarker. After electrophoresis the paper was dried at $70-80^{\circ} \mathrm{C}$ for $10-15 \mathrm{~min}$ and sprayed with $0.2 \%$ ninhydrin in ethanol. Subsequent heating at $70-80^{\circ} \mathrm{C}$ resulted in purple spots for most of the peptide-like material, except for B-aspartylglycine which yields a gray colour. Additional heating at $110^{\circ} \mathrm{C}$ for 10 min gives a clear blue spot for B-aspartylglycine (Welling, 1974) (17).

\section{Bacteriological procedures.}

Rats were anaesthesized with ether and immediately placed in an anaerobic glovebox. The small intestine, coecum and colon were remowed and the luminal contents separated from intestine. Small segments of approximately ane gram were removed fram the entire thickness of the wall of the small intestine, coecum and colon and washed with prereduced anaerabic sterilized (PRAS) diluent. These samples and approximately one gram of the contents of the small intestine, coecum and colon ware all separately weighed.

One part of each was thouroughly mixed with nine parts of PRAS diluent. The homogenates were serially diluted tenfold $\left(10^{1}-10^{5}\right)$ and an aliquot of 0.036 ml of each dilution was spread over the surface of agar plates using spiral plater (Spiral System, model B, Lameris, Utrecht, The Netherlands). The isolated intestinal flora was presumptively identified and, grouped by the use of selective and elective media. The dilutions $10^{0}-10^{3}$ were spread on the following plates: $5 \%$ sheep bloodagar (oxaid Cm 55), endoagar (BBL 11199), MacConkey agar (oxoid M7) with $0.02 \%$ sodiumazide, mannitol salt agar (oxoid M85) and sheep blood agar with selective streptococcal supplement (oxold SR74). The plates were incubated for 48 hours under atmospheric conditions at $37^{\circ} \mathrm{C}$ before counting the colonies. For detection of fungal overgrowth $0.1 \mathrm{ml}$ of the $10^{1}$ dilution of faeces of the decontaminated rats was spread over a Sabouraud dextrose agar (oxoid M4) with $0.4 \%$ chloramphenicol and incubated 
for ten days at $37^{\circ} \mathrm{C}$

For the presumptive identification, grouping and enumeration of obligate anaerobic bacteria the dilutions $10^{3}-10^{6}$ were spread over Wensinck agar (24), Wensinck agar with vancomycin $\left(7.5 \mathrm{mg} / \mathrm{L}_{\mathrm{s}}\right)$ and kanamycin (100 $\left.\mathrm{mg} / \mathrm{L}\right)$, bile aesculine agar (25) and egg-yolk agar with neomycin (100 mg/L) (26). These plates were incubated anderobically at $37^{\circ} \mathrm{C}$ and the colonies counted after 72 hours and 7 days of incubation.

The concentrations of microorganisms were expressed as the logarithm to the base ten of colony forming units per gram (log CFU/g) of specimen. For the detection of bacteria in low numbers $0.1 \mathrm{ml}$ of the $10^{1}$ dilution was inoculated in thioglycolatice broth (oxoid M23) with additional Vit $k_{2}$ and haemine, anaerobically incubated and checked for growth during one week.

\section{Doerative procedure.}

Each rat was operated under ether anaesthesia. Operations were performed between 8.00 am and $1.00 \mathrm{pm}$. After abdominal incision, rats were prepared for sampling venous effluent of the small and large intestine and for sampling effluent of the whole intestine. For sampling the effluent of the small intestine, arteries and veins of the colon were ligated and for the colon effluent, arteries and veins of the small intestine were ligated. In all models spleen, stomach and pancreas were excluded.

For sampling of the whole intestine only spleen, stomach and pancreas were excluded and blood was drawn from the vena porta.

\section{Ammonia determination.}

Ammonia was determined in plasma using the ion exchange method by Kingsly (18). The analysis of the plasina ammonia concentration with this method invalves a two-stage procedure. First the ammonia is separated from other plasma constituents by using a strongly acidic cation exchange resin $\mathrm{Na}^{+} \mathrm{K}^{*}$ form of the resin Dowex 50w $-\times 8,50-100$ mesh). Thereafter, quantitation of ammonia is performed by using the Berthelat phenol-hypochlorite reaction. The 
following procedure is used to detemine the almonia content:

1. To $2 \mathrm{ml}$ ammonia free water, $1 \mathrm{ml}$ resin suspension is added together, tubes directly stoppered and placed on ice. All further handings are performed on ice.

2. To these tubes, respectively 200 fll standard solution (eight different standard solutions from 25 to 500 umol/L were used). $200 \mu 1$ of plasma is added. The test procedure is directly started after blood collection in heparinized tubes on ice. Plasma is obtained by centrifugation for 10 min at $1000 \times g\left(4^{\circ} \mathrm{C}\right)$ (Sorvall centrifuge).

3. The solutions are mixed during 5 min at $4^{\circ} \mathrm{C}$.

4. The resin is subsequently washed with $20 \mathrm{ml}$ ammonia free water. When the resin is settled the supernatant is removed. This washing procedure is repeated three times.

5. To the resin (at $20^{\circ} \mathrm{C}$ ) $600 \ldots 10.1 \mathrm{M} \mathrm{NaOH}$ is added and mixed exactly for 2 $\min$.

6. Then $1.6 \mathrm{ml}$ phenol is added, mixed, directly followed by adding $1.6 \mathrm{ml}$ hypochlorite and mixed aglin. The solution is then incubated for 15 min in a water bath $\left(37^{\circ} \mathrm{C}\right)$.

7. After one hour the absorption at $630 \mathrm{~nm}$ is measured with a universal Photometer (Vitatron).

\section{V.3. Results}

Table Il represents the mean portal ammonia concentrations of the effluents from small and large intestine of conventional, selectively decontaminated and germ-free animals. In conventional and gem-free rats, the small intestine releases more ammonia into portal blood than the large intestine, if a flow rate of small/large of $3: 1$ is taken into account (19). 


Controls Selectively decontaminated Selectively decontaminated Germ-frea
without enterobacteriaceae whout anaerobic flora

Plasma Plasma Plasma Plasma

\begin{tabular}{|c|c|c|c|c|}
\hline & $n=5$ & $n=6$ & $n=6$ & $n=6$ \\
\hline \multicolumn{5}{|l|}{ Stra 11} \\
\hline \multirow[t]{2}{*}{ intestine } & $426 \pm 35.8$ & $331 \pm 56$ & $169.6 \pm 10.7$ & $187 \pm 13$ \\
\hline & $n=5$ & $n=6$ & $n=6$ & $n=5$ \\
\hline \multicolumn{5}{|l|}{ Large } \\
\hline intestine & $548 \pm 57.4$ & $545 \pm 49$ & $262.5 \pm 24.8$ & $186 \div 10.2$ \\
\hline
\end{tabular}

Table II: Mean portal ammonia concentration of small and large intestine in controls, selectively decontaminated (without Enterobacteriaceae or without anaerobic floral and germ-free animals, in $\mu \mathrm{mol} / \mathrm{L}$ (mean \pm SEM).

Table III

$\begin{array}{ccccc}\text { Convertional Gnotobiotic } & \text { Gnotobiotic } & \text { Gnotobiatic } & \text { Germ-free } \\ \text { Plasmal } & \text { Plasobes } & \text { anaerobes } & \text { aerobestanaterobes } & \\ & \text { Plasma } & \text { Plasma } & \text { Plasma } & \text { Plasma }\end{array}$

Vena
porta $\quad 422 \pm 19.6 \quad 196 \pm 20.7 \quad 266 \pm 37 \quad 245.5 \pm 9.5 \quad 200 \pm 16.7$

Table III: Mean portal ammonia concentration of conventional, gnotobiotic and germ-free rats in $\mu$ mol $/ L$ (mean $\pm S E M)(n=5)$. Ammonia concentrations were determined in the combined portal effluent of small and large intestine. 
Total bacterial counts did not change significantly after decontamination of the aerobic flora in lleum, coecum and colon, al though the Enterobacteriaceae were removed (table IV). The anaerobic counts expressed as 109 CFU/g decreased from 8.80 to 8.35 in the ileum lumen which might have been due to dilution of the luminal content during treatment (table $V$ ). No changes in total anaerobic counts were observed in the gutwall associated flora. Removal of the Enterobacteriaceae however did not result in a decreased concentration of ammonia in the portal effluent of small and large bowel (table II). Rats treated with a mixture of antibiatics during 14 days, until anaerobic bacterial cultures were negative, showed a slight decrease in aerobic counts of ileum lumen and wall, most likely due to dillution (table IV). Ammonia concentration of the venous effluent of the small intestine of this group showed a decrease from 426 to $169.9 \mu \mathrm{mol} / \mathrm{L}$ in the plasma (table II). Ammonia in the effluent of the large intestine decreased from 548 to $262.5 \mu \mathrm{mol} / \mathrm{L}$ in the pllasma The animals which were colonized with an anaerobic flora (group GAF) showed an increase in portal ammonia (table III). Bacterial counts of anaerobic flora expressed as log CFU/g were equal to those of the conventional animals (table $V$ ). When germ-free animals were colonized with both aerobic and anaerobic flora (group GMF) the increase in portal ammonia was the same as in the anaerobically colonized gnotobiotic animals (group GAnf) (table III). Total bacterial counts of animals in group GMF were the same as in the conventional animals (table IV and $V$ ). 


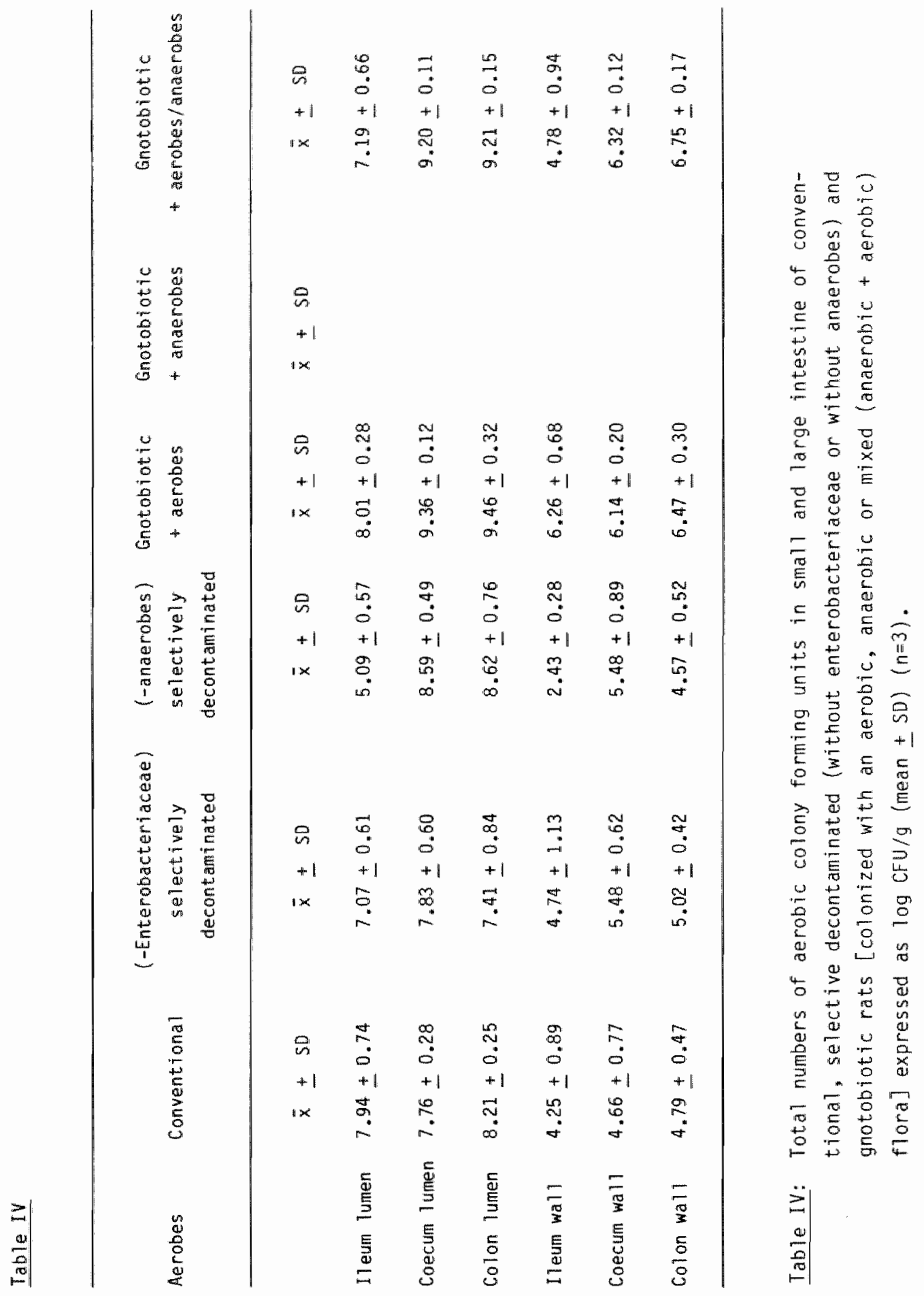




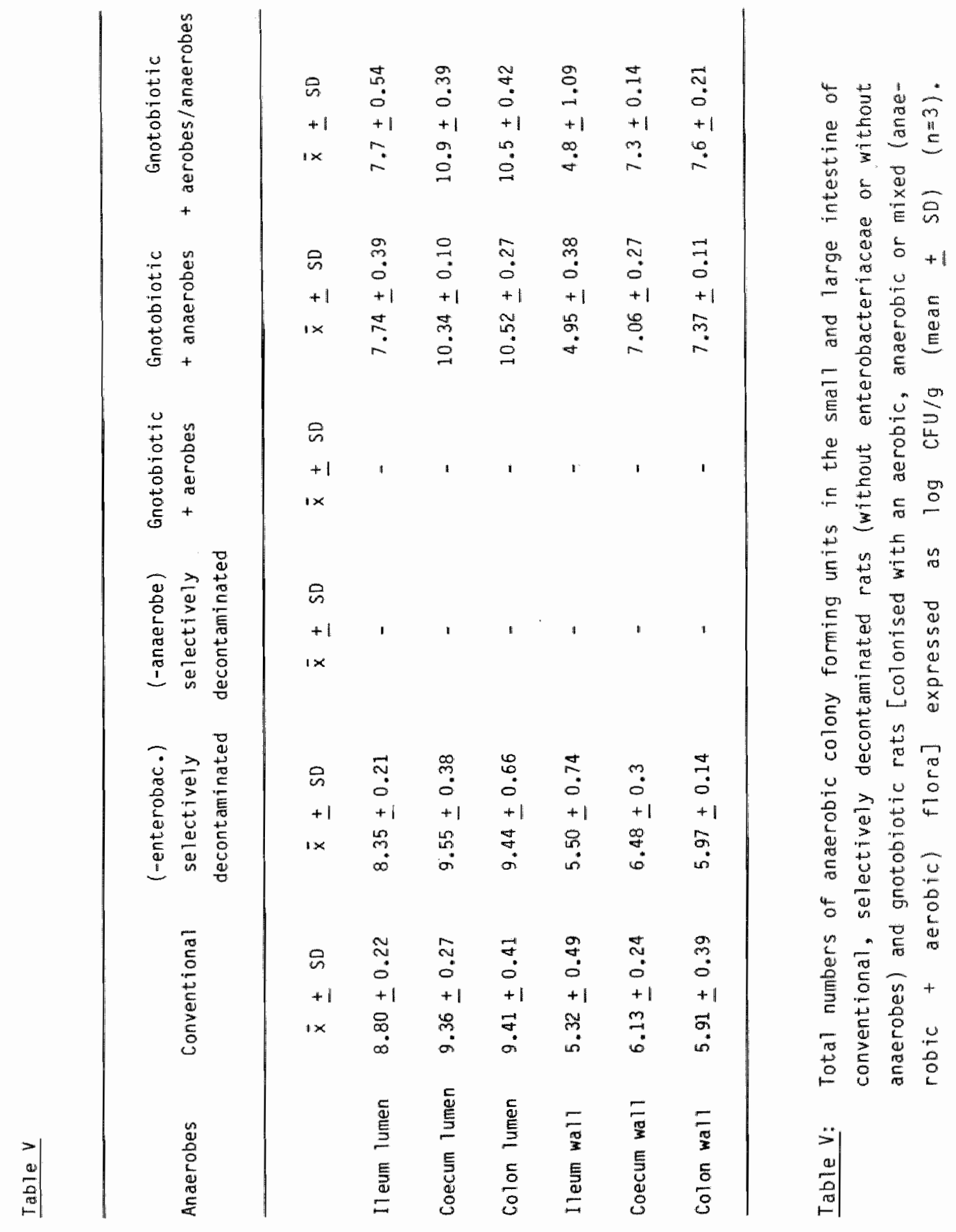


V.4. Discussion

Neonycin acts mainly on aerobic bacteria, especially the Enterobacteriaceae $(10,11)$ and is capable of lowering ammonia levels in the intestine (12). Selective decontamination, by removing the Enterobacteriaceae should result in decreased amonia levels in the portal blood of the large intestine where the bacteria are chilefly situated, if this hypothesis is true.

The results demonstrated however that ammonia levels did not decrease substantially. The anaerobic flora however seemed to have a greater impact on ammonia generation. When the anaerobic flora was completely removed by selective decontamination, ammonia levels decreased strongly. In a second model with gnotobiotic animals, colonized with a defined aerobic and an anaerobic flora results were not completely in accordance with the selectively decontaminated rats. In group GAF ammonia levels did not increase substantially, but in group GAnf there was an increase, al though the same levels as in conventional animals were not reached. Animals of group GMF with a total bacterial count equal to those of conventional animals did not reach the ammonia levels of conventional animals either. These results suggest that the given anaerobic flora plays a role in ammonia generation which is in accordance with the results of Vince (21) but it does not restore ammonia to conventional levels. Missing species might play an active role in restoring the physiology of the intestine. Atthough some parameters commonly used (22) to define nomal physiology of the intestine reached the same levels as in conventional animals, others did not. The relative coecum weights were too high and the concentration of VFA was significantly lower than in conventional animals, but also significantly higher than in germ-free animals. A number of species, some of which cannot yet be cultured, may be essential like for example the gutwall associated segmentated bacteria in the ileum, as described by Koopman (27). From these results it is clear that the aerobic flora plays almost no role in ammonia generation. When considering these results, the mechanism by which nemycin exerts its action is difficult to 
explain. If nemycin acts on the aerobic flora and if this part of the flora does not contribute to ammonia generation, how does neomycin lower ammonia levels? Because not much is known about the effect of lactulose on the composition of the bacterial flora the results of this chapter do not provide further insight in the working mechanism of lactulase. Results can be better understood when lactulose and neomycin act also on the metabolism of the mucasa cell. If this is true lactulose and neomycin should lower ammonia levels in germ-free rats which is the case in vitro (chapter II and III). The mechanism by which lactulose and neomycin exert their influence on metabolism of the mucosal cell remains to be elucidated.

\section{V.5. References}

1. Walser, M. and Bodenloos, L.J.: Urea metabalism in man. a. Clin. Invest. 38: 1617-1626 (1959).

2. Jones, E.A., Smallwood, R.A., Graigin, A. and Rosenver, V.M.: The enterohepatic circulation of urea nitrogen. Clin. Sci. 37: 825-836 (1969).

3. Vince, A., Down, P.F., Murison, J., Twigy, F.J. and Wrong, D.M.: Generation of anmonia from non-urea sources in a fecal incubation system. Clin. Sci. Mol. Med. 51: 313-322 (1976).

4. Summerskill, W.H.J. and Wolpert, E.: Ammonia metabolism in the gut. Am. J. Clin. Nutr. 23: 633-639 (1970).

5. Wrong, 0.: Nitrogen metabolism in the gut. Am. J. Clin. Nutr. 31: $1587-1593(1978)$.

6. Caste11, D.0. and Moore, F.W.: Ammonia absorption from the human colon. The role of non-ionic diffusion. Gastroenterology 60: 33-42 (1971).

7. D'Grady, F.V.: Differences in ammonia production by faecal bacteriae of patients with hepatic encephalopathy. Proc. R. Soc. Lond. 59: 1246-1249 (1966). 
8. Schenker, S., McCandless, D.K., Brophy, E. and Lewis, M.S.: Studies on the intracerebral toxicity of ammonia. 3. Clin. Invest. $46: 338-848$ $(1967)$.

9. Havens, L.L. and Child, C.G.: III. Recurrent psychosis associated with liver disease and elevated blood ammonia. N. Engl. J. Med. 252: 756-759 (1955).

10. Imler, M., Schlienger, P.P., Lavillameaux, J. and Stahl, J.: L"amoniogénèse intestinal du rat nomal. Mëd. Chir. Dig. 4 (1): 15-20 (1975).

11. Walter, A.M. and Heilmeyer, L.: Antibiotika-Fibel, 2e Auflage. Georg Thieme Verlag, Stuttgart (1965).

12. Silen, W., Harper, H.A., Mawelsley, D.L. and Weinrich, W.L.: Effect of antibacterial agents on ammonia production within the intestine. Proc. Soc. Exp. Biol. 88: 138-140 (1955).

13. Vince, A., Killingley, M. and Wrong, 0.M.: Effect of lactulose on ammonia production in a fecal incubation system. Gastroenterology 74: 544-549 (1978).

14. Dawson, A.M*, McLaren, J. and Sherlock, S.: Neomycin in the treatment of hepatic coma. Lancet dec. 21, 1957, p. 1263 (1957).

15. Wolpert, E., Phillips, S.F. and Summerski11, H.H.J.: Transport of urea and ammonia production in the human colon. Lancet $2: 1387-1390$ (1971).

16. Gibson, J.A., Park, N.J., S1aden, G.E., Dawson, A.M.: "The role of the colon in urea metabolism im man. Clin. Sci. 50: 51-59 (1976).

17. Welling, G.W., Groen, G.: Bèta-aspartyl glycine, a substance unique to coecal contents of germ-free and antibiotic treated mice. Biochem. $J$. 175: 807 (1978).

18. Kinglsley, G.R., Fager, H.S.: Ion-exchange method for the determination of plasma ammonia nitrogen with the Barthelot reaction. Stand. Meth. clin. Chem. 6: 115-126 (1970). 
19. Ferrone, R.A.; Walsh, G.M.; Tsuchikaya, M. and Frohlich, E.D.: comparison of hemodynamics in conscious spontaneous and renal hypertensive rats. Am. J. Phys. 236: H403-H408 (1979).

20. Bown, R.L.; Gibson, J.A.; Fenton, J.C.B.; Snedden, H.; Clark, M.L. and Sladen, G.E.: Amonia and urea transport by the excluded human colon. Clin. Sci. Molec. Med. 48: 279-285 (1975).

21. Vince, A.J. and Burridge, S.M.: Ammonia production by intestinal bacteria. The effects of lactose, lactulose and glucose. J. Med. Microbiol. 13: 177-191 (1980).

22. Pesti, L.: Intestinal microflora: el imination of germ-free characteristics by components of the nomal microbial flora. Comp. Immun. Microbiol. Infect. Dis. 1: 141-152 (1979).

23. Wrong, O.M., Vince, A.J. and waterlow, J.C.: The origin and bacterial metabolism of fecal ammonia. Falk symposium 32, 1981: Colon and Mutrition, ed. by H. Kasper and H. Goelbbel, p. 133-139.

24. Wensinck, F. and Ruseler-Embden v., J.G.H.: The intestinal flora of colonization resistant mice. J. Hyg. Camb. 69: 413-417 (1971).

25. Holdeman V., L. and Moore, W.E.C. (eds.): Anaerobe 1aboratory manual (2nd. ed.), Southern Printing Co., Biacksburg, Virginia (1973).

26. Chan, P.C.K. and Porschen, R.K.: Evaluation of kamamycin, esculin, bile agar for isolation and presumptive identification of bacteroides fragilis group. J. Clin. Microbiol. 5: 528-529 (1977).

27. Koopman, J.P., Stadhouders, A.M. and de Boer, H.: De damfiora van de muis. Tijdschr. Diergeneeskd. 106: 748-755 (1981). 
THE EFFECT OF NEOMYCIN AND LACTULOSE ON AMMONIA PRODUCTION IN THE SMALL AND LARGE INTESTINE IN RELATION TO THE INTESTINAL FLORA.

VI.1. Introduction

Lactulose (1-4 8 -galactosido-fructose) has been used as an alternative to neomycin in patients with acute and chronic portal-systemic encephalopathy. The introduction in 1966 of lactulose promised a new therapeutic modality based on acidification of the contents of the intestinal tract. Taken by mouth, lactulose passes the small intestine unchanged and reaches the terminal ileum and colon where it is metabolized by the intestinal flora to volatile fatty acids and alcohols, the accumulation of which causes the colonic pH to fall and diarrhoea (1) to develop. It was initially suggested that acidification fawoured the growth of lactobacilli (2) and other acidophilic fermentative bacteria and caused a suppression of acidophobic proteolytic bacteria (3). Quantitative studies however, have failed to confirm this change in composition of the intestinal flora $(4,5)$. More recently it has been postulated that the beneficial response to lactulose results from the creation of a pH gradient between the extracellular fiuid and the intestinal lumen which favours the trapping of ammonia (6) although studies on ammonia loss in the faeces did not show the expected increase (8). The last hypothesis that has been put forward is that lactulose might increase the metabolic activity of the intestinal flora. The intestinal flora is capable of increasing ammonia incorporation since the presence of carbohydrates as an energy source facilitates the growth of bacteria which requires the incorporation of anmonia into bacterial protein (9). As a consequence of this theory bacterial counts should increase after lactulose treatinent which has not been demon- 
strated. In sumary, several theories have been postulated but the mechanism still remains unclear. Similarly it is difficult to understand how neomycin lowers ammonia levels. Poorly absorbed neomycin has been thought to act by reducing the activity of the microflora. It predominantly reduces the aerobic Gram-negative flora (10). Such an effect of neonycin on anmonia levels is difficult to understand since the aerobic flora represents only a minor fraction of the total flora in the intestinal tract. Moreover clinical state and blood ammonia levels do not always correlate with the observed alterations in flora induced by neomycin (11). Explanations of how lactulose and neomycin alter the flora and how this change is correlated with ammonia levels remain conflicting, because the postulated changes in flora were not confirmed in stool cultures and because at least half of the ammonia produced in the gut is deriwed from small bowel where much lower numbers of bacteria are present (12). Also, in studies of lactulose and neonycin treatment, gutwall associated flora was not investigated, despite studies from Savage (13) showing that the bacterial population associated with the gastrointestinal mucosa of mice differs qualitatively and quantitatively from the intestinal lumen flora. This has not been confirmed yet in man, but studies by Plant (14) revealed that the gutwall associated flora of man could not be renoved by vigorous washing. To elucidate these problems, studies were undertaken to determine the influence of lactulose and neonycin on the bacterial lumen and gutwall associated flora of both the small and large intestine of rats. Animals which did not develop diarrhoea after lactulose treatment were also investigated to see whether diarrhoed is essential in the change of flora and ammonia levels. The changes in flara were correlated with the concentrations of ammonia in the portal effiuent of small and large intestine separately. 


\section{W.2. Material and methods}

Animals.

Male Wistar rats (supplied by the centralized experimental animal facilities (CPV) of the University of Limburg) weighing 250-300 gr and kept under standardized conditions with free access to water and sterilized rat chow (formula SRM-A.120 Mopefarms, Hoerden, NL) were used for this study and divided randomly into three groups. Rats received daily neomycin $(500 \mathrm{mg})$ for 10 days or 20\% lactulose W/N (Duphalac, Duphar, Weesp, ML) twice daily by stomach tube. Control animals were given water as placebo. The rats receiving lactulose were divided into two groups. Rats showing diarrhoea were sellected for the "lactulose with diarrhoea" group and the others in the group "lactulose without diarrhoea". All groups consisted of 6 rats.

\section{Surgical procedures:}

Each rat was operated under ether anaesthesia. Operations were performed between $8.00 \mathrm{a} . \mathrm{m}$. and $1.00 \mathrm{p} . \mathrm{m}$. After abdominal incision, rats were prepared for sampling of venous effluent of the small and large intestine. For sampling of the effluent of the small intestine, arteries and veins of the colon were ligated and for sampling of the effluent of the colon the arteries and veins of the small bowel. In all models, spleen, stomach and pancreas were excluded.

Ammon ita analys is:

Ammonia was determined in plasma and using the indophenol blue reaction as described by Kingsly (15) (see chapter V).

\section{Bacteriological methods.}

Rats were sacrificed by the administration of an overdose of ether and immediately placed in an anaerobic glove box. Small intestine, colon and coecum were removed aseptically and luminal content separated from intestine. The contents of ileum, coecum and colon were collected separately and, after weighing, thouroughly mixed with prereduced anaerobic sterilised (PRAS) 
diluent (saline with $0.05 \%$ cysteine HCl) using a turrax mixer. A segment of the entire thickmess of the wall of ileum, coecum and colon was cut and washed three times in PRAS diluent to remove the intestinal contents and after weighing, also mixed with PRAS diluent to assess the total colony forming units of gutwall associated bacteria per gram tissue, and homogenized with a turraxmixer.

Al1 homogenates were serially diluted tenfold $\left(10^{1}-10^{6}\right)$ and an aliquot of $0.036 \mathrm{ml}$ of each dilution was spread over the surface of plates using a spiral plater (Spiral System Model B, Lameris, Utrecht, The Netherlands). The facultative aerobic microflora was quantitated, presumptively identified and grouped by plating the dilutions $10^{1}-10^{3}$ onto selective and elective plates. Five percent sheepblood agar (0xoid CM 55) was used for the total count of facultative aerobes; endoagar (0xoid CM 479) for counting coliforms; sheepblood agar with antibiotic supplenent for selection of streptococci (Oxoid SR 74); Macconkey agar (0xoid CM 7) with $0.2 \mathrm{~g} / \mathrm{L}$ sodiumazide for enterococci and mannitol salt agar (Dxoid CM 85) for staphylococcí. Al so plates were inoculated with $0.1 \mathrm{mi}$ of the homogenates spread over the surface for detection of Pseudomonas spp: pseudomonas selective medium (CM 457), and yeasts: Sabouraud dextrose agar (Oxoid CM 41) with $0.4 \%$ chloramphenicol. All plates were incubated for 48 hours at $37^{\circ} \mathrm{C}$ under atmospheric conditions before counting the colonies. The Sabouraud plates were also read after one and two weeks. For the total obligatory anaerobic counts dilution $10^{3}-10^{6}$ were inoculated on Wensinck medium (16) using the spiral plater. Anaerobic Gram-negative rods were counted an a Wensinck medium containing kanamycin $(100 \mathrm{mg} / \mathrm{L})$ and vancomycin $(7.5 \mathrm{mg} / \mathrm{L})$. A selective medium containing bile salts and aesculine was used for quantitation of the Bacteroides fragilis group (17) and egg yolk agar (18) with neomycin $(10 \mathrm{mg} / L)$ for Clostridium species. A11 plates for anaerobes were incubated in an anaerobic glove box at $37^{\circ} \mathrm{C}$ in an atmosphere containing $10 \% \mathrm{H}_{2}, 10 \% \mathrm{CO}_{2}$ and $80 \% \mathrm{~N}_{2}$. The plates were counted after 48 hours and after one week. 


\section{V1. 3. Results}

We were able to culture a significant number of aerobic and anaerobic bacteria from the small intestine (table I and $\mathbb{I} I$ ).

The number was relatively small however, when compared to the numbers of bacterta cultured from coecum arid callon. Lower numbers of bacteria were present in the proximal part than in the distal part of the small intestine. This was true for both gutcontent and gutwall.

\section{Table I}

\begin{tabular}{|c|c|c|c|c|}
\hline & Controls & $\begin{array}{l}\text { Lactulose } \\
+ \text { diarrhoea }\end{array}$ & $\begin{array}{l}\text { Lactulose } \\
\text { - diarrhoea }\end{array}$ & Neonycin \\
\hline Aerobes & $\bar{x} \pm S D$ & $\bar{x} \pm S O$ & $\bar{x} \pm S D$ & $\vec{x} \pm 50$ \\
\hline lleun lumen & $7.94 \pm 0.74$ & $6.69 \pm 0.87$ & $7.67 \pm 0.78$ & $5.45 \pm 0.35$ \\
\hline Coecum lumen & $7.76 \pm 0.28$ & $8.41 \pm 0.33$ & $8.32 \pm 0.58$ & $6.96 \pm 0.67 *$ \\
\hline Colon lumen & $8.21 \pm 0.25$ & $8.68 \pm 0.41$ & $8.50 \pm 0.50$ & $7.21 \pm 0.66 *$ \\
\hline Il eum wall & $4.25 \pm 0.89$ & $4.49 \pm 0.41$ & $4.26 \pm 0.82$ & $5.32 \pm 1.66$ \\
\hline Coecum wall & $4.66 \pm 0.77$ & $5.85 \pm 0.69$ & $5.55 \pm 0.76$ & $5.62 \pm 1.65$ \\
\hline Colon wall & $4.79 \pm 0.42$ & $5.90 \pm 0.66$ & $5.46 \pm 0.91$ & $4.44 \pm 0.78$ \\
\hline Anaerobes & $\ddot{x} \pm S D$ & $\bar{x}-50$ & $\bar{x} \pm S D$ & $\bar{x} \pm 50$ \\
\hline I 7 eum lumen & $8.80 \pm 0.22$ & $8.37 \pm 0.13^{*}$ & $8.56 \pm 0.52$ & $7.67 \pm 0.24$ \\
\hline Coecum lumen & $9.36 \pm 0.27$ & $9.99 \pm 0.61$ & $10.05 \pm 0.54$ & $10.10 \pm 0.05 *$ \\
\hline Colon lumen & $9.41 \pm 0.41$ & $9.91 \pm 0.40$ & $10.33 \pm 0.61$ & $9.97 \pm 0.34$ \\
\hline 11 eum wall 1 & $5.32 \pm 0.49$ & $6.28 \pm 0.28$ & $5.68 \pm 0.08$ & $7.05 \pm 0.48 *$ \\
\hline Coecum wall & $6.13 \pm 0.24$ & $7.27 \pm 0.61$ & $7.62 \pm 0.36$ & $7.51 \pm 0.34 *$ \\
\hline Colon wall & $5.91 \pm 0.39$ & $6.26 \pm 0.31$ & $7.45 \pm 0.19$ & $7.67 \pm 0.16^{\star}$ \\
\hline
\end{tabular}

$\star p<0.05$

Table I: Total number of bacteria (aerobes and anaerobes) cultured from the lumen and wall of the small and large intestine in controls, lactulose and neomycin treated rats expressed as log CFU/g (mean \pm SD) $(n=3)$. 


\section{Table II}

\begin{tabular}{|c|c|c|c|}
\hline & Lumen & Lumen & Lumen \\
\hline & Proximal & Afid & Distal \\
\hline Aerobes: & $7.78 \pm 0.44$ & $8.19 \pm 0.25$ & $8.41+0.3$ \\
\hline \multirow[t]{3}{*}{ Ariaerobes } & $8.28 \pm 0.38$ & $8.49+0.23$ & $9.08 \pm 0.04$ \\
\hline & Wall & Wall & $\mathrm{WA11}$ \\
\hline & Proximal & $M 1 d$ & Disteil \\
\hline Aerobes & $4.30+0.15$ & $5.08 \pm 0.49$ & $5.26 \pm 0.16$ \\
\hline Anaerobes & $4.64 \pm 0.19$ & $5.30 \pm 0.52$ & $5.31+0.23$ \\
\hline
\end{tabular}

Table II: Total number of bacteria (aerobes and anaerobes) cultured from the lumen of the small intestine in the proximal, mid and distal part, expressed as $\log (\mathrm{CHU} / \mathrm{g}$ (mean $\pm S D)(n=3)$.

\section{The influence of lactulose on the intestinal flora.}

Total counts of flora of animals with lactulose are represented in table I. Lactulose did not change the total aerobic count in the small and large intestine. It did however lower the tatal numbers of obligatory anaerobic bacteria in the lumen of the ileum. With regard to the specific cultures of aerobes and anaerobes it is noteworthy that lactulose increased the total number of streptococci (table III) in the lactulose with diarmoea and without diarrhoea group. In the lactulose without diarrhoea group a slight increase in the number of gutwall associated Gram-negative anaerobic rods was detected (table IV) and in the number of clostridia inside the lumen and wall of the coecum and the calon (table W). 


\begin{tabular}{|c|c|c|}
\hline Convent ional & Lactulose & Lactulose \\
\hline ratt & + dlarmoea & - diarrhoea \\
\hline
\end{tabular}

\begin{tabular}{|c|c|c|c|c|}
\hline 11 exmi lumen & $7.39 \pm 0.98$ & $7.17 \pm 0.34$ & $7.515 \pm 0.51$ & - \\
\hline Coecum 1umier & $6.58 \pm 0.45$ & $8.20 \div 0.27 *$ & $7.70 \pm 0.36 *$ & - \\
\hline Colon lumen & $7.06+0.3$ & $7.86+0.23^{\star}$ & $8.01+0.49 *$ & - \\
\hline
\end{tabular}

\begin{tabular}{|c|c|c|c|c|}
\hline Ileum wall & $3.85 \pm 1.24$ & $4.39 \pm 0.32 *$ & $3.89 \pm 0.65$ & - \\
\hline Coecum wall & $3.68 \pm 0.69$ & $5.19 \pm 0.68 *$ & $5.17 \pm 0.35 *$ & - \\
\hline Colon wall & $3.35 \pm 0.63$ & $4.17 \pm 1.22^{*}$ & $5.17+0.68 *$ & - \\
\hline
\end{tabular}

$* p<0.05$

Table III: Total number of streptococci, cultured from the lumen and wall of the small and large intestine in controls, lactulose and nemycin treated rats expressed as $\log C F U / g$ (mean $\pm S D)(n=3)$.

Table IV

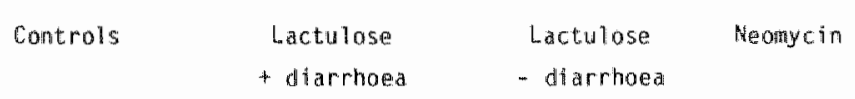

\begin{tabular}{|c|c|c|c|c|}
\hline 11 eum lumen & $7.04 \pm 0.17$ & $6.84 \pm 0.3$ & $6.86 \pm 0.86$ & $6.82+0.11$ \\
\hline Coecum 1 unters & $8.60 \pm 0.31$ & $9.19 \pm 0.66$ & $8.96 \pm 0.34$ & $9.73 \pm 0.21 *$ \\
\hline Colon lumen & $9.80 \pm 0.17$ & $8.74 \pm 1.07$ & $9.15 \pm 0.71$ & $9.59 \pm 0.36 *$ \\
\hline II lietun wa11 & $<4.38 \pm 0.06$ & $4.71 \pm 0.4$ & $5.03 \pm 0.31$ & $5.10 \pm 0.67 *$ \\
\hline Coecum wall & $5.29 \pm 0.17$ & $5.97 \pm 0.94$ & $6.77 \pm 0.32$ & $6.49 \pm 0.26$ \\
\hline Colon wall & $5.44 \pm 0.35$ & $5.93 \pm 0.79$ & $6.65 \pm 0.57$ & $7.17 \pm 0.12^{*}$ \\
\hline
\end{tabular}

* $p<0.05$

Table IV: Total number of Gram-negative anaerobic rods cultured from the lumen and wall of small and large intestine in controls, lactulose and neomycin treated rats, expressed as 109 CFU/g (mean \pm SD) $(n=3)$. 
Table W

\begin{tabular}{|c|c|c|c|}
\hline & Conventianal & Lactulose - giarrhoea & Neonycin \\
\hline I lewn li umen & $7.67+0.17$ & $7.34 \pm 0.82$ & $4.52 \pm 0.67 *$ \\
\hline Coecum lumen & $4.56 \pm 1.65$ & $7.78 \pm 0.08 *$ & $5.53+0.22$ \\
\hline Colon Iumen & $5.99 \pm 1.26$ & $9.68 \div 0.04 *$ & $5.32 \# 0.17$ \\
\hline 11 eurio ma II & $4.36+0.45$ & $4.25 \pm 0.57$ & $2.15=1.90$ \\
\hline Coecum wall & $4.56+0.59$ & $5.44 \pm 0.93^{*}$ & $3.59 \pm 0.37 \mathrm{k}$ \\
\hline Colon wall & $<3.70 \pm 0.47$ & $5.43 \pm 0.98 *$ & $4.12 \pm 0.26$ \\
\hline
\end{tabular}

$* p<0.05$

Table V: Total number of clostridia cultured from the lumen and wall of small and large intestine in controls, lactulose without diarrhoea and neomycin treated rats expressed as $\log$ CFU/g (mean \pm Sio) $(n=3)$.

The influence of neonycin on the gut flora.

Neamycin decreased the total aerobic numbers in the lumen of the coecum and colon. Numbers in the ileum lumen also decreased although this was not significant (table I). From the qualitative cultures, it appeared that neonycin considerably lowered the number of Enterobacteriaceae (table VI), enterocacci (table VII) and staphylococcil. In the anaerobic cultures an increase in the total number of anaerobic bacteria was detected in the lumen of the coecum (table 1), the wall of the ileum, coecum and colon. This increase was due to an increase of the Grammegative anaerobic rods (table IV), mainly the Bacteroides fragilis group (table VIII) although no significance was reached for the total bacterial numbers in the colon lumen and ileum lumen (table I). 
Table $V 1$

\begin{tabular}{|c|c|c|c|}
\hline & Controls & Neonyctin & treated $r$ \\
\hline Ileun 1 unten & $5.23 \pm 1.26$ & & $<1 *$ \\
\hline Coecum lumen & $6.066+0.51$ & & $<1 *$ \\
\hline Colon Iuthen & $6.30 \pm 0.31$ & & $<1 *$ \\
\hline Meum way! & $<2.45 \div 0.85$ & & $<1^{\star}$ \\
\hline Coecurn wal1 & $3.44 \pm 1.10$ & & $<1 *$ \\
\hline Co? on wall & $3.05 \pm 0.46$ & & $<1 *$ \\
\hline
\end{tabular}

$* p<0.05$

Table VI: Total number of Enterobacteriaceae cultured from the lumen and wall of small and large intestine in controls and neomycin treated rats, expressed as $\log C F U / g$ (mean $\pm S D)(n=3)$.

\section{Table WII}

\begin{tabular}{|c|c|c|c|}
\hline & Control & Neonycin & treated rats \\
\hline 1) eum umen & $6.42+0.23$ & & $<1^{*}$ \\
\hline Coecum lumen & $6.31 \pm 0.04$ & & $<1^{*}$ \\
\hline Colon llumen & $6.70 \pm 0.28$ & & $<1 *$ \\
\hline 11 atm 的 11 & $42.62 \pm 0.70$ & & $<1 *$ \\
\hline Coecum wall & $3.30 \# 0.52$ & & $<1 *$ \\
\hline Colon wa 11 & $2.97 \pm 0.86$ & & $<1 *$ \\
\hline
\end{tabular}

$\star p<0.05$

Table VII: Total number of enterococci cultured from the lumen and wall of sma11 and large intestine in controls and neonycin treated rats, expressed as $\log \mathrm{CFU} / \mathrm{g}$ (mean \pm SD) $(n=3)$. 
The influence of neomycin and lactulase on portal ammonia concentrations.

Table IX represents the mean portal ammonia concentrations of small and large portal effluent in conventional, lactulose treated and neomycin treated rats. Lactulase lowered the portal ammonia concentration in the effluent of the small and large intestine in plasma if compared to controls. The decrease was most significant in the small bowel effluent where it reached a total decrease of $36 \%$. Ammonia concentration in the portal effluent of the colon showed a decrease of only $25 \%$. In the lactuiose group without diarrhoea, plasma from the portal effluent of the small intestine decreased, but in the large bowel a significant rise in plasma levels accurred despite the low pH. Neanycin decreased plasma levels in the small and large bowel portal effluent.

\section{Table VIII}

\begin{tabular}{lrl}
\hline & Controi & Neomycin treated rats \\
& $5.28 \pm 0.40$ & $6.81 \pm 0.17 *$ \\
Ileum lumen & $7.99 \pm 0.73$ & $9.25 \pm 0.27 *$ \\
Coecum lumen & $8.08 \pm 0.93$ & $9.18 \pm 0.59 *$ \\
Colon l lumen & $4.38 \pm 0.06$ & $5.03 \pm 0.73 *$ \\
Iletum wall & $4.47 \pm 0.65$ & $6.46 \pm 0.25 *$ \\
Coecum wall & $4.67 \pm 0.49$ & $6.32 \pm 0.46 *$ \\
Colon wall & & \\
\hline
\end{tabular}

$\star p<0.05$

Table VIII: Total number of Bacteroides fragilis cultured from the lumen and wall of small and large intestine in controls and neomycin treated rats expressed as $\log \mathrm{CFU} / \mathrm{g}$ (mean \pm SD) $(n=3)$. 
controls

P.

Small

bowell

Large

bowel

$$
\begin{aligned}
426 & \pm 35.8 \\
p H & =6.8
\end{aligned}
$$

$$
548 \pm 57.4
$$$$
p H=6.8
$$

Lactulose diarrioed

Plasma
Lactulose diarmoea

plasma
Hecmycin

Plasma

Table IX: Mean portal ammonia concentration of small and large intestine in conventional, lactulose and neomycin treated rats in $\mu$ mol/ $\mathrm{L}$ (mean SEM) $(n=5)$.

\section{VI.4. Discussion}

The changes in bacterial numbers in small and large intestine caused by lactulose and neomycin can not explain the significant decrease in ammonia levels in the portal vein. Lactulose significantly lowered the plasma ammonia in the small and large portal effluent, when diarrhoea was present. Lactulose however did not drastically change the flora of the small and large intestine in the lumen nor the flora associated with the gutwall. Our study does not support a role for the low $\mathrm{pH}$, due to breakdown of lactulose, in the ammonia lowering effect of lactulase, which is in accordance with the study of Vince (24). In the lactulose with diarrhoea group we measured a $\mathrm{pH}$ of 5.3 and 4.9 together with a decrease in ammonia both in small and large intestine. The decrease in $\mathrm{pH}$ in this group could explain the ammonia decrease in small and large bowel portal effluent al though in the lactulose without diarrhoea group a low pH of 5.6 did not result in a decrease in ammonia content in the effluent of the large intestine. In contrast, ammonia rose from 548 to 758 umol/L in plasma. It emerges from these data that diarrhoea has a greater impact on decreasing ammonia levels than the $\mathrm{pH}$ has. If the hypothesis of 
Vince (9), that lactulose serves as an energy source, facilitating the growth of bacteria and the incorporation of nitrogen into bacterial protein, is true, it should result in an increase in the total number of bacteria. In this study no increase in the total number of bacteria after lactulose treatment was noted, but this may not have been noted because of the effects of dilution. However, in the lactulose treated group without diarrhoea an increase in the tatal number of anaerobic bacteria occurred in the 7 umen and wall of the coecum and colon (table I). According to the hypothesis of Vince this should have resulted in a decrease in ammonia concentration in plasma of the portal effluent of the large intestine. An increase occurred however (table IX) which casts doubt on the validity of the hypothesis of Vince. The possibility that in the lactulose with diarrhoea group an increased bacterial growth rate exists but that this is not noted due to dilution, can only apply to the luminal flora, since the gutwall associated flora does not change after dilution, not even after vigorous washing (14). Yet in this study no increase in bacterial number of the gutwall associated flora was detected in the lactulose with diarrhoea group. Neonycin decreased the total aerobic count in the coecum lumen and in the lumen of the colon (table I). In the anderobic cultures it only decreased bacterial counts in the fleum lumen which might be explained by dilution. Neomycin acts on the Enterobacteriaceae and enterococci which is in accordance with the results of Imler (10). Taking these results into account, it does not adequately explain the ammonia lowering effect of neomycin, because the aerobic flora represents only a small fraction of the total number of bacteria and moreover, the anaerobic flora is more active in ammonia production than the aerobic flora $(24)$. Furthermore, we demonstrated in the previous chapter that the aerobic flora does not contribute significantly to ammonia production. Also in cirrhotic patients, where urea splitting bacteria e.g. Klebsiella and Proteus spp increase in number (23), the ammonia lowering effect due to the effect of neomycin on these species, can not explain the clinical improvement because the colon is relatively impermeable to urea (20) and only small amounts of 
urea are avallable in the colon lumen (21). Wrong even demonstrated that exogenous urea is not, as has generally been assumed, the major source of ammonia (22). Consequently the mechanism of action of lactulose and neomycin can not satisfactorily be explained by changes in the gut flora, especially not since both neomycin and lactulose decrease ammonita levels in the portal effluent of the small intestine, although relatively few bacteria are present. When the ammonia lowering effect of these drugs is not due to their effect on the intestinal flora, one might consider the fact that they may have an impact on nonbacterial netabolism. Weber (12) already indicated that in dogs $75 \%$ of the ammonia production in the gastrointestinal tract is glutamine dependent. Therefore, the possibility should be considered that the therapeutic effect of these drugs is also based on effects of nombacterial metabolism and that studies with lactulose and neomycin on nonbacterial metabolism production are needed to test this hypothesis.

\section{VI.5. References}

1. Hoffman. K., Mossel, D.A., Horns, W. and Kamer, J.H.: Untersuchungen uber die Wirkungsweise der Laktulase (-galactosido-fructose) in Darm (Investigations on the mode of action of lactulose (-galactosidofructose) in the human intestine). Klin. Wschr. 42: 126-130 (1964).

2. Bennet, A, and Eley, K.G.: Intestinal $\mathrm{pH}$ and propulsion; an explanation of diarrhea in lactose deficiency and laxation by lactulose. J. Pharm. Phammaco1. 28: 192-195 (1976).

3. Bircher, J., Muller, J., Guggenheim, P., Haemmuli, U.P.: Treatment of chronic portal systemic encephalopathy with lactulose. Lancet 1 : $890-892(1966)$.

4. Elkington, S.G., Flock, M.H. and Conn, H.O.: Lactulase in the treatment of chronic portal systemic encephalopathy: a double biind clinical trial. N. Engl. ]. Med. 281: 408-412 (1969). 
5. Conn, H.O. and Flock, M.H.: Effects of lactulose and lactobacillus acidophilus on the fecal flora. Am. J. Clin. Nutr. 23: 1588-1594 $(1970)$.

6. Caste11, D.0., Moare, E.V.: Ammonia absorption from the human colon. The role of non-ionic diffusion. Gastroenterology $60: 33-42$ (1971).

7. Zeeger, R., Drinkwater, J.E., Feston, J.C.B., Vince, A. and Dawson, A.M.: Some observations on the effects of treatment with lactulose with chronic hepatic encephalopathy. Quart. J. Med. 39: 245-263 (1970).

8. Agostini, L., Down, P.F., Murison, J. and Wrong, 0.M.: Faecal ammonia and $\mathrm{pH}$ during lactulose administration in man: Comparison with other cathartics. Gut 13: 859-866 (1972).

9. Vince, A.J., Killingley, M. and Wrong, 0.M.: Effect of lactulose on ammonium production in a fecal incubation system. Gastroenterology 74 : $544-549(1978)$.

10. Imler, H., Peter, B., Schlienger, J.L., Lavillamieux, J. and Stah1, J.: L'ammoniogénèse intestinale du rat normal. Mëd. Chir. Dig. 4: 15-20 $(1975)$.

11. Dawson, A.M., McLaren, J. and Sherlock, S.: Neomycin in the treatment of hepatic cona. Lancet dec. 21, 1957, p. 1263 (1957).

12. Weber, F. and Veach, G.: The importance of the small intestine in gut ammonia production in the fasting dog. Gastroenterology 37: 235-240 (1979).

13. Savage, D.C.: Association of indigenous microorganisms with gastrointestinal mucosal epithelia. Am. J. C1in. Mutr. 23: 1495-1501 (1970).

14. P1 ant, A.B., Gorbach, S.L., Nahas, L. et al: Studies of intestinal microflora. III. The microbial flora of human small intestine mucosa and fluids. Gastroenterology 53: 868-873 (1967).

15. Kingsiy, G.R., Fager, H.S.: Ion-exchange method for the determination of plasma ammonia nitrogen with the Barthelot reaction. Stand. Meth. c1in. Chem 6: 115-126 (1970). 
16. Hensinck, F., Ruseler-Enbden $v_{*}$ J.G.H.: The intestinal flora of colonization resistant mice. J. Hyg. Camb. 69: 413-417 (1971).

17. Livingston, S.J., Kaminos, S.D., Yee, R.B.: A new medium for selection and presumptive identification of the Bacteroides fragilis group. $J$. Clin. Microbiol. 7: 448-453 (1978).

18. Holdeman, L.V., Moore, W.E.C.: Anaerobe laboratory manual. Virginia, Polytechnic Institute. B1 acksburg, Virginia, U.S.A. (1972).

19. Simon, G.L., Sherwood, M.P. and Gorbach, L.: Intestinal microflora. Med. C1 in. North Am. 66: No. 3, p. 557-574 (1982).

20. Wolpert, E., Philips, S. and Summerskill, W.H.J.: Transport of urea and ammonia production in the human colon. Lancet II: 1387-1390 (1971).

21. Gibson, J.A., Park, N.J., Sladen, G.E. and Dawson, A.M.: The role of the colon in urea metabolism in man. Clin. Sci. 50: 51-59 (1976). .

22. Wrong, 0.M., Vince, A.J. and Waterlow, J.C.: The origin and bacterial metabolism of faecal ammonia. Falk Symposium 32, 1981: Colon and Nutrition, eds. H. Kasper and H. Goebbe1, p. 133-139 (1981).

23. Heeraglaj, D., Gorbach, S.L. and Levitan, R.: Intestinal microflora in patients with alcoholic cirrhosis: urea splitting bacteria and neomycin resistance. Gastroenterology 62: 275-279 (1972).

24. Vince, A.J. and Burridge, S.M.: Ammonia production by intestinal bacteria. The effects of lactose, lactulose and glucose. J. Med. Microbiol. 13: 177-191 (1980). 
PORTAL ARTERIAL DIFFERENCES FOR AMINO ACIDS AND AMMONIA ACROSS THE INTESTINE IN CONVENTIONAL ANO GERM-FREE RATS AND THE INFLUENCE OF LACTULOSE AND NEOMYCIN.

\section{VII.1. Introduction}

Ammonia generation in the gut is still believed to result from bacterial degradation of Tuminal nitrogen derived from diet, desquamated eplthelial cells and hydrolysis of urea $(1,2,3,4)$.

Bacterial ammonia generation is so firmly established that virtually all treatment for the hepatic coma syndrome has been directed towards altering the role of bacteria within the colon. However, there is ample evidence to suggest that there are sources of gut ammonia production not attributable to bacterial metabolism within the intestinal tract, but to intracellular non bacterial metabolism in the mucosa $(5,6)$. Windmueller indicated that this armonia production is glutamine dependent. Uptake of glutarnine by rat small intestine, derived either from the lumen or from the blood resulted in the appearance of ammonia, alanine, ornithine, citrulline, glutamate, and proline in the venous effluent of the gut (7). Whether this metabolic process also takes place in the colon has not been investigated extensively, although Weber in his study indicated that in dogs 50 percent of ammonia released by the colom can be accounted for by the uptake of giutamine (8). Neomycin and lactulose are both used in hepatic coma and are generally accepted to have beneficial effects $(9,10)$. Neomycin is known to exert its action mainly on the aerobic part of the flora, which represents only a small part of the total flora (11). Lactulose decreases pH resulting in decreased production of ammonia by gut fiora and decreased absorption of ammonia by gut mucosa. It 
also acts as a laxative and according to Vince serves as an energy substrate for bacteria thereby facilitating the assimilation of $\mathrm{NH}_{3}$ into bacterial protein (12). These explanations do not take into account the suggestions in the literature indicating that a large part, possibly half to three quarters of the total ammonia production in the intestinal tract, is not bacterialiy mediated. Moreower according to Weber $50 \%$ of the total ammonia production originates in the small intestine where relatively few bacteria are present (8). The aitim of the study was:

1. to measure the amnonia production in small and large bowel respectively in conventional and germ-free rats;

2. to determine the influence of lactulose and neamycin on ammonia production.

\section{VII.2. Material and methods}

Animals.

Male Wistar (specific pathogen free) SPF rats weighing 250-300 g were used and kept at $21^{\circ} \mathrm{C}$ and allowed free access to water and rat chow. Germ-free rats were housed in plastic isolators. Air was filtered with bacteria-filters (M11ler-filters, Firma Millipore, U.S.A.). Enviromental conditions were kept constant. Entries of supplies and removal of waste products were carried out under strict aseptic condition. The diet consisted of special laboratory chow (formula SRM-A120, Hope Farm, Woerden) prepared for germ-free and SPF animals. Rats were given lactulose $(2 \times 2.5 \mathrm{ml} /$ day of a solution of $20 \% \mathrm{~W} / \mathrm{V})$ (Duphalac, Duphar, Weesp, ML) or neomycin $2 \times 2.5 \mathrm{ml}$ (10 g/100 ml) (Lundbeck, Amsterdam, NL) by stomach tube for seven days. Controls were given water as placebo in the same manner.

\section{Surgical procedure.}

Each rat was operated under ether anaesthesia. Operations were performed between $8.00 \mathrm{a} . \mathrm{m}$. and $1.00 \mathrm{p.m}$. After laparatomy porta-arterial differences 
from the venous effluent of the small and large intestine. For sampling the effluent of the small intestine, arteries and veins of the colon were ligated and for sampling the effluent of the colon, the arteries and veins of the small bowel. In the germ-free animals no distinction was made between portal blood of colon and small intestine, but the portal effluent of both small and large bowel was sampled. In all antmals stomach, spleen and pancreas were excluded. Ammonia, citrulline, ornithine, glutamate, giutamine and alanine were measured in plasma. Amino acids were determined on an automatic analyzer $(L K B \quad 4400)$. The coefficient of variation $(C V)$ is smaller than $1 \%$.

\section{Ammonia determination.}

Ammonia was determined in plasma using the ion exchange method by Kingsley (14) (see chapter $V$ ).

\section{VII.3. Results}

Results indicate when positive P-A differences are expressed as production and negative P-A differences as uptake, that small and large intestine of conventional and germ-free rats generate ammonia, alanine, citrulline, ornithine and glutamate and take up glutamine (fig. 1 and 2).

The smal intestine of germ-free animals generates roughly an equal amount of alanine and ornithine, but less ammonia and glutamate and takes up less glutamine if compared to the conventional rats. The colon of the germ-free animals generates more alanine than the conventional colon. However, equall amounts of glutamate, citrulline and ornithine were produced. Much less ammonia was produced by the collon of the germ-free animal if compared to the conventional rats and less glutamine was taken up by the colon in the germfree animals. 
Small intestine of conventional and germ-free rats generate more ammonia, alanine, glutamate, ornithine, citrulline, and take up more glutamine than the large intestine, when a flow rate of small: large of $3: 1$ is taken into account $(13)$.

The influence of lactulose and neonycin on the portal-arterial differences of conventional animals.

Fig. 3 represents the portal-arterial amonia concentration in plasma of the control group, the lactulose group with and without diarrhoea and the neomycin treated group.
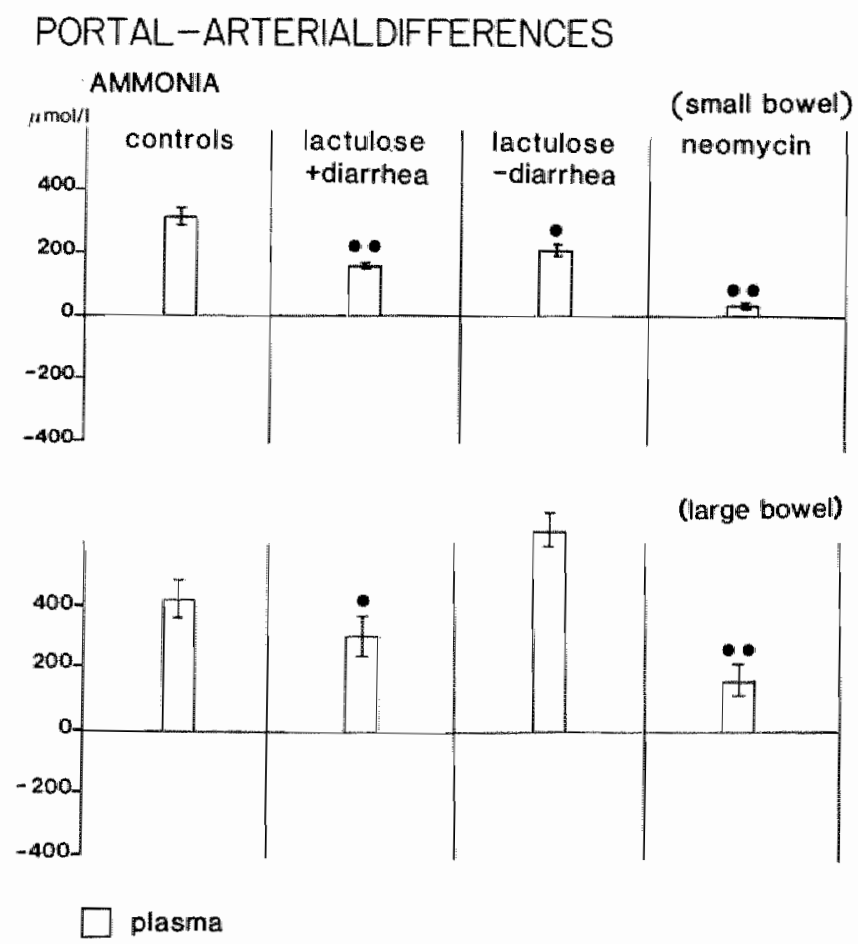

CONVENTIONAL RATS

Figure 3: Portal-arterial ammonia concentrations in the small and large intestine of conventional rats (fed state) measured in plasma of control, lactulose and neomycin treated rats. Positive and negative values represent output and uptake respectively in umol/L (mean \pm SEM).

$\star p<0.05 ; * * p<0.01$. 
As indicated by a positive P.A. difference, a significant amount of ammonia is generated in the small intestine. This ammonia praduction of the small Intestine is decreased after treatment with lactulase and neamycin. In the colon a significant decrease in ammonia production was noted in the plasma of the lactulose with diarrhoea group and in the plasma of the neomycin group. An increase in plasma ammonia concentration was noted in the lactulose without diarrhoea group, suggesting that the ammonia not taken up by the small bowel is now taken up by the colon.

Production of glutamate in the small intestine (Fig. 4) was decreased in the plasma of the lactulose group with and without diarrhoea and in the plasma of the neamycin treated group.

PORTAL ARTERIAL DIFFERENCES

GLUTAMATE
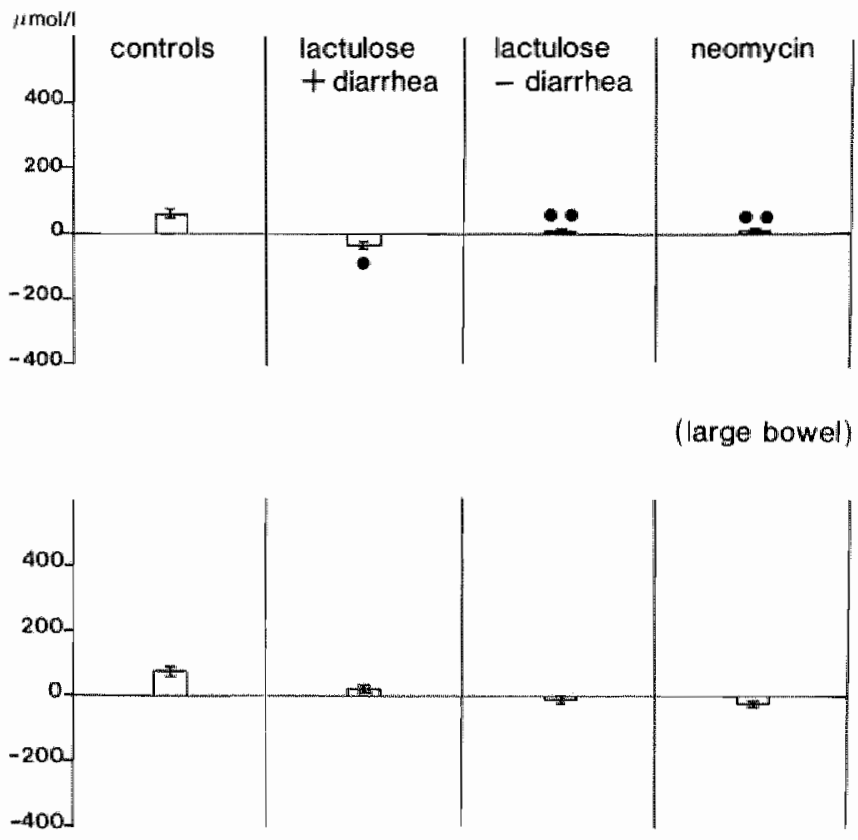

plasma (large bowel)

(small bowel)

\section{CONVENTIONAL RATS}

Figure 4: Portal-arterial glutamate concentrations in the small intestine and large intestine of conventional rats (fed state) measured in plasma of control, lactulose and neomycin treated rats. Positive and negative values represent output and uptake respectively in $\mu$ mol $/ \mathrm{L}$ (nean \pm SEM).* $p<0.05 ; * * p<0.01$. 
In the colon no decrease of giutamate production was abserved after treatment with lactulose and neomycin. A net production of alanine (fig. 5) occurred in the small intestine which decreased significantly in the neomycin group and in plasma of the lactulose with and without diarrhoea group. The decrease in P.A. alanine concentration (table II) is mainly due to a decrease in the alanine portal vein concentration. Large intestine generates less alanine than the small intestine as expressed in the P.A. differences. Decreased plasma concentrations were noted after treatment with neonycin although no significance was reached. No decrease in al anine concentration was noted in the plasma of the lactulose with diarrhoea group in contrast to the lactulose without diarrhoea group, who showed an uptake.

\section{PORTAL-ARTERIAL DIFFERENCES}

ALANINE
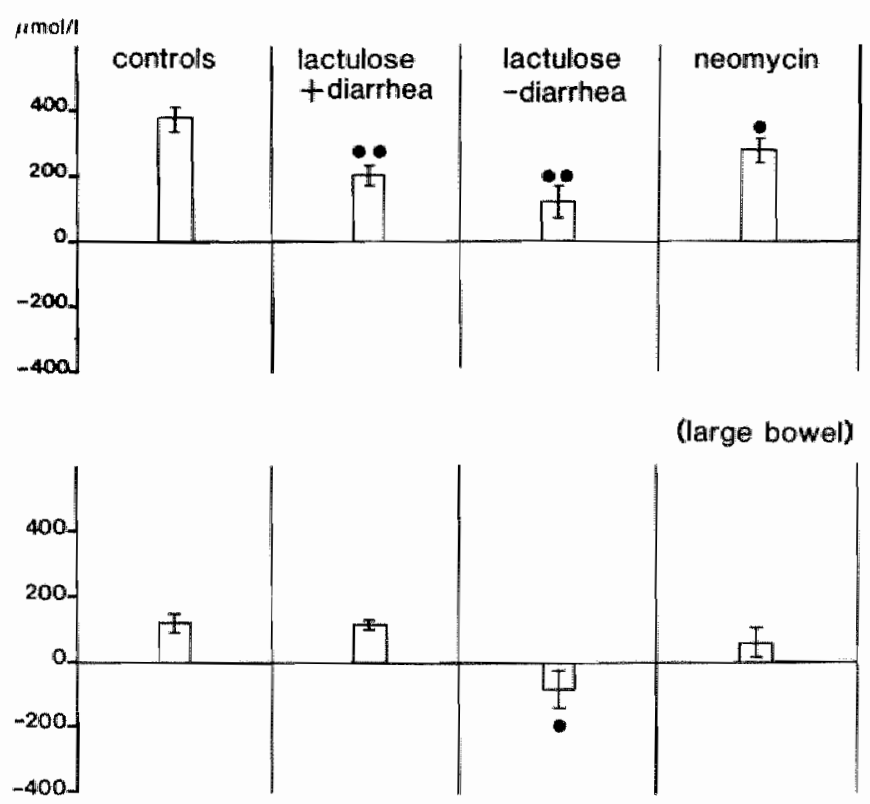

T plasma (large bowel)

(small bowel)

\section{CONVENTIONAL RATS}

Figure 5: Portal-arterial alanine concentrations in the small and large intestine of conwentional rats (fed state) measured in plasma af control, lactulose and neomycin treated rats. Positive and negative values represent output and uptake respectively in unol/L (mean SEM). 
In the small intestine (fig. 6) both lactulose and neomycin significantly decreased glutamine uptake. In the colon glutamine uptake was decreased in the lactulose with diarrhoea, lactulose without diarrhoea and neomycin group. No decrease was noted in the $P-A$ differences of citrulline and ornithine.

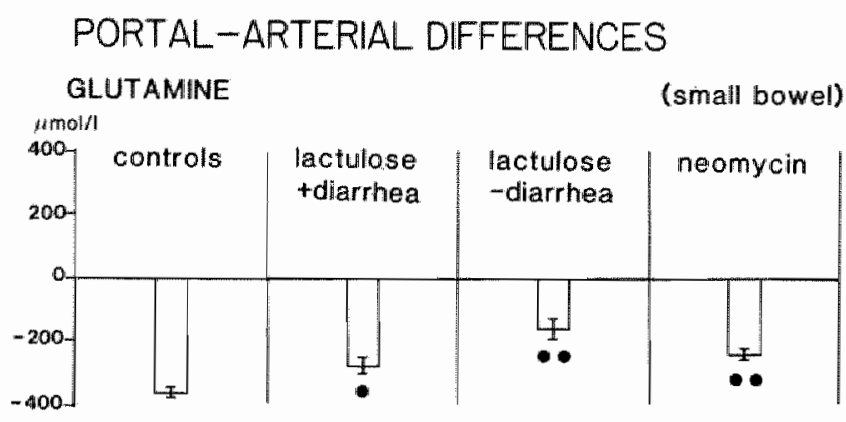

(large bowel)

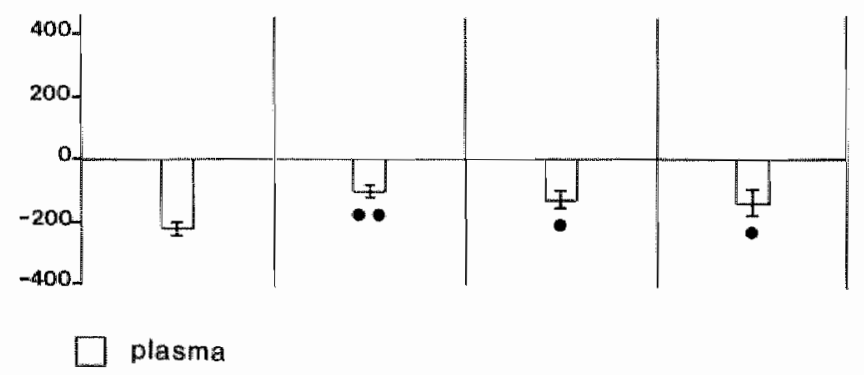

CONVENTIONAL RATS

Figure 6: Portal-arterial glutamine concentrations in the small and large intestine of conventional rats (fed state) measured in plasma of control, lactulose and neonycin treated rats. Positive and negative values represent output and uptake respectively in umol/L (mean \pm SEM).

* $p<0.05 ; * * p<0.01$. 
The influence of 1 actulose and neomycin on portal-arterial differences in germ-free rats.

In the germ-free animals after treatment with lactulose and neonycin we did not distinguish between portal blood of colon and small intestine but for economical reasons the combined portal effluent of small and large bowel was used. Stomach and spleen were excluded however. In the lactulose group only the animals with diarrhoea were studied. Lactulose significantly decreased the ammonia concentration in plasma in contrast to neomycin $(f i g .7)$.
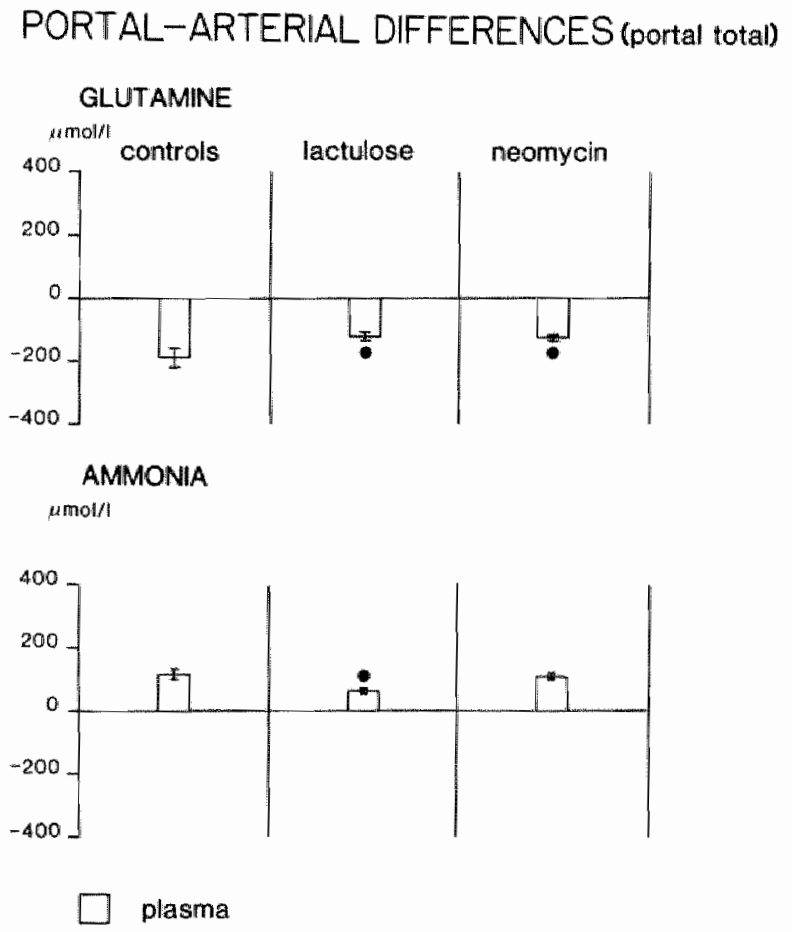

GERM FREE RATS

Figure 7: Portal-arterial ammonia and glutamine concentrations in the combined portal effluent of smali and large intestine measured in plasma of control, lactulose and neomycin treated germ-free rats. Positive and negative values represent output and uptake respectively in HMol/L (mean + SEN).

$\star p<0.05 ; * * p<0.01$. 
The glutamate P.A. dffference was decreased after treatment with lactulose and neomycin in plasma (Fig. 8). Alanine production decreased in plasma after lactulose treatment (Fig. 8). Uptake of glutamine was decreased after treatment with lactulose and neomycin (Fig. 7). Mo decrease was noted in the P.A.-differences of citrulline and ornithine.

\section{PORTAL-ARTERIAL DIFFERENCES (portal total)}
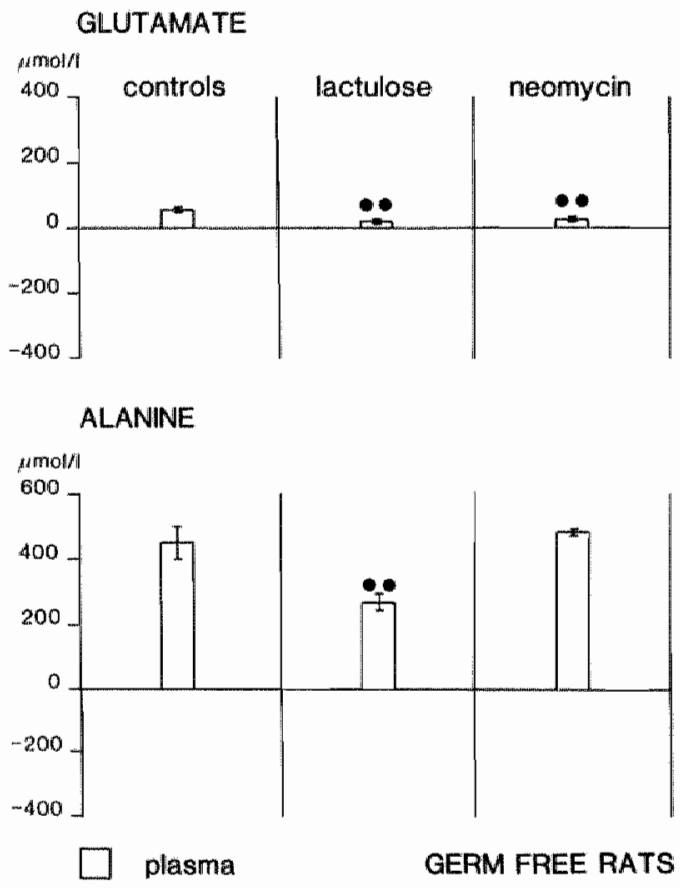

Figure 8: Portal-arterial alanine and glutamate concentrations in the combined portal effluent of small and large intestine measured in plasma of control, lactulose and neomycin treated germ-free rats. Positive and negative values represent output and uptake respectively in umo $1 / L( \pm$ SEM) .

$\star p<0.05 ; * * p<0.01$. 
The P-A differences as demonstrated in fig. 1-8 were calculated from absolute values, as shown in tables 1-5.

Table I

\begin{tabular}{|c|c|c|}
\hline & Lactulose + diarrhoea & Lactulose - difarrhoea \\
\hline
\end{tabular}

$\begin{array}{lcccc}\text { Amnonia } & 114.0 \pm 13.6 & 106.6 \pm 7.8 & 121.6 \pm 16.0 & 81.2 \pm 4.2 \\ \text { Glutamic acio } & 48.0 \pm 3.0 & 101.2 \pm 7.51 & 118.0 \pm 14.5 & 118.8 \pm 7.9 \\ \text { Alanine } & 326.0 \pm 8.0 & 349.6 \pm 23.1 & 485.0 \pm 49.8 & 353.1 \pm 21.8 \\ \text { Citrulline } & 68.0 \pm 2.0 & 35.8 \pm 2.74 & 60.5 \pm 0.8 & 44.8 \pm 6.06 \\ \text { Ornithine } & 52.0 \pm 3.0 & 39.8 \pm 2.13 & 55.0 \pm 3.97 & 37.3 \pm 5.15 \\ \text { Glutamine } & 697.0 \pm 25.0 & 552.0 \pm 22.6 & 548.7 \pm 32.06 & 514.1 \pm 14.98\end{array}$
$n=15$
$n=9$
$n=9$
$n=8$

Table I: Arterial ammonia and amino acid concentrations in plasma of conventional rats (fed state). Arterial biood was callected from the aorta of controls, lactulose and neomycin treated rats. Results are expressed in umal/L ( \pm SEM). 


\section{Table 11}

$\begin{array}{cccc}\text { Controls } & \text { Lactulose + diarmoea } & \text { Lactulose - diarrhoea } & \text { Meomycin } \\ \text { Plasma } & \text { Plasma } & \text { Plasma } & \text { Plasma }\end{array}$

$\begin{array}{lcccc}\text { Ammonia } & 426.0 \pm 35.8 & 270.0 \pm 12.8 & 334.0 \pm 45.7 & 135.3 \pm 16.5 \\ \text { Giutanic acid } & 105.6 \pm 8.1 & 67.6 \pm 12.5 & 120.0 \pm 14.5 & 110.6 \pm 10.3 \\ \text { Alanine } & 709.4 \pm 42.8 & 551.4 \pm 21.2 & 605.3 \pm 60.1 & 640.3 \pm 63.2 \\ \text { Citruline } & 110.4 \pm 5.9 & 84.8 \pm 7.2 & 81.8 \pm 7.8 & 106.5 \pm 11.3 \\ \text { Ornithine } & 64.4 \pm 3.7 & 48.6 \pm 2.8 & 59.5 \pm 1.7 & 54.0 \pm 2.5 \\ \text { Glutamine } & 330.6 \pm 38.4 & 280.1 \pm 23.9 & 393.6 \pm 35.6 & 276.3 \pm 12.7\end{array}$

$n=5$

$n=6$

$n=6$

$n=5$

Table II: Portal ammonia and amino acid concentrations in the plasma of conventional rats (fed state). Portal concentrations were selectivelly measured in the partal effluent of the small intestine of controls, lactulose and neomycin treated rats. Results are expressed in $\mu$ mol/L $( \pm$ SEM). 


\section{Table III}

Controls

piasma

Lactulose + diarrhoea

Lactulose - diarrhoea

Weonycin

Plasma

plasma

plasina

Atrononia

$548.0 \pm 57.4$

$408.0 \pm 70.7$

$758.0 \pm 56.7$

$237.2 \pm 58.5$

G) utamic acid

$118.0 \pm 11.0$

$121.6 \pm 8.8$

$119.5 \pm 11.7$

$108.4 \pm 8.6$

Allarine

$452.0 \pm 20.0$

$437.0 \pm 25.9$

$357.0 \pm 43.9$

$433.6 \pm 23.5$

citrulline

$86.0 \pm 3.0$

$48.0 \pm 3.5$

$46.5 \pm 3.5$

$73.8 * 1.3$

Drnithine

$65.0 \pm 3.0$

$43.6 \pm 3.9$

$56.0 \pm 2.5$

$49.6 \pm 1.2$

Glutamine

$447.0+18.0$

$467.0 \pm 11.2$

$403.0 \pm 45.4$

$372.0 \pm 42.2$

$n=5$

$n=5$

$n=5$

$n=5$

Table 11I: Portal ammonia and arino acid concentrations in the plasma of conventional rats (fed state). Portal concentrations were selectively measured in the portal effluent of the large intestine of controls, lactulose and neomycin treated rats. Results are expressed in $\mu$ moll $/ L( \pm$ SEM). 


\begin{tabular}{|c|c|c|c|}
\hline & $\begin{array}{l}\text { Controls } \\
\text { Plasma }\end{array}$ & $\begin{array}{c}\text { Lactulose + diarrhoea } \\
\text { Pliasma }\end{array}$ & $\begin{array}{l}\text { Neomycini } \\
\text { Plasma }\end{array}$ \\
\hline Ammonta: & $200.0 \pm 12.45$ & $136.0 \pm 7.25$ & $184.2 \pm 10.98$ \\
\hline Glutanic acid & $126.2 \pm 8.7$ & $107.3 \pm 6.67$ & $118.7 \pm 3.8$ \\
\hline Alarifo: & $873.2 \pm 44.1$ & $675.1 \pm 21.0$ & $904.2 \pm 37.4$ \\
\hline citrulline & $133.6 \pm 8.0$ & $118.8 \pm 4.0$ & $140.0 \pm 11.67$ \\
\hline Ornithine & $62.2 \pm 5.9$ & $48.3 \pm 2.9$ & $70.2 \pm 7.9$ \\
\hline Glutamine & $216.8 \pm 33.7$ & $140.3 \pm 24$ & $136.0 \pm 3.0$ \\
\hline & $m=5$ & $n=6$ & $n=5$ \\
\hline
\end{tabular}

Table IV: Partal ammonia and amino acid concentrations in plasma of germfree rats (fed state). Portal concentrations were determined in the combined portal effluent of small and large intestine. Results are expressed in umol/L ( $\mathbb{S}$ SEM). 
Table W

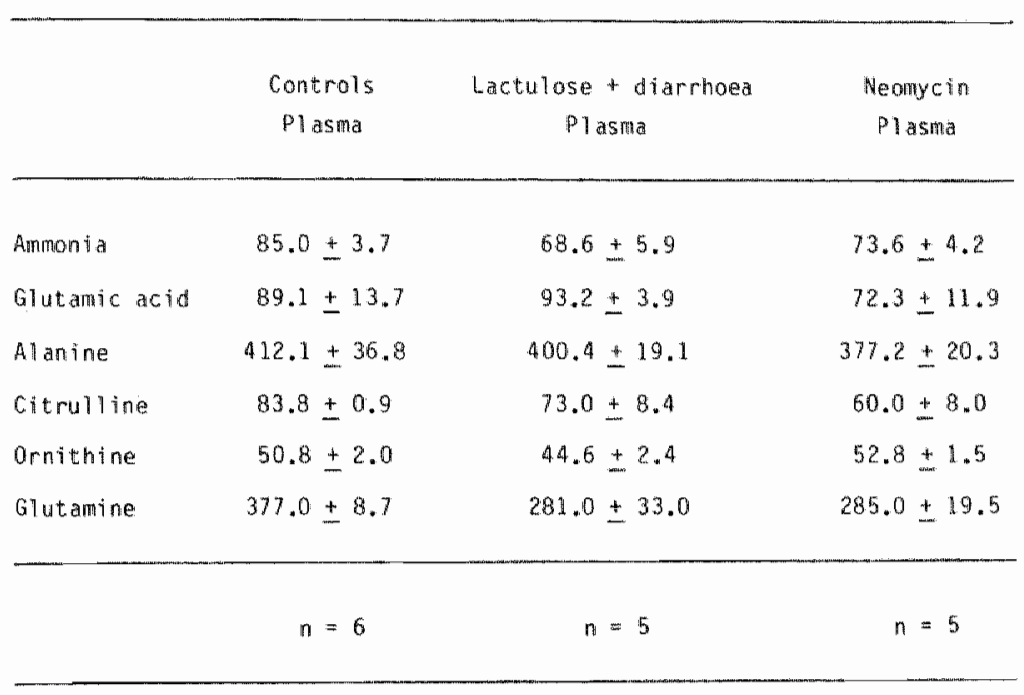

Table V: Arterial ammonia and amino acid concentrations in plasma of germ-firee rats (fed state). Arterial blood was collected from the aorta of controls, lactulose and neomycin treated rats. Results. are expressed in $\mu$ mol/L $( \pm S E M)$. 
VII.4. Discussion

In contradistinction with to the clinical literature, which still defines the colonic flora as the main producer of ammonia, this study clearly indicates that annonia production in the small intestine is quantitatively more important than the large intestine. The small intestine produces more ammonia than the large intestine especially when a flow rate of small : large of $3: 1$ is taken into account (13).

Together with this ammonia production, alanine, citrulline, ornithine, proline and glutamic acid is formed. This production is not only bacterially mediated since germ-free rats also were capable of generating a significant amount of ammonia. Neomycin is supposed to act on the colonic flora thereby reducing ammonia levels (11). In this study however neomycin significantly decreased armonia production in both the sma 11 and large intestine. That this ammonia lowering effect was due to a decrease in the aerobic flora is difficult to believe since the aerobic flora represents a small fraction of the total flora in the intestine and since the aerobic flora has been demonstrated not to contribute significamtly to ammonia production (chapter V). Also relatively few bacteria are present in the small intestine when compared to the colon, where a lesser decrease was noted. Lactulose, like neonycin, is also supposed to act by interfering with the colonic flora. In this study however lactulose clearly interferes with intermediary metabolism in germfree rats and therefore also in conventional rats. The precise mechanisin of action of both neomycin and lactulose on glutamine metabolism is speculative. First of all one should keep in mind that this experimental model has its limitations. In this model, it was not possible to measure flow rates in the venous effluent of small and large intestine. Also the surgical procedure, which included ligation of arteries and veins and subsequently blood sampling from the vena porta, could have an impact on the determination. Keeping the limitations of this model in mind, there still is a consistent picture. Both lactulose and neomycin appear to be capable of interfering with intermediary 
metabolism. Lactulose, if looking also at portal arterial differences of other amino acids like leucine, waline and tyrosine reduces uptake (data not shown). Most if not all amino acids shift into the direction of the lumen. This may be explained by an osmotic effect of lactulose. In this way giutamine availability for glutaminase activity is diminished, so that less amnomia is produced. Similarly meonycin causes amino acids to shift into the direction of the 1 umen, in this manner al so reducing glutamine availability for glutaminase activity. More precise biochemical studies however are needed to reveal the precise mode of action of both drugs. Studies with a large animal model are needed to study ammonia and amino acid metabolism in different parts of the intestinal tract over langer periods of time and to study the influence of administration of lactulose and neomycin.

\section{VII.5. References}

1. Walser, M., Bodenloos, L.d.: Urea metabolism in man. J. Clin. Invest. 38: $1617-1626(1959)$.

2. Wolpert, E., Philips, S.F., Summerski11, H.H.J.: Ammonia production in the human colon. N. Engl. J. Med. 159-164 (1970).

3. Phear, E.A. and Ruebner, B.: The in vitro production of ammonium and amines by intestinal bacteria in relation to nitragen toxicity as a factor in hepatic coma. Br. J. Exp. Path. 37: 253-259 (1956).

4. Flock, M.H.K. and Conn, H.O.: Qualitative and quantitative relationships of the fecal flora in cirrhotic patients with portal systemic encephalopathy and following porta-caval anastomosis. Gastroenterology 59: $70-79$ (1970).

5. Watford, M., Lund, P., Krebs, H.A.: Isolation and metabolic characteristics of rat and chicken enterocytes. Biachem. J. 178: 589-596 (1979). 
6. Matsutaka, H., Aikawa, T., Yamamoto, H. and Ishikawa, E.: Gluconeogenesis and amino acid metabolism III. Uptake of glutamine and output of alanine and ammonia by non-hepatic splanchnic organs of fasted rats and their metabolic significance. J. Biochem. 74: 1019-1029 (1973).

7. Windmueller, H.G.: GTutamine utilization by the small intestine. Adv. Enzymol. 53: 201-229 (1982).

8. Weber, F.L. and Veach, G.L.: The importance of the small intestine in gut ammonium production in the fasting dog. Gastroenterology 77 : $235-240,1979$.

9. Fisher, C.J. and Faloon, W.W.: Blood ammonia levels in hepatic cirrhosis. N. Engl. J. Med. 256: 1031-1035 (1957).

10. Simmons, F., Goldstein, H. and Boyle, J.D.: A controlled clinical trial of lactulose in hepatic encephalopathy. Gastroenterology 6: 827-832 (1970).

11. Imler, M., Peter, B., Schlienger, J.L., Lavillanieva, J.L., Stah1, J.: L'ammoniogénèse intestinale du rat nomal. Méd. Chï. Dig. 4: 15-20 (1975).

12. Vince, A., Zeeger, R., Drinkwater, J.E., O"Grady, F., Dawson, A.M.: The effect of lactulase on the fecal flora of patients with hepatic encephalopathy. J. Med. Microbial. 7: 163-168 (1974).

13. Ferrone, R.A., Walsh, G.M., Tsuchiya, M. and Frohlich, E.D.: Comparison of hemodynamics in conscious spontaneous and rural hypertensive rats. Am. J. Physiol. 236: H403-H408 (1979).

14. Kingsly, G.R., Fager, H.S.: Ion-exchange method for the determination of plasma ammonia nitrogen with the Barthelot reaction. Stand. Meth. C1 in. Chem. 6: 115-126 (1970). 


\section{GENERAL DISCUSSION}

The results of this study indicate that large and small intestine generate ammonia. In vitro the amounts of ammonia produced by conventional and germfree rats are comparable and are greatiy increased when glutamine is supplied as a substrate. This signifies that in vitro gut production of ammonia in conventional rats is largely glutamine dependent and not mediated by bacterial action. From our studies it is clear that glutamine uptake and ammonia production occurs in both villous and crypt cells. Ammonia production in the small bowel in vitro is greater than in the colon. The difference in metabolic ammonia production in vivo should even be greater because the smali bowel receives three times as much arterial flow and thus glutamine as the colon. Furthermore resorption of amino acids and thus substrate, occurs predominant$7 y$ in the small bowel and to a much lesser extent in the colon. In vivo ammonia production in the small intestine was also quantitatively more important than in the large intestine. This production is to a large extent not bacterially mediated since al so germ-free rats were capable of generating a significant amount of ammonia, and because the small intestine contalins less bacteria if compared to the colon. In contradistinction with the in vitro situation however, in vivo germ-free rats produce less ammonia than conventional rats.

Why do conventional rats produce more ammonia than germ-firee rats?

As far as we can see there are two possible reasons:

1. In conventional animals bacteria contribute significantiy to ammonia production. 
2. In conventional animals arterial blood contains significantiy higher concentrations of glutamine than in germ-free animais.

A higher concentration of substrate (glutamine) is therefore presented to the gut, which may result in increased uptake of glutamine and increased production of ammonia. Glutamine concentrations and similarly the glutamine/alanine ratio present in venous blood from the extremities have been shown to vary with different clinical states. In patients with liver cirrhosis for instance Imller has shown that the glutamine/alanine ratio greatly increases, compared to healthy controls. The same phenomenon was demonstrated when experimental animals were infused with ammonium acetate. Imler (1) attributes this to ammonia which is presented to the peripheral tissues in cirrhotic patients. This ammonia is "detoxified" by the formation of glutamine from glutamic acid. Glutamic acid is formed from alpha-ketogiutarate via a transamination reaction with branched chain amino acids. This mechanism has been claimed by Holm (2) to underlie the decrease in plasma branched chain amino acid levels encountered in patients with chronic liver disease or in experimental animals infused with ammonium salts.

In the studies described in chapter VII we found in germ-free rats an arterial glutamine/alanine ratio which was much lower than in conventional rats. Not only the ratio was lower however, but also the absolute arterial plasma levels of glutamine. In accordance with the mechanism posturated in patients with chronic liver disease or after ammonia infusions, the decreased glutamine/alanine ratio in germ-free rats may then be explained by decreased arterial $\mathrm{NH}_{3}$ levels present in germ-free rats. It is very likely that this mechanism indeed is operative in germ-free rats and influences the glutamine/al anine ratio. The extent however of the increase of the glutamine/alanine ratio and of absolute glutamine levels in arterial blood in conventional rats compared to germ-free rats, appears to be much greater than can be explained by the only moderate increases in arterial ammonia levels in conventional rats (conventional rats: $85 \mu \mathrm{mol} / \mathrm{L} ;$ germ-free rats: $115 \mu \mathrm{mol} / \mathrm{L}$ ). The large extent of the increase in arterial glutamine levels in conventional rats 
needs therefore further investigation. There are several possibllities:

1. The extraction rate of ammonia in muscle is possibly increased, resulting in higher glutamine production than would seem appropriate when only the slight excess of arterial ammonia in conventional rats would be taken up and transformed into glutamine. Venous $\mathrm{NH}_{3}$ levels were not neasured however.

2. Another possibility is that glutamine production is emhanced by ammomia out of proportion with the slight increase in arterial ammonia. Amonia might for instance influence transport or enzyme systems, in turn influencing the glutamine/alanine ratio. Indeed our data show that the increase of glutamine accurs at the expense of al anine in conventional rats and vice versa in germ-free rats (chapter VII, tabel V).

3. Also other influences can not be ruled out. Kipnis and his group (3) demonstrated that hormones (epinephrine, thyroxine) and amino acids can influence the glutamine/alanine ratio as meleased in vitro by rat epitrochlearis muscle. It is unlikely that germ-free rats have homonal and amino acid patterns that differ substantially from conventional rats. It would however seem to be more relevant to study substances like Interleukin I released by macrophages operative in the gut in the defense against bacteria.

In conclusion our data do not allow precise quantitation of bacterial and metabolic ammonia generation. Weber (4) has concluded from his experiments in dogs that almost all ammonia production in the small bowel can be accounted for by glutamine dependent metabolism in the mucosa. In the colon half of the ammonia production was claimed to be ghutamine dependent. Taking these data together, considerably less than $25 \%$ of total ammonia production in the gut would be bacterialily mediated because the colon receives less flow than the small bowel. Still total ammonia production in the gut of conventional rats is roughiy a factor $2-3$ greater than in germ-free rats. We suggest that the presence of bacteria in the gut increases ammonia in the portal vein which is 
largely taken up by the 71 wer. A small part of it escapes howewer into the general circulation where it influences the glutamine/alanine ratio disproportionately, i.e. above the amount required to clear the excess of "toxic" arterial ammonia. The mechanisms underlying this process are not entirely clear. The increase in systemic glutamine levels has been shown (chapter VII) to result in increased uptake and degradation in the gut mucosa. In the degradation process of glutamine at least $80 \%$ of the amide nitrogen of glutamine is released into the portal vein as ammonia.

Therefore the presence of bacteria in the gut influences whole bady nitrogen in such a way that much more ammonia is produced in the gut than can be accounted for by bacterial action alone.

How relevant are these findings in terms of whole body nitrogen metabolism ?

Ninety percent of all nitrogen resulting from muscle proteolys is is released into the systemic circulation, not as the constituting amino acids, but as glutamine and alanine. This occurs in most organs, notably skeletal muscle, heart muscle, adipose tissue and brain. To our knowledge it has not been the subject of study what happens with muscle tissue in the gut and with protein in the kidney, lungs, etc. In addition all these tissues (skeletal muscle, cardiac muscle, brain) can take up ammonia, which results in glutamine formation. Therefore products of protein degradation in the body are largely released into the circulation as glutamine and alanime. As discussed before the ratio between glutamine and alanine varies from $3: 2$ in normal humans to 2 : 1 (chapter VII) in conventional rats in this study. To achieve homeostasis the glutamine and alanine produced have to and can only be taken up in the gut and in the kidney. It has been demanstrated that the liver can take up glutamine but does so only to a very limited degree. Alanine is of all amino acids the major precursor for gluconeogenesis and urea genes is in the liver. Glutamine therefore has to be taken up largely by the gutmucosa and the kidney. The first step in the degradation of glutamine is deamidation 
which results in ammonia production. Some 80 percent of this ammonia is released into the portal circulation. Only a minor part is directed into citrulline synthesis. In the kidney glutanine degradation is quantitatively less important but anmonia is also produced and then excreted into urine as long as urinary pH is low.

The use of such a set up is evident! The bulk of the products of peripheral protein degradation gets access to the systemic circulation as glutamine and alanine. Glutamine then acts as a non-toxic carrier of two nitrogen atons per molecule of glutamine, and is almost exclusively taken up by gutmucosa and kidney. Ammonia is produced in the gut and released into the portal circulation where it can almost completely be cleared by the liver in a first pass, so that very little escapes into the systemic circulation. Similarly ammonia derived from glutamine degradation in the kidney can be excreted in a harmless way in an acid urine, so that it does not get access into the general circulation (and thus the brain). In addition it may also be useful that the major part of amino acids do not escape into the general circulation as such because they also may have harmful and even toxic effects, if present in excess.

From the chain of events described above, one can roughly estimate that 20-30\% of the nitrogen excreted per day in the urine is glutamine derived anmonia, produced in the gut and presented to the liver where it is transformed into urea. This means that, iff we assume that in a normal grown-up person $10 \mathrm{~g}$ of urinary nitrogen is excreted per day, 2-3 $\mathrm{g}$ is derived from metabolic ammonia produced in the gut, equalling to 143-214 mMol of ammonia. It has been hypothesized that catabolism precipitates hepatic encephalopathy by the release of amino acids derived from the breakdown of endogenous protein (5). The hypothesis was based upon the observation that disease, shock and other catabolic insults, in clinical practice frequently induce hepatic encephalopathy, and upon the amino acid neurotransmitter hypothesis which claims that a distorted amino acid pattern influences brain neurotransmitter metabolism, resulting in hepatic encephalopathy. 
The amino acid neurotraninitter hypothesis was modified however and Iinked to ammonia metabollsm (chapter 1). The blochemical literature and the results of this thesis provide further insight in potential mechanisms underlying the encephalopathy precipitating effect of catabolic states. Similar as in the hedithy organism increased breakdown of peripheral protein presents the organism with glutamine and alanine, albeit in increased amounts. Likewise increased glutamine flow results in increased ammonia production in the gut, which either due to diminished hepatic metabolic function or due to collateral circulation, gets access to the systemic circulation and consequently to the brain.

Another clinical observation is that different types of dietary protein have different influences on hepatic encephalopathy. Blood appears to be more toxic than meat and meat more toxic than vegetable protein. Blood contains much more glutamine than whole protein, but we are not aware of studies establishing the glutamine content of meat, milk, fish, vegetables etc. It may be worthwile to explore this matter in more detail.

\section{Effects of lactulose and neomycin.}

Our fifst studies (chapter II, chapter III) demonstrate the likelihood that lactulose directly interferes with the uptake of glutamine and its subsequent. metabolism. Studies regarding the potential influence of lactulose on bacterial flora did not reveal major changes in bacterial counts. Lactulose may however have interfered with uptake of nitrogen containing products of bacterial metabolism, including ammonia, from the lumen across the gutwall into the partal blood. In these studies we did not measure total nitrogen and ammonia in the stools of these rats however. Study of arterial and portal concentrations of amino acids and ammonia in germ-free and conventional rats in vivo reveals that lactulose interferes with glutamine uptake which results in a diminished release of ammonia, alanine, glutamic acid etc. into the portal blood, especially in the small bowel. These findings prove that 
lactulose via this action significantly inhibits ammonia generation in the gut mucosa. As al ready mentioned, the discrepancy between estimated ammonia production by bacteria (less than 25\%) (4) and the $2-3$ fold increase in total ammonia production in conventional rats compared to germ-free rats has been explained by the change in venous $c . q$. arterial glutamine/alanine ratio in some way brought about by the presence of bacteria in the gut. Lactulose appears to interfere slightly with the ratio by decreasing arterial glutamine levels, but alanine levels remain constant. It is therefore unlikely that lactulose influences the glutamine/alanine ratio of degradation products of peripheral proteins like muscle. Rather it appears that it exerts its action at the bowel wall itself for two reasons:

1. Diarrhoea should be present to achieve the full lactulose effect suggesting that its actions takes place predominantly in the gut.

2. Study of the full pattern of amino acids across the bowel wall reveals that lactulose inhibits resorption from the gut lumen of all amino acids including glutamine or/and even induces a shift of glutamine and other amino acids from the gutwall to the gut lumen (data not shown). The moderate decline in the glutamine/allanine ratio therefore appears to be the result of diminished uptake from or release into the gut lumen rather than of interference with the composition of degradation products of peripheral protein.

The action of neomycin is even more of an enigma. Its antibacterial effect is exclusively directed against the enterobacteriaceae, which constitute only a minute part of the total flora, and which have been shown in our studies to produce negligable amounts of ammonia. Still we can not exclude the possibility, and even think that it is probable, that neomycin interferes with the way products of bacterial metabolism are handled in the gut, and that neomycin changes the fate of these products, possibly in a similar way as the metabolism of the gut mucosa is influenced. Following the same line of reasoning as with lactulose our data suggest that nemycin interferes with 
uptake of glutamine by the gutwal1, either by diminishing uptake from the lumen, orland by diminishing uptake from the arterial blood. Prortal arterial differences even suggest that neomycin induces a shift af all amino acids from the gutwall to the gut lumen, alheit smaller than is achieved by lactulose. Extra evidence is derived from morphological data described in chapter IV. Although qualitative rather than quantitative in nature this investigation provides evidence that neomycin interferes with mucosal enzyme systems and therefore most likely also interferes with aspects of mucosal metabolism. It should be realized that the predominant importance that is attached by clinicians to bacterial metabolism in the pathogenes is of hyperammonaemia and hepatic encephalopathy has resulted from two factors with paramount influence.

1. Dame Sheila Sherlock herself emphasized the role of bacteria (6).

2. The importance of bacteria was derived from the observation that antibiatics (chlortetracyclin) amellorated hepatic encephalopathy.

of the more general anti"biotic" actions of antibiotics too much attention was concentrated on their anti"bacterial" action resulting in the conviction of clinicians that antibiotics exert an exclusive action on bacteria without at all interfering with metabolism of the tissues of the host. In other areas of medicine however nowadays it is appreciated that bacteria cam have important toxic and even deleterious effects on host tissues including the gut. Furthermore lack of contact between clinical and basic science allows misunderstandings to persist in one area of the scientific world despite more advanced knowledge in other areas. This problem has been extensively illustrated for glutamine metabolism and ammonia generation in the introductory chapter of this thesis. At present the same phenomena can be observed for -amino-butyric acid (GABA), believed to have an important role in the genesis of acute hepatic encephalopathy due to acute hepatic failure: GABA again is belitewed by clinicians to be generated in the gut by bacteriall action, whereas the biochemists know that the gutmucosa contains all enzymes to produce GABA. It would not surpirise us at all if further study would show 
that GABA is produced in the gutwall, increases after meals and is glutanine dependent.

\section{Areas for future research.}

We are aware of the crude nature of a part of our experiments, specifically the sampling of portal effluent of small and large bowel in a seni in vivo situation (living animal, open abdomen, clamping of certain areas of the gut, and sampling of amounts of blood that induce hypovolemia during the taking of the second sample).

All the results point into one direction however which warrants further investigations in a larger animal, preferably im a non stressed condition. Furthermore this thesis does only provide circumstantial evidence with regard to the mechanisms involved in the actions of neanycin and lactulose on the gutwal1. In addition factors (ammonia and others) influencing the arterial glutamine/alanine ratio should be better defined.

Finally because of recent interest in the GABA hypothesis and because of the possibility that glutamine degradation can substantially contribute to GABA generation in the gut, this area needs further study.

\section{References}

1. Imler, M., Schlienger, J.L.. Frick, A. et al: Study of muscular glutamine and alanine release in cirrhotics with hyperammonemia and in anmonium infused rats. In: Holm, $\mathbb{E}$. (ed.), Verlag Gerhard Witzstrock, Baden-Baden, p. $33-39(1982)$.

2. Leweling, H., Holm, E., Staedt, U., Striebel, J.-P., Tschepe, A.: Intra- and extracellular amino acid concentrations in anmonium-infused rats. Evidence that hyperammonemia reduces BCAA levels. In: Kleinberger, G., Ferenci, P., Riederer, P., Thaler, H.: Adwances in hepatic encephalopathy and urea cycle diseases. Proceedings 5 th International Symposium on Armonia, Semmering, Austria, May 16-19, 1984, Karger, Vienna, p. $552-555(1984)$. 
3. Graber, A.J., Karl, 1.E., Kipnis, D.M.: Alanine and glutamine synthesis and release from skeletal muscle. The precursor role of amina acids in alanine and glutamine synthesis: I, II, III, IV. J. Bial. Chem. 251 (3): $826-857(1976)$.

4. Weber, F.L., Veach, G.L.: The importance of the small intestine in gut ammonium production in the fasting dog. Gastroenteralogy 77: 235-240 (1979).

5. Soeters, P.B., Fischer, J.E.: Insulin, glucagon, amino-acid imbalance and hepatic encephalopathy. Lancet II: 880-882 (1976).

6. Phear, E.A., Ruebner, B., Sherlock, 5., Summerski11, W.H.d.: Methionine toxicity in liver disease and its prevention by chlortetracycline. clin. Sci. 15: 93 (1956). 
In chapter I the Viterature is reviewed concerning the mechanism involved in ammonia generation in the gut. Apart from bacterial ammonia generation, there are indications that there is a substantial ammonia production in the mucosa of the jejunum, ileum and colon, in that order of magnitude. This metabolic ammonia praduction is glutamime dependent. Ammonia still figures in most theories concerning the pathogenesis of hepatic encephalopathy (H.E.). The relevance of this study is underlined by a review of the literature demonstrating that neomycin and lactulose are indeed effective in ameliorating H.E., probably by their ammonia decreasing effect, although a well designed double-blind trial with a placebo has never been performed. The experiments described in this study were undertaken to establish if lactulose and neomycin interfere with mucosal ammonia metabolism, since this effect has never been considered in their mode of action. Current explanations ahout the mode of action of lactulose and neomycin are contradictory and unsatisfactory.

As a first approach to the problem we performed incubation studies with intact pieces of small and large intestine in a Krebs-Ringer solution (with and without glutanine) and with lactulose and neamycin added to the incubation medium (chapter 11 ). Small and large intestine were capable of metaboTizing large quantities of glutamine. Small intestine produced per unit of weight more ammonia than large intestine when glutamine was added. Lactulose inhibited degradation of glutamine in a dose dependent manner. Theoretically the muscle in the gut could have a major effect on metabolism of ammonia. Therefore we carried out experiments, as described in chapter II, with isolated mucosa cells to pinpoint the site where ammonia metabolism occurs. In addition these studies allowed us to distinguish between ammonia production of villous and crypt cells. Furthermore the effect of neomycin and lactuliose was investigated. Isolated cells were prepared according to the 
method of Harrison and Webster. Results indicated that glutamine is metabolized by both villous and crypt cells and that amonia, glutamic acid and alanine is produced. Both lactulose and neomycin were capable of inhibiting the alanine dependent production of ammonia by villous and crypt cells of conventional and germ-free rats. This glutamine degradation appears not to be mediated by bacterial action since processing these mucosa cells does not allow bacteria to stay on the surface of the mucosa cells. Furthermore mucosa cells of germ-free rats were capable of generating comparable amounts of ammonia as cells of conventional rats in both villous and crypt cells. In a separate study (chapter IV) we evaluated the effect of neomycin on gut-morphology with several histochemical staining reactions. Neomycin diminished both in normal and germ-free rats the activity of NAD-tetrazoliumreductase (NADHtr), succinate dehydrogenase (SDH), alkaline phosphatase (A1Ph) and acid phosphatase (AcPh). The findings of this study indicate that explanations for the benefical effects of neomycin on hyperammonemia in liver disease should not only include the antimicrobial activity of neomycin but also its influence on absorptive and metabolic function of the mucosa cell. With the study described in chapter $V$ we tried to establish, which bacteria are responsible for ammonia production, and if bacteria are responsible. Therefore rats were selectively decontaminated, which means that a defined portion (aerobic or anaerobic) was selectively eliminated by the use of specific antibiotics. Elimination of the amaerobic flora decreases, in contrast to statements in the literature, portal ammonia levels. The study however does not prove that elimination of the anaerobic flora is largely responsible for the decrease in portal ammonia concentration because the antibiotics used may apart from the bactericidal action, also exert metabolic effects. We therefore created gnotobiatic rats with a defined fiora. In these rats ammonia was determined in the portal blood and related to the flora present in the intestine. After colonization of germ-free rats with anaerobic or aerobic intestinal flara or a combination of both, portal plasma levels increased in the anaerobic, combined anaerobic and aerobic, but not in the 
aerobic gnotobiotic animals. Although the anaerobic flora consisting of Clostridum perfringens, Clostridium inocuum, Bacteroides ruminiculum, Bacteroides fragilis. Pepto-streptococci, Bifido bacteria and Lactobacillit. generates a significant amount of ammonia, the portal ammonia concentration did not reach levels of conventional rats, suggesting that additional, possibly unknown unclassified species may be needed to restore armonia levels in the portal vein to plasma levels in the portal vein of conventional rats. In chapter VI studies are described concerning the influence of lactulose and neomycin on the luminal and gutwall associated flora of both the small and large intestine. The changes in flora were correlated with the concentration of ammonia in the portal effluent of small and large intestine. The bacterial counts in small and large intestine of the rats after treatment with lactulose and meomycin cannot explain the significant decrease in ammonia levels in the portal vein. Consequently, the mechanism of action af lactulase and neomycin can not be exclusively explained by these changes in the gut flora, especially not since both neonycin and lactulose also decrease ammonia levels in the portal effluent of the small intestine where few bacteria are present. Finally (chapter VII) we determined portal and arterial amino acid and ammonia concentrations and calculated portal-arterial differences in small and large bowel of control animals and of lactulose and neomycin treated rats. Both conventional and germ-free rats were used. Under these in vivo conditions colon and small bowel take up glutamine and produce alanine, glutarnate and ammonia. Small intestine releases more alanine and ammonia than the colon especially when a flow rate of small versus large bowel of $3: 1$ is taken into account. Glutamine uptake and production of aỉanine, glutamate amd ammonia were decreased by lactulose and neomycin in small and large bowel. In chapter vIII these results are discussed. 


\section{SAMENHATTING}

In hoofdstuk I wordt een 1 it teratuuroverzicht gegeven betreffende de mechanismen die een rol spelen bij de ammoniak productie in de dam. Buiten het feit dat er ammoniak gegenereerd wordt door de bacteriën, zijn er aanwijzingen dat er een belangrijke hoeveel hejd ammonjak gemaakt wordt in de mucosa wan het jejunum, ileum en colon in die volgorde van grootte. Ammoniak wordt nog steeds genoemd in de hypotheses van het hepatisch coma. De relevantie van deze studie wordt onderbouwd door een literaturoverzicht dat aangeeft dat zowel lactulose als neomycine hun effect hebben in verbetering van het coma, hoogstwaarschijnlijk door hun ammoniakverlagende effect. Een goed dubbelblind onderzoek met een placebo is echter tot op heden nooit uitgevoerd. De studies beschreven in dit proefschrift werden gedaan on na te gaan of lactulose en neomycime thun invloed uitoefenen op het intermediair metabolisme in de darm, gezien het feit dat deze magelijkheid nog nooit onderzocht is. De algeneen gangbare verklaringen omtrent de werking van lactulose en neomycine zijn contraversiëel en onbevredigend.

Als een eerste aanzet tot het probleem werden incubatie studies gedaan met intacte stukjes weefsel van dunne en dikke darm in een krebs-Ringer oplossing (met en zonder glutamine) en met lactulose of neomycine toegevoegd aan het incubatiemedium (hoofdstuk II). Dunne en dikke darm bleken in staat te zijn on grate hoeveelheden glutamine te metaboliseren waarbij de dunne darm meer ammontak produceerde wanneer glutamine werd toegevoegd aan het medium. Lactulose remde de degradatie van glutamine op een concentratie afhankerijke manier. Gezien het theoretische feit dat de spier een invlaed zou kunnen uitoefenen op deze ammoniakproductie werden experimenten gedaan zoals beschreven in hoofdstuk III met geïsoleerde mucosacellen, om de plats van de ammoniakproductie vast te stellen. Tevens gaf dit ons de mogelijkheid de ammoniakproductie van zowel de villus als de crypt te bestuderen en te vergelijken. Bovendien werd het effect van lactulose en neomycine op deze anmoniakproductie bestudeerd. 
Mucosacellen werden geïsoleerd volgens de methode van Harrison Webster. De resultaten gaven aan dat zowel villus als crypt cellen beiden in staat waren glutamine te metaboliseren tot ammoniak, glutaminezuur en alanine. Zowel lactulose als neomycine remden de glutamine afhankel ijke ammoniakproductie in de villus en cryptcellen van steriele en conventionele ratten. De afbraak van deze glutamine blijkt volledig onafhankelijk te zijn van bacterièn, daar ten eerste bij deze methode van isoleren vrijwel geen bacteriën achterblijven en ten tweede mucosacellen van steriele ratten ook in staat bleken te zijn vergelijkbare hoeveetheden ammoniak te maken zowel in de villus als in de crypt.

In hoofdstuk IV wordt het effect bestudeerd van neomycine op de morfologie van de darm door middel van verschillende enzymkleuringen. Neomycine bleek zowel bij steriele als bij conventionele ratten de activiteit van NAD tetrazoliumreductase, succinat-dehydrogenase, alkalische en zure fosfatase te remmen. De resultaten van deze studie suggereren dat de verkiaringen omtrent de werking van neomycine bij het hepatisch coma, niet alleen door de antimicrobiële werking verklaard kan worden, maar ook door een mogelijk effect op resorbtie, transport c.q. intermediair metabolisme.

Met de studie in hoofdstuk $V$ hebben we geprobeerd na te gaan of bacteriën verantwoordelijk zijn voor de ammoniakproductie in de dam en zo ja, welke. Daartoe werden ratten selectief gedecontamineerd hetgeen inhoudt dat bepaalde groepen bacteriën (aerobe of anaerobe) geëlimineerd werden met amtibiotica. Deze veranderingen werden gerelateerd aan de ammoniak concentratie in de vena porta. Eliminatie van de anaerobe flora verminderde, in tegenstelling tot hetgeen beweerd wordt in de literatuur, de ammoniak concentratie in de vena porta. Dit deel van de studie bewijst echter niet dat de anaerobe flora verantwoordelijk is voor de ammoniakproductie daar de gebruikte antibiotica tevens invloed zouden kunnen hebben op het niet bacterie gereliateerde metabolisme van de darm. Daartoe werden steriele ratten gecoloniseerd met een vooraf vastgestelde bekende flora (gnoto-bionten). Bij deze gnotobionten werd de ammoniakproductie in de vena porta gerelateerd aan de bacteriezle inhoud 
van de dam. Wa colonisatie met een anaerobe of aerobe flora, of een combinatie van beiden, werd een stijging wargenomen van amoniak in de vena porta In de anaerobe, gecombineerd anaerobe * aerobe, echter niet in de aerobe gnotobionten. Ondanks het felt dat de anaerobe flora de volgende species bevatte: clostridium perfringens, clostridium inocuum, bacteroides ruminiculum, bacteroides fragilits, pepto-streptococcen, bifido bacillen en lactobacillen, wardoor een aanzienlijke ammoniak stijging optrad, bereikte de uiteindelijke concentratie in de vena porta riet die van de conventionele ratten, hetgeen betekent dat andere, nog nader te specificeren of nooit eerder gekweekte soorten nodig zijn an de fysiologie te herstellen in de darm.

In hoofdstuk VI wordt een studie beschreven betreffende de invioed van lactulose en neomycine op de luminale en darmwand geassociëerde flora vam zowel de dunne als de dikke dam. Deze floraveranderingen werden gecorreleerd aan de ammoniak concentratie in de vena porta. De resultaten geven aan dat de veranderingen van deze flora ten gevolge van de behandeling met neomycine en lactulose niet gerelateerd kunnen worden aan de ammoniakdalingen in de vena porta zodat de werking van neamycime en lactulose miet verklaard kan worden uit deze veranderingen temeer daar zowel lactulose als neomycine anmoniakdalingen te zien gaven in de dunne darm war relatief weinig bacteriën aanwezig zijn.

Tenslotte bepalden we in hoofdstuk VII de ammoniak - en aminozuurconcentraties in arteriëel en portaal bloed bij met lactulose en neomycine behandelde ratten. Zowel steriele als conventionele ratten werden gebruikt. Vanuit deze waarden werden portale-arteriële verschillen berekend. In deze in vivo studies blijkt zowel het colon als de dunne darm glutamine op te nemen en ammoniak, glutamine, alanine, citrulline en ormithine te produceren. De dunne darm produceert duidelijk meer ammoniak, zeker als men ook de grotere flow naar de dunne darm dan naar de dikke darm in acht neemt.

De opname van glutamine en de productie van alanine, glutaminezuur en ammonia werden zowel in de dunne als dikke dann gerend.

In hoofdstuk VIII worden deze resultaten besproken. 


\section{ACKNOWLEDGEMENTS}

The experiments on which this thesis is based were perfomed in the Department of Surgery, (head Prof. Dr. J.M. Greep), the Department of Microbiology (head Prof. Dr. C. van Boven), the Department of Anatomy (head Prof. Dr. J. Drukker), University of Limburg and the Department of Biochemistry, University of Rotterdam (head Prof. Dr. H.C. Hiilsmann).

Many persons have helped me with the study, which finally led to the publication of this thesis. It is impossible to thank everyone in person, but I want to acknowledge specifically those without whom this thes is would never have been written.

In particular I wish to thank Prof. Co Greep, who gave me the opportunity to work on this thesis. Prof. Cees van Boven greatly supported the thesis because of all the work that was done in his laboratory. Prof. Jan Drukker made useful comments on the morphological part of this manuscript, which was 1 argely executed in his 1 aboratory.

Prof. J. Bircher has in the past initiated many original thoughts concerning hepatic coma and $i$ ts treatment. I am honoured that he wanted to be a referee and was much impressed by his critical reading of the thesis. Prof. G. Flendrig thoroughly read the manuscript and his remarks were very much appreciated and used in the final form of the manuscript. Prof. P. Brombacher kindly offered me his advice and the facilities of his laboratory.

The basic idea for this study originated largely from Peter soeters under whose guidance the work was really perfomed. I want to express my sincere thanks to him for all the time and energy he spent to reach the present level of this thesis.

Ton van den Boogaard supported the thesis greatly with his ideas, critical comments and useful suggestions. Hugo de Jonge introduced me in the field of biochemistry. His critical comments were of great help.

I am greatly indebted to Mieke Janssen, who performed most of the enormous 
amount of laboratory work in her inimitable and conscientious way. I feel that her energetic and meticulous way of working substantially improved the thesis. Math Hazen did with great patience all the bacteriological incubations. Johan van Dongen in his own way introduced me in the microsurgery. Hans van Eyk performed all the amino acild analyses. Noma Kleyn did all the staining procedures. Eep van Dam, Frans Weekers and Paul Hemans were allways prepared to look after the germ-free animals, even in the weekends. Kees Hodde helped me with the scanning electromicroscopy. John wan Bork did the final english corrections.

I want to convey special thanks to Marcia van Puijenbroek, who did all the typing and retyping and to Chris Voskamp for his illustrations and preparation of the lay out.

Finally 1 1ike to thank my colleagues for their support despite the inconvenience caused by my involvement in this thesis.

Last but not least, I owe great debt to Mieke for her tender support and friendship. 
Paul van Leeuwen was born on March 1, 1952 in Amsterdam, The Netherlands. He attended high-school HBS-B at the Ignatius College in Ansterdam. From 1973-1981 he studied medicine at the Free University of Ansterdam. From March 1981 - October 1981 he was a research fellow in the M.D. Anderson Hospital and Tumor Institute (Houston, Texas), Department of Internal Medicine (head Prof. K.A. Dicke) and observer at the department of General surgery (head Prof. A. Martin). From Apri1 1982 to october 1984 he worked as a research fellow at the University of Mastricht (Department of General Surgery). At present he is a surgical residemt at the department of General surgery, University of Maastricht (head Prof. Dr. J.M. Greep). 
Met dank aan Duphar Nederland B.W., Lundbeck Nederland B.V., Jan Dekker Stïchting \& Dr. Ludgardine Bouwman Stichting. 